Dear filter, take tins highish posy, culled. In alien fields bey pond the severing sea: Iata it in reentry of the boy you meed Doe chill Canadian winter on your knee.

Its flowers are hit chance fiends of alter years, Whose very manes any cliedtwood hardly thew; Cum sven today far tweeter in any ears

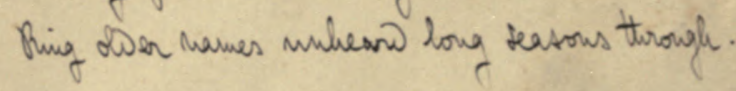

J loved treen all - the bloodroot, waxen white,

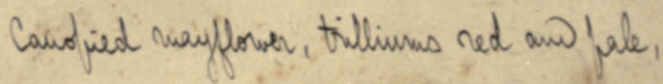
Ilountiua lobelia, lilies richly dight,

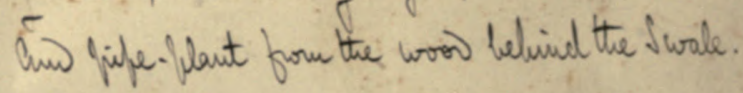

I knew each dell where yellow bidets blow, Rack bid or leaf the changing severs bring I nierken reade if pot where form the melting f wow Peeled forte the first heletica of Paring. 
I watched the fireflies on the shingly ridge Reside the scram tut bounds the Barons hill: Dr tempter sunfish i by the ebbing bid age, Dr hooked a bass by thirty Goings mill.

These were any budding fancy's another - tongue: Bant daisies, cowslips, dodder, priwurose-hips, Cell beasts a birds any little bosk has sung, fit like a borrowed sech on stammering ifs.

And stile' S build fond dreams of happier days, If haw -earned fence may bride the recon vier; That yet our boy may see any nowteris face, ain getter shells beside Ontario's shore:

They get behold Canadian woodlands dime tum forgers and binds his fatter lover to see; While you ans it by am stile on him 1 As down grey years you sat an smiled on one. g. $a$. 
By the same Author.

PHYSIOLOGICAL ESTHETICS : a Scientific Theory of Beauty (London: C Kegan Paul \& Co.)

THE COLOUR-SENSE : its Origin and Development. An Essay on Comparative Psychology. (London : TrUBNer \& Co.) 
THE

\section{EVOLUTIONIST AT LARGE}


LONDON : PRINTED BY SFOTTISWOODE AND CO., NEW-STREET SQUARE AND PARLIAMENT STREET 
${ }_{A}^{B i o l}$

\author{
THE
}

\title{
EVOLUTIONIST AT LARGE
}

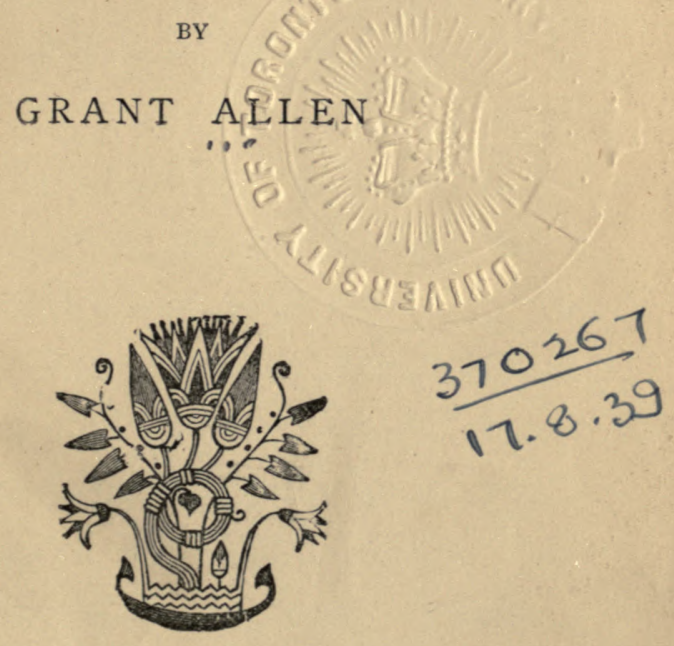

\section{a्Qnomon}

CHATTO \& WINDUS, PICCADILLY I $88 \mathrm{I}$ 


$$
\begin{aligned}
& \text { andil }
\end{aligned}
$$

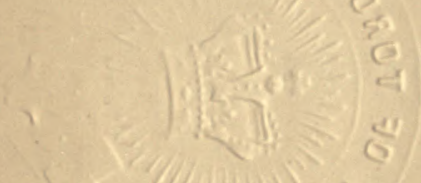

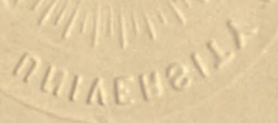




\section{PREFACE.}

These Essays originally appeared in the columns of the 'St. James's Gazette,' and I have to thank the courtesy of the Editor for kind permission to republish them. My object in writing them was to make the general principles and methods of evolutionists a little more familiar to unscientific readers. Biologists usually deal with those underlying points of structure which are most really important, and on which all technical discussion must necessarily be based. But ordinary people care little for such minute anatomical and physiological details. They cannot be expected to interest themselves in the flexor 
pollicis longus, or the hippocampus major about whose very existence they are ignorant, and whose names suggest to them nothing but unpleasant ideas. What they want to find out is how the outward and visible forms of plants and animals were produced. They would much rather learn why birds have feathers than why they have a keeled sternum; and they think the origin of bright flowers far more attractive than the origin of monocotyledonous seeds or exogenous stems. It is with these surface questions of obvious outward appearance that I have attempted to deal in this little series. My plan is to take a simple and well-known natural object, and give such an explanation as evolutionary principles afford of its most striking external features. A strawberry, a snail-shell, a tadpole, a bird, a wayside flower-these are the sort of things which I have tried to explain. If I have not gone very deep, I hope at least 
that I have suggested in simple language the right way to go to work.

I must make an apology for the form in which the essays are cast, so far as regards the apparent egotism of the first person. When they appeared anonymously in the columns of a daily paper, this air of personality was not so obtrusive: now that they reappear under my own name, I fear it may prove somewhat too marked. Nevertheless, to cut out the personal pronoun would be to destroy the whole machinery of the work : so I have reluctantly decided to retain it, only begging the reader to bear in mind that the $I$ of the essays is not a real personage, but the singular number of the editorial we.

I have made a few alterations and corrections in some of the papers, so as to bring the statements into closer accordance with scientific accuracy. At the same time, I should like to add that I have intentionally 
simplified the scientific facts as far as possible. Thus, instead of saying that the groundsel is a composite, I have said that it is a daisy by family; and instead of saying that the ascidian larva belongs to the sub-kingdom Chordata, I have said that it is a first cousin of the tadpole. For these simplifications, I hope technical biologists will pardon me. After all, if you wish to be understood, it is best to speak to people in words whose meanings they know. Definite and accurate terminology is necessary to express definite and accurate knowledge; but one may use vague expressions where the definite ones would convey no ideas.

I have to thank the kindness of my friend the Rev. E. Purcell, of Lincoln College, Oxford, for the clever and appropriate design which appears upon the cover. 


\section{CONTENTS.}

A Ballade of Evolution. . . . . . I

I. Microscopic Brains .

II. A WAYSIDE BerRy . . . . . 16

III. IN Summer FieldS • • . . . 25

IV. A Sprig of Water Crowfoot . $\quad 36$

V. Slugs and SNails . . . . . . 48

VI. A Study of Bones . $\quad$. 59

VII. Blue Mud . . . . . . . 67

VIII. Cuckoo-Pint • . . . . . . 77

IX. Berries AND Berries ‘ . . . 87

X. Distant Relations • . . . 96

XI. Among the Heather . . . . 105

XII. SPECKLED TROUT • . . . . . II4

XIII. DODDER AND BROOMRAPE . . . . 124

XIV. Dog's Mercury and Plantain . . 133 
XV. Butterfly Psychology • . . 142 XVI. BUtTERfLy ÆSThetics . . . . ${ }^{153}$ XVII. The Origin of Walnuts . . . I6I XVIII. A Pretty Land-Shell . . . . 172 XIX. Dogs and Masters . . . . $18 \mathrm{t}$ XX. BLACKCOCK * * * + . $\quad$ + 189 XXI. BINDWEED * . . . . . 198 XXII. On Cornish Cliffs . . . . 207 
A BALLADE OF EVOLUTION.

In the mud of the Cambrian main

Did our earliest ancestor dive :

From a shapeless albuminous grain

We mortals our being derive.

He could split himself up into five,

Or roll himself round like a ball;

For the fittest will álways survive,

While the weakliest go to the wall.

As an active ascidian again

Fresh forms he began to contrive,

Till he grew to a fish with a brain,

And brought forth a mammal alive.

With his rivals he next had to strive,

To woo him a mate and a thrall;

So the handsomest managed to wive,

While the ugliest went to the wall.

At length as an ape he was fain

The nuts of the forest to rive ;

Till he took to the low-lying plain,

And proceeded his fellow to knive.

Thus did cannibal men first arrive,

One another to swallow and maul;

And the strongest continued to thrive,

While the weakliest went to the wall.

\section{Envoy.}

Prince, in our civilised hive,

Now money's the measure of all ; And the wealthy in coaches can drive,

While the needier go to the wall. 
THE

EVOLUTIONIST AT LARGE.

$$
\text { I. }
$$

MICROSCOPIC BRAINS,

SitTing on this little rounded boss of gneiss beside the path which cuts obliquely through the meadow, I am engaged in watching a brigade of ants out on foraging duty, and intent on securing for the nest three whole segments of a deceased earthworm. They look for all the world like those busy companies one sees in the Egyptian wall-paintings, dragging home a huge granite colossus by sheer force of bone and sinew. Every muscle in their tiny bodies is strained to the utmost as they prise themselves laboriously against 
the great boulders which strew the path, and which are known to our Brobdingnagian intelligence as grains of sand. Besides the workers themselves, a whole battalion of stragglers runs to and fro upon the broad line which leads to the head-quarters of the community. The province of these stragglers, who seem so busy doing nothing, probably consists in keeping communications open, and encouraging the sturdy pullers by occasional relays of fresh workmen. I often wish that I could for a while get inside those tiny brains, and see, or rather smell, the world as ants do. For there can be little doubt that to these brave little carnivores here the universe is chiefly known as a collective bundle of odours, simultaneous or consecutive. As our world is mainly a world of visible objects, theirs, I believe, is mainly a world of olfactible things.

In the head of every one of these little creatures is something that we may fairly call a brain. Of course most insects have no real 
brains; the nerve-substance in their heads is a mere collection of ill-arranged ganglia, directly connected with their organs of sense. Whatever man may be, an earwig at least is a conscious, or rather a semi-conscious, automaton. He has just a few knots of nerve-cells in his little pate, each of which leads straight from his dim eye or his vague ear or his indefinite organs of taste; and his muscles obey the promptings of external sensations without possibility of hesitation or consideration, as mechanically as the valve of a steam-engine obeys the governor-balls. You may say of him truly, 'Nihil est in intellectu quod non fuerit in sensu;' and you need not even add the Leibnitzian saving clause, 'nisi ipse intellectus ;' for the poor soul's intellect is wholly deficient, and the senses alone make up all that there is of him, subjectively considered. But it is not so with the highest insects. They have something which truly answers to the real brain of men, apes, and dogs, to the cerebral hemispheres 
and the cerebellum which are superadded in us mammals upon the simple sense-centres of lower creatures. Besides the eye, with its optic nerve and optic perceptive organs-besides the ear, with its similar mechanism-we mammalian lords of creation have a higher and more genuine brain, which collects and compares the information given to the senses, and sends down the appropriate messages to the muscles accordingly. Now, bees and flies and ants have got much the same sort of arrangement, on a smaller scale, within their tiny heads. On top of the little knots which do duty as nerve-centres for their eyes and mouths, stand two stalked bits of nervous matter, whose duty is analogous to that of our own brains. And that is why these three sorts of insects think and reason so much more intellectually than beetles or butterflies, and why the larger part of them have organised their domestic arrangements on such an excellent co-operative plan.

We know well enough what forms the 
main material of thought with bees and flies, and that is visible objects. For you must think about something if you think at all; and you can hardly imagine a contemplative blow-fly setting itself down to reflect, like a Hindu devotee, on the syllable Om, or on the oneness of existence. Abstract ideas are not likely to play a large part in apian consciousness. A bee has a very perfect eye, and with this eye it can see not only form, but also colour, as Sir John Lubbock's experiments have shown us. The information which it gets through its eye, coupled with other ideas derived from touch, smell, and taste, no doubt makes up the main thinkable and knowable universe as it reveals itself to the apian intelligence. To ourselves and to bees alike the world is, on the whole, a coloured picture, with the notions of distance and solidity thrown in by touch and muscular effort; but sight undoubtedly plays the first part in forming our total conception of things generally. 
What, however, forms the thinkable universe of these little ants running to and fro so eagerly at my feet? That is a question which used long to puzzle me in my afternoon walks. The ant has a brain and an intelligence, but that brain and that intelligence must have been developed out of something. Ex nihilo nihil fit. You cannot think and know if you have nothing to think about. The intelligence of the bee and the fly was evolved in the course of their flying about and looking at things: the more they flew, and the more they saw, the more they knew; and the more brain they got to think with. But the ant does not generally fly, and, as with most comparatively unlocomotive animals, its sight is bad. True, the winged males and females have retained in part the usual sharp eyes of their class-for they are first cousins to the bees-and they also possess three little eyelets or ocelli, which are wanting to the wingless neuters. Without these they would never have found one another in their courtship, and 
they would have run their heads against the nearest tree, or rushed down the gaping throat of the first expectant swallow, and so effectually extinguished their race. Flying animals cannot do without eyes, and they always possess the most highly developed vision of any living creatures. But the wingless neuters are almost blind-in some species quite so ; and Sir John Lubbock has shown that their appreciation of colour is mostly confined to an aversion to red light, and a comparative endurance of blue. Moreover, they are apparently deaf, and most of their other senses seem little developed. What can be the raw material on which that pin's head of a brain sets itself working? For, small as it is, it is a wonderful organ of intellect; and though Sir John Lubbock has shown us all too decisively that the originality and inventive genius of ants have been sadly overrated by Solomon and others, yet Darwin is probably right none the less in saying that no more marvellous atom of matter exists in the uni- 
verse than this same wee lump of microscopic nerve substance.

My dog Grip, running about on the path there, with his nose to the ground, and sniffing at every stick and stone he meets on his way, gives us the clue to solve the problem. Grip, as Professor Croom Robertson suggests, seems capable of extracting a separate and distinguishable smell from everything. I have only to shy a stone on the beach among a thousand other stones, and my dog, like a well-bred retriever as he is, selects and brings back to me that individual stone from all the stones around, by exercise of his nose alone. It is plain that Grip's world is not merely a world of sights, but a world of smells as well. He not only smells smells, but he remembers smells, he thinks smells, he even dreams smells, as you may see by his sniffing and growling in his sleep. Now, if I were to cut open Grip's head (which heaven forfend), I should find in it a correspondingly big smellnerve and smell-centre-an olfactory lobe, as the anatomists say. All the accumulated nasal 
experiences of his ancestors have made that lobe enormously developed. But in a man's head you would find a very large and fine optic centre, and only a mere shrivelled relic to represent the olfactory lobes. You and I and our ancestors have had but little occasion for sniffing and scenting; our sight and our touch have done duty as chief intelligencers from the outer world; and the nerves of smell, with their connected centres, have withered away to the degenerate condition in which they now are. Consequently, smell plays but a small part in our thought and our memories. The world that we know is chiefly a world of sights and touches. But in the brain of dos, or deer, or antelope, smell is a prevailing faculty; it colours all their ideas, and it has innumerable nervous connections with every part of their brain. The big olfactory lobes are in direct communication with a thousand other nerves; odours rouse trains of thought or powerful emotions in their minds just as visible objects do in our own. 
Now, in the dog or the horse sight and smell are equally developed; so that they probably think of most things about equally in terms of each. In ourselves, sight is highly developed, and smell is a mere relic ; so that we think of most things in terms of sight alone, and only rarely, as with a rose or a lily, in terms of both. But in ants, on the contrary, smell is highly developed and sight a mere relic; so that they probably think of most things as smellable only, and very little as visible in form or colour. Dr. Bastian has shown that bees and butterflies are largely guided by scent; and though he is certainly wrong in supposing that sight has little to do with leading them to flowers (for if you cut off the bright-coloured corolla they will never discover the mutilated blossoms, even when they visit others on the same plant), yet the mere fact that so many flowers are scented is by itself enough to show that perfume has a great deal to do with the matter. In wingless ants, while the eyes have undergone 
degeneration, this high sense of smell has been continued and further developed, till it has become their principal sense-endowment, and the chief raw material of their intelligence. Their active little brains are almost wholly engaged in correlating and co-ordinating smells with actions. Their olfactory nerves give them nearly all the information they can gain about the external world, and their brains take in this information and work out the proper movements which it indicates. By smell they find their way about and carry on the business of their lives. Just as you and I know the road from Regent's Circus to Pall Mall by visible signs of the street-corners and the Duke of York's Column, so these little ants know the way from the nest to the corpse of the dismembered worm by observing and remembering the smells which they met with on their way. See: I obliterate the track for an inch or two with my stick, and the little creatures go beside themselves with astonishment and dismay. They rush 
about wildly, inquiring of one another with their antennæ whether this is really Doomsday, and whether the whole course of nature has been suddenly revolutionised. Then, after a short consultation, they determine upon action; and every ant starts off in a different direction to hunt the lost track, head to the ground, exactly as a pointer hunts the missing trail of a bird or hare. Each ventures an inch or so off, and then runs back to find the rest, for fear he should get isolated altogether. At last, after many failures, one lucky fellow hits upon the well-remembered train of scents, and rushes back. leaving smelltracks no doubt upon the soil behind him. The message goes quickly round from post to post, each sentry making passes with his antennæ to the next picket, and so sending on the news to the main body in the rear. Within five minutes communications are re-established, and the precious bit of worm-meat continues triumphantly on its way along the recovered path. An ingenious writer would 
even have us believe that ants possess a scent-language of their own, and emit various odours from their antennæ which the other ants perceive with theirs, and recognise as distinct in meaning. Be this as it may, you cannot doubt, if you watch them long, that scents and scents alone form the chief means by which they recollect and know one another, or the external objects with which they come in contact. The whole universe is clearly to them a complicated picture made up entirely of infinite interfusing smells. 


\section{II.}

A WAYSIDE BERRY.

HALF-HIDdEN in the luxuriant growth of leaves and flowers that drape the deep side of this green lane, I have just espied a little picture in miniature, a tall wild strawberrystalk with three full red berries standing out on its graceful branchlets. There are glossy hart's-tongues on the matted bank, and yellow hawkweeds, and bright bunches of red campion; but somehow, amid all that wealth of shape and colour, my eye falls and rests instinctively upon the three little ruddy berries, and upon nothing else. I pick the single stalk from the bank and hold it here in my hands. The origin and development of these pretty bits of red pulp is one of the many curious 
questions upon which modern theories of life have cast such a sudden and unexpected flood of light. What makes the strawberry stalk grow out into this odd and brightly coloured lump, bearing its small fruits embedded on its swollen surface? Clearly the agency of those same small birds who have been mainly instrumental in dressing the haw in its scarlet coat, and clothing the spindle-berries with their two-fold covering of crimson doublet and orange cloak.

In common language we speak of each single strawberry as a fruit. But it is in reality a collection of separate fruits, the tiny yellow-brown grains which stud its sides being each of them an individual little nut; while the sweet pulp is, in fact, no part of the true fruit at all, but merely a swollen stalk. There is a white potentilla so like a strawberry blossom that even a botanist must look closely at the plant before he can be sure of its identity. While they are-in flower the two heads remain almost indistinguishable; 
but when the seed begins to set the potentilla develops only a collection of dry fruitlets, seated upon a green receptacle, the bed or soft expansion which hangs on to the 'hull' or calyx. Each fruitlet consists of a thin covering, enclosing a solitary seed. You may compare one of them separately to a plum, with its single kernel, only that in the plum the covering is thick and juicy, while in the potentilla and the fruitlets of the strawberry it is thin and dry. An almond comes still nearer to the mark. Now the potentilla shows us, as it were, the primitive form of the strawberry. But in the developed ripe strawberry as we now find it the fruitlets are not crowded upon a green receptacle. After flowering, the strawberry receptacle lengthens and broadens, so as to form a roundish mass of succulent pulp; and as the fruitlets approach maturity this sour green pulp becomes soft, sweet, and red. The little seed-like fruits, which are the important organs, stand out upon its surface like mere specks; while 
the comparatively unimportant receptacle is all that we usually think of when we talk about strawberries. After our usual Protagorean fashion we regard man as the measure of all things, and pay little heed to any part of the compound fruit-cluster save that which ministers directly to our own tastes.

But why does the strawberry develop this large mass of apparently useless matter? Simply in order the better to ensure the dispersion of its small brown fruitlets. Birds are always hunting for seeds and insects along the hedge-rows, and devouring such among them as contain any available foodstuff. In most cases they crush the seeds to pieces with their gizzards, and digest and assimilate their contents. Seeds of this class are generally enclosed in green or brown capsules, which often escape the notice of the birds, and so succeed in perpetuating their species. But there is another class of plants whose members possess hard and indigestible seeds, and so turn the greedy birds from dangerous 
enemies into useful allies. Supposing there was by chance, ages ago, one of these primitive ancestral strawberries, whose receptacle was a little more pulpy than usual, and contained a small quantity of sugary matter, such as is often found in various parts of plants; then it might happen to attract the attention of some hungry bird, which, by eating the soft pulp, would help in dispersing the indigestible fruitlets. As these fruitlets sprang up into healthy young plants, they would tend to reproduce the peculiarity in the structure of the receptacle which marked the parent stock, and some of them would probably display it in a more marked degree. These would be sure to get eaten in their turn, and so to become the originators of a still more pronounced strawberry type. As time went on, the largest and sweetest berries would constantly be chosen by the birds, till the whole species began to assume its existing character. The receptacle would become softer and sweeter, and the fruits themselves harder and more 
indigestible: because, on the one hand, all sour or hard berries would stand a poorer chance of getting dispersed in good situations for their growth, while, on the other hand, all soft-shelled fruitlets would be ground up and digested by the bird, and thus effectually prevented from ever growing into future plants. Just in like manner, many tropical nuts have extravagantly hard shells, as only those survive which can successfully defy the teeth and hands of the clever and persistent monkey.

This accounts for the strawberry being sweet and pulpy, but not for its being red. Here, however, a similar reason comes into play. All ripening fruits and opening flowers have a natural tendency to grow bright red, or purple, or blue, though in many of them the tendency is repressed by the dangers attending brilliant displays of colour. This natural habit depends upon the oxidation of their tissues, and is exactly analogous to the assumption of autumn tints by leaves. If a 
plant, or part of a plant, is injured by such a change of colour, through being rendered more conspicuous to its foes, it soon loses the tendency under the influence of natural selection; in other words, those individuals which most display it get killed out, while those which least display it survive and thrive. On the other hand, if conspicuousness is an advantage to the plant, the exact opposite happens, and the tendency becomes developed into a confirmed habit. This is the case with the strawberry, as with many other fruits. The more bright-coloured the berry is, the better its chance of getting its fruitlets dispersed. Birds have quick eyes for colour, especially for red and white; and therefore almost all edible berries have assumed one or other of these two hues. So long as the fruitlets remain unripe, and would therefore be injured by being eaten, the pulp remains sour, green, and hard; but as soon as they have become fit for dispersion it grows soft, fills with sugary juice, and acquires its ruddy 
outer flesh. Then the birds see and recognise it as edible, and govern themselves accordingly.

But if this is the genesis of the strawberry, asks somebody, why have not all the potentillas and the whole strawberry tribe also become berries of the same type? Why are there still potentilla fruit-clusters which consist of groups of dry seed-like nuts? Ay, there's the rub. Science cannot answer as yet. After all, these questions are still in their infancy, and we can scarcely yet do more than discover a single stray interpretation here and there. In the present case a botanist can only suggest either that the potentilla finds its own mode of dispersion equally well adapted to its own peculiar circumstances, or else that the lucky accident, the casual combination of circumstances, which produced the first elongation of the receptacle in the strawberry has never happened to befall its more modest kinsfolk. For on such occasional freaks of nature the whole evolution of new 
varieties entirely depends. A gardener may raise a thousand seedlings, and only one or none among them may present a single new and important feature. So a species may wait for a thousand years, or for ever, before its circumstances happen to produce the first step towards some desirable improvement. One extra petal may be invaluable to a fiverayed flower as effecting some immense saving of pollen in its fertilisation; and yet the 'sport' which shall give it this sixth ray may never occur, or may be trodden down in the mire and destroyed by a passing cow. 


\section{III.}

IN SUMMER FIELDS.

GRIP and I have come out for a morning stroll among the close-cropped pastures beside the beck, in the very centre of our green little dingle. Here I can sit, as is my wont, on a dry knoll, and watch the birds, beasts, insects, and herbs of the field, while Grip scours the place in every direction, intent, no doubt, upon those more practical objectsmostly rats, I fancy-which possess a congenial interest for the canine intelligence. From my coign of vantage on the knoll I can take care that he inflicts no grievous bodily injury upon the sheep, and that he receives none from the quick-tempered cow with the brass-knobbed horns. For a kind of ancestral feud seems to smoulder for ever 
between Grip and the whole race of kine, breaking out every now and then into open warfare, which calls for my prompt interference, in an attitude of armed but benevolent neutrality, merely for the friendly purpose of keeping the peace.

This ancient feud, I imagine, is really ancestral, and dates many ages further back in time than Grip's individual experiences. Cows hate dogs instinctively, from their earliest calfhood upward. I used to doubt once upon a time whether the hatred was not of artificial origin and wholly induced by the inveterate human habit of egging on every dog to worry every other animal that comes in its way. But I tried a mild experiment one day by putting a half-grown town-bred puppy into a small enclosure with some hitherto unworried calves, and they all turned to make a common headway against the intruder with the same striking unanimity as the most ancient and experienced cows. Hence I am inclined to suspect that the 
antipathy does actually result from a vaguely inherited instinct derived from the days when the ancestor of our kine was a wild bull, and the ancestor of our dogs a wolf, on the wide forest-clad plains of Central Europe. When a cow puts up its tail at sight of a dog entering its paddock at the present day, it has probably some dim instinctive consciousness that it stands in the presence of a dangerous hereditary foe; and as the wolves could only seize with safety a single isolated wild bull, so the cows now usually make common cause against the intruding dog, turning their heads in one direction with very unwonted unanimity, till his tail finally disappears under the opposite gate. Such inherited antipathies seem common and natural enough. Every species knows and dreads the ordinary enemies of its race. Mice scamper away from the very smell of a cat. Young chickens run to the shelter of their mother's wings when the shadow of a hawk passes over their heads. Mr. Darwin put a small snake into a paper 
bag, which he gave to the monkeys at the Zoo; and one monkey after another opened the bag, looked in upon the deadly foe of the quadrumanous kind, and promptly dropped the whole package with every gesture of horror and dismay. Even man himselfthough his instincts have all weakened so greatly with the growth of his more plastic intelligence, adapted to a wider and more modifiable set of external circumstancesseems to retain a vague and original terror of the serpentine form.

If we think of parallel cases, it is not curious that animals should thus instinctively recognise their natural enemies. We are not surprised that they recognise their own fellows : and yet they must do so by means of some equally strange automatic and inherited mechanism in their nervous system. One butterfly can tell its mates at once from a thousand other species, though it may differ from some of them only by a single spot or line, which would escape the notice of all but 
the most attentive observers. Must we not conclude that there are elements in the butterfly's feeble brain exactly answering to the blank picture of its specific type? So, too, must we not suppose that in every race of animals there arises a perceptive structure specially adapted to the recognition of its own kind? Babies notice human faces long before they notice any other living thing. In like manner we know that most creatures can judge instinctively of their proper food. One young bird just fledged naturally pecks at red berries; another exhibits an untaught desire to chase down grasshoppers; a third, which happens to be born an owl, turns at once to the congenial pursuit of small sparrows, mice, and frogs. Each species seems to have certain faculties so arranged that the sight of certain external objects, frequently connected with food in their ancestral experience, immediately arouses in them the appropriate actions for its capture. Mr. Douglas Spalding found that newly-hatched chickens 
darted rapidly and accurately at flies on the wing. When we recollect that even so late an acquisition as articulate speech in human beings has its special physical seat in the brain, it is not astonishing that complicated mechanisms should have arisen among animals for the due perception of mates, food, and foes respectively. Thus, doubtless, the serpent form has imprinted itself indelibly on the senses of monkeys, and the wolf or dog form on those of cows: so that even with a young ape or calf the sight of these their ancestral enemies at once calls up uneasy or terrified feelings in their half-developed minds. Our own infants in arms have no personal experience of the real meaning to be attached to angry tones, yet they shrink from the sound of a gruff voice even before they have learned to distinguish their nurse's face.

When Grip gets among the sheep, their hereditary traits come out in a very different manner. They are by nature and descent 
timid mountain animals, and they have never been accustomed to face a foe, as cows and buffaloes are wont to do, especially when in a herd together. You cannot see many traces of the original mountain life among sheep, and yet there are still a few remaining to mark their real pedigree. Mr. Herbert Spencer has noticed the fondness of lambs for frisking on a hillock, however small ; and when I come to my little knoll here, I generally find it occupied by a couple, who rush away on my approach, but take their stand instead on the merest ant-hill which they can find in the field. I once knew three young goats, kids of a mountain breed, and the only elevated object in the paddock where they were kept was a single old elm stump. For the possession of this. stump the goats fought incessantly; and the victor would proudly perch himself on the top, with all four legs inclined inward (for the whole diameter of the tree was but some fifteen inches), maintaining himself in his place with the greatest diff- 
culty, and butting at his two brothers until at last he lost his balance and fell. This one old stump was the sole representative in their limited experience of the rocky pinnacle upon which their forefathers kept watch like sentinels; and their instinctive yearnings prompted them to perch themselves upon the only available memento of their native haunts. Thus, too, but in a dimmer and vaguer way, the sheep, especially during his younger days, loves to revert, so far as his small opportunities permit him, to the unconsciously remembered habits of his race. But in mountain countries, every one must have noticed how the sheep at once becomes a different being. On the Welsh hills he casts away all the dull and heavy serenity of his brethren on the South Downs, and displays once more the freedom, and even the comparative boldness, of a mountain breed. A Merionethshire ewe thinks nothing of running up one side of a low-roofed barn and down the other, or of clearing a stone wall 
which a Leicestershire farmer would consider extravagantly high.

Another mountain trait in the stereotyped character of sheep is their well-known sequaciousness. When Grip runs after them they all run away together : if one goes through a certain gap in the hedge, every other follows ; and if the leader jumps the beck at a certain spot, every lamb in the flock jumps in the self-same place. It is said that if you hold a stick for the first sheep to leap over, and then withdraw it, all the succeeding sheep will leap with mathematical accuracy at the corresponding point ; and this habit is usually held up to ridicule as proving the utter stupidity of the whole race. It really proves nothing but the goodness of their ancestral instincts. For mountain animals, accustomed to follow a leader, that leader being the bravest and strongest ram of the flock, must necessarily follow him with the most implicit obedience. He alone can see what obstacles come in the way; and each of the succeeding train must 
watch and imitate the actions of their predecessors. Otherwise, if the flock happens to come to a chasm, running as they often must with some speed, any individual which stopped to look and decide for itself before leaping would inevitably be pushed over the edge by those behind it, and so would lose all chance of handing down its cautious and sceptical spirit to any possible descendants. On the other hand, those uninquiring and blindly obedient animals which simply did as they saw others do would both survive themselves and become the parents of future and similar generations. Thus there would be handed down from dam to lamb a general tendency to sequaciousness-a follow-myleader spirit, which was really the best safeguard for the race against the evils of insubordination, still so fatal to Alpine climbers. And now that our sheep have settled down to a tame and monotonous existence on the downs of Sussex or the levels of the Midlands, the old instinct clings to them still, and 
speaks out plainly for their mountain origin. There are few things in nature more interesting to notice than these constant survivals of instinctive habits in altered circumstances. They are to the mental life what rudimentary organs are to the bodily structure: they remind us of an older order of things, just as the abortive legs of the blind-worm show us that he was once a lizard, and the hidden shell of the slug that he was once a snail. 
A SPRIG OF WATER CROWFOOT.

THE little streamlet whose tiny ranges and stickles form the middle thread of this green combe in the Dorset downs is just at present richly clad with varied foliage. Tall spikes of the yellow flag rise above the slow-flowing pools, while purple loose-strife overhangs the bank, and bunches of the arrowhead stand high out of their watery home, just unfolding their pretty waxen white flowers to the air. In the rapids, on the other hand, I find the curious water crowfoot, a spray of which I have this moment pulled out of the stream and am now holding in my hand as I sit on the little stone bridge, with my legs dangling 
over the pool below, known to me as the undoubted residence of a pair of trout. It is a queer plant, this crowfoot, with its two distinct types of leaves, much cleft below and broad above; and I often wonder why so strange a phenomenon has attracted such very scant attention. But then we knew so little of life in any form till the day before yesterday that perhaps it is not surprising we should still have left so many odd problems quite untouched.

This problem of the shape of leaves certainly seems to me a most important one ; and yet it has hardly been even recognised by our scientific pastors and masters. At best, Mr. Herbert Spencer devotes to it a passing short chapter, or Mr. Darwin a stray sentence. The practice of classifying plants mainly by means of their flowers has given the flower a wholly factitious and overwrought importance. Besides, flowers are so pretty, and we cultivate them so largely, with little regard to the leaves, that they 
have come to usurp almost the entire interest of botanists and horticulturists alike. Darwinism itself has only heightened this exclusive interest by calling attention to the reciprocal relations which exist between the honey-bearing blossom and the fertilising insect, the bright-coloured petals and the myriad facets of the butterfly's eye. Yet the leaf is after all the real plant, and the flower is but a sort of afterthought, an embryo colony set apart for the propagation of like plants in future. Each leaf is in truth a separate individual organism, united with many others into a compound community, but possessing in full its own mouths and digestive organs, and carrying on its own life to a great extent independently of the rest. It may die without detriment to them; it may be lopped off with a few others as a cutting, and it continues its life-cycle quite unconcerned. An oak tree in full foliage is a magnificent group of such separate individuals - a whole nation in miniature : it may 
be compared to a branched coral polypedom covered with a thousand little insect workers, while each leaf answers rather to the separate polypes themselves. The leaves are even capable of producing new individuals by what they contribute to the buds on every branch; and the seeds which the tree as a whole produces are to be looked upon rather as the founders of fresh colonies, like the swarms of bees, than as fresh individuals alone. Every plant community, in short, both adds new members to its own commonwealth, and sends off totally distinct germs to form new commonwealths elsewhere. Thus the leaf is, in truth, the central reality of the whole plant, while the flower exists only for the sake of sending out a shipload of young emigrants every now and then to try their fortunes in some unknown soil.

The whole life-business of a leaf is, of course, to eat and grow, just as these same functions form the whole life-business of a 
caterpillar or a tadpole. But the way a plant eats, we all know, is by taking carbon and hydrogen from air and water under the influence of sunlight, and building them up into appropriate compounds in its own body.

Certain little green worms or convoluta have the same habit, and live for the most part cheaply off sunlight, making starch out of carbonic acid and water by means of their enclosed chlorophyll, exactly as if they were leaves. Now, as this is what a leaf has to do, its form will almost entirely depend upon the way it is affected by sunlight and the elements around it-except, indeed, in so far as it may be called upon to perform other functions, such as those of defence or defiance. This crowfoot is a good example of the results produced by such agents. Its lower leaves, which grow under water, are minutely subdivided into little branching lancelike segınents; while its upper ones, which raise their heads above the surface, are broad and united, like the common crowfoot type. 
How am I to account for these peculiarities? I fancy somehow thus :-

Plants which live habitually under water almost always have thin, long, pointed leaves, often thread-like or mere waving filaments. The reason for this is plain enough. Gases are not very abundant in water, as it only holds in solution a limited quantity of oxygen and carbonic acid. Both of these the plant needs, though in varying quantities : the carbon to build up its starch, and the oxygen to use up in its growth. Accordingly, broad and large leaves would starve under water: there is not material enough diffused through it for them to make a living from. But small, long, waving leaves which can move up and down in the stream would manage to catch almost every passing particle of gaseous matter, and to utilise it under the influence of sunlight. Hence all plants which live in fresh water, and especially all plants of higher rank, have necessarily acquired such a type of leaf. It is the only form in 
which growth can possibly take place under their circumstances. Of course, however, the particular pattern of leaf depends largely upon the ancestral form. Thus this crowfoot, even in its submerged leaves, preserves the general arrangement of ribs and leaflets common to the whole buttercup tribe. For the crowfoot family is a large and eminently adaptable race. Some of them are larkspurs and similar queerly-shaped blossoms; others are columbines which hang their complicated bells on dry and rocky hillsides; but the larger part are buttercups or marsh marigolds which have simple cup-shaped flowers, and mostly frequent low and marshy ground. One of these typical crowfoots under stress of circumstances-inundation, or the liketook once upon a time to living pretty permanently in the water. As its native meadows grew deeper and deeper in flood it managed from year to year to assume a more nautical life. So, while its leaf necessarily remained in general structure a true crowfoot leaf, it 
was naturally compelled to split itself up into thinner and narrower segments, each of which grew out in the direction where it could find most stray carbon atoms, and most sunlight, without interference from its neighbours. This, I take it, was the origin of the muchdivided lower leaves.

But a crowfoot could never live permanently under water. Seaweeds and their like, which propagate by a kind of spores, may remain below the surface for ever; but flowering plants for the most part must come up to the open air to blossom. The sea-weeds are in the same position as fish, originally developed in the water and wholly adapted to it, whereas flowering plants are rather analogous to seals and whales, air-breathing creatures, whose ancestors lived on land, and who can themselves manage an aquatic existence only by frequent visits to the surface. So some flowering water-plants actually detach their male blossoms altogether, and let them float loose on the top of the water; 
while they send up their female flowers by means of a spiral coil, and draw them down again as soon as the wind or the fertilising insects have carried the pollen to its proper receptacle, so as to ripen their seeds at leisure beneath the pond. Similarly, you may see the arrowhead and the water-lilies sending up their buds to open freely in the air, or loll at ease upon the surface of the stream. Thus the crowfoot, too, cannot blossom to any purpose below the water; and as such among its ancestors as at first tried to do so must of course have failed in producing any seed, they and their kind have died out for ever; while only those lucky individuals whose chance lot it was to grow a little taller and weedier than the rest, and so overtop the stream, have handed down their race to our own time.

But as soon as the crowfoot finds itself above the level of the river, all the causes which made its leaf like those of other aquatic plants have ceased to operate. The 
new leaves which sprout in the air meet with abundance of carbon and sunlight on every side; and we know that plants grow fast just in proportion to the supply of carbon. They have pushed their way into an unoccupied field, and they may thrive apace without let or hindrance. So, instead of splitting up into little lance-like leaflets, they loll on the surface, and spread out broader and fuller, like the rest of their race. The leaf becomes at once a broad type of crowfoot leaf. Even the ends of the submerged leaves, when any fall of the water in time of drought raises them above the level, have a tendency (as I have often noticed) to grow broader and fatter, with increased facilities for food; but when the whole leaf rises from the first to the top the inherited family instinct finds full play for its genius, and the blades fill out as naturally as well-bred pigs. The two types of leaf remind one much of gills and lungs respectively.

But above water, as below it, the crow- 
foot remains in principle a crowfoot still. The traditions of its race, acquired in damp marshy meadows, not actually under water, cling to it yet in spite of every change. Born river and pond plants which rise to the surface, like the water-lily or the duck-weed, have broad floating leaves that contrast strongly with the waving filaments of wholly submerged species. They can find plenty of food everywhere, and as the sunlight falls flat upon them, they may as well spread out flat to catch the sunlight. No other elbowing plants overtop them and appropriate the rays, so compelling them to run up a useless waste of stem in order to pocket their fair share of the golden flood. Moreover, they thus save the needless expense of a stout leaf-stalk, as the water supports their lolling leaves and blossoms; while the broad shade which they cast on the bottom below prevents the undue competition of other species. But the crowfoot, being by descent a kind of buttercup, has taken to the water for a few hundred generations only, 
while the water-lily's ancestors have been to the manner born for millions of years; and therefore it happens that the crowfoot is at heart but a meadow buttercup still. One glance at its simple little flower will show you that in a moment. 


\section{V.}

SLUGS AND SNAILS.

Hoeing among the flower-beds on my lawn this morning-for I am a bit of a gardener in my way-I have had the ill-luck to maim a poor yellow slug, who had hidden himself among the encroaching grass on the edge of my little parterre of sky-blue lobelias. This unavoidable wounding and hacking of worms and insects, despite all one's care, is no small drawback to the pleasures of gardening in propriâ personâ. Vivisection for genuine scientific purposes in responsible hands, one can understand and tolerate, even though lacking the heart for it oneself ; but the useless and causeless vivisection which cannot be prevented in every ordinary piece of farm- 
work seems a gratuitous blot upon the face of beneficent nature. My only consolation lies in the half-formed belief that feeling among these lower creatures is indefinite, and that pain appears to affect them far less acutely than it affects warm-blooded animals. Their nerves are so rudely distributed in loose knots all over the body, instead of being closely bound together into a single central system as with ourselves, that they can scarcely possess a consciousness of pain at all analogous to our own. A wasp whose head has been severed from its body and stuck upon a pin, will still greedily suck up honey with its throatless mouth; while an Italian mantis, similarly treated, will calmly continue to hunt and dart at midges with its decapitated trunk and limbs, quite forgetful of the fact that it has got no mandibles left to eat them with. These peculiarities lead one to hope that insects may feel pain less than we fear. Yet I dare scarcely utter the hope, lest it should lead any thoughtless 
hearer to act upon the very questionable belief, as they say even the amiable enthusiasts of Port Royal acted upon the doctrine that animals were mere unconscious automata, by pushing their theory to the too practical length of active cruelty. Let us at least give the slugs and beetles the benefit of the doubt. People often say that science makes men unfeeling : for my own part, I fancy it makes them only the more humane, since they are the better able dimly to figure to themselves the pleasures and pains of humbler beings as they really are. The man of science perhaps realises more vividly than all other men the inner life and vague rights even of crawling worms and ugly earwigs.

I will take up this poor slug whose mishap has set me preaching, and put him out of his misery at once, if misery it be. My hoe - has cut through the soft flesh of the mantle and hit against the little embedded shell. Very few people know that a slug has a shell, but it has, though quite hidden from view; 
at least, in this yellow kind-for there are other sorts which have got rid of it altogether. I am not sure that I have wounded the poor thing very seriously; for the shell protects the heart and vital organs, and the hoe has glanced off on striking it, so that the mantle alone is injured, and that by no means irrecoverably. Snail flesh heals fast, and on the whole I shall be justified, I think, in letting him go. But it is a very curious thing that this slug should have a shell at all! Of course it is by descent a snail, and, indeed, there are very few differences between the two races except in the presence or absence of a house. 'You may trace a curiously complete set of gradations between the perfect snail and the perfect slug in this respect ; for all the intermediate forms still survive with only an almost imperceptible gap between each species and the next. Some kinds, like the common brown garden snail, have comparatively small bodies and big shells, so that they can retire comfortably within them 
when attacked; and if they only had a lid or door to their houses they could shut themselves up hermetically, as periwinkles and similar mollusks actually do. Other kinds, like the pretty golden amber-snails which frequent marshy places, have a body much too big for its house, so that they cannot possibly retire within their shells completely. Then come a number of intermediate species, each with progressively smaller and thinner shells, till at length we reach the testacella, which has only a sort of limpet-shaped shield on his tail, so that he is generally recognised as being the first of the slugs rather than the last of the snails. You will not find a testacella unless you particularly look for him, for he seldom comes above ground, being a most bloodthirsty subterraneous carnivore who follows the burrows of earthworms as savagely as a ferret tracks those of rabbits ; but in all the southern and western counties you may light upon stray specimens if you search carefully in damp places under fallen 
leaves. Even in testacellæ, however, the small shell is still external. In this yellow slug here, on the contrary, it does not show itself at all, but is buried under the closely wrinkled skin of the glossy mantle. It has become a mere saucer, with no more symmetry or regularity than an oyster-shell. Among the various kinds of slugs, you may watch this relic or rudiment gradually dwindling further and further towards annihilation; till finally, in the great fat black slugs which appear so plentifully on the roads after summer showers, it is represented only by a few rough calcareous grains, scattered up and down through the mantle; and sometimes even these are wanting. The organs which used to secrete the shell in their remote ancestors have either ceased to work altogether or are reduced to performing a useless office by mere organic routine.

The reason why some mollusks have thus lost their shells is clear enough. Shells are of two kinds, calcareous and horny. Both 
of them require more or less lime or other mineral matters, though in varying proportions. Now, the snails which thrive best on the bare chalk downs behind my little combe belong to that pretty banded black-and-white sort which everybody must have noticed feeding in abundance on all chalk soils. Indeed, Sussex farmers will tell you that South Down mutton owes its excellence to these fat little mollusks, not to the scanty herbage of their thin pasture-lands. The pretty banded shells in question are almost wholly composed of lime, which the snails can, of course, obtain in any required quantity from the chalk. In most limestone districts you. will similarly find that snails with calcareous shells predominate. But if you go into a granite or sandstone tract you will see that horny shells have it all their own way. Now, some snails with such houses took to living in very damp and marshy places, which they were naturally apt to do-as indeed the landsnails in a body are merely pond-snails which 
have taken to crawling up the leaves of marsh-plants, and have thus gradually acclimatised themselves to a terrestrial existence. We can trace a perfectly regular series from the most aquatic to the most land-loving species, just as I have tried to trace a regular series from the shell-bearing snails to the shell-less slugs. Well, when the earliest common ancestor of both these last-named races first took to living above water, he possessed a horny shell (like that of the amber-snail), which his progenitors used to manufacture from the mineral matters dissolved in their native streams. Some of the younger branches descended from this primæval land-snail took to living on very dry land, and when they reached chalky districts manufactured their shells, on an easy and improved principle, almost entirely out of lime. But others took to living in moist and boggy places, where mineral matter was rare, and where the soil consisted for the most part of decaying vegetable mould. 
Here they could get little or no lime, and so their shells grew smaller and smaller, in proportion as their habits became more decidedly terrestrial. But to the last, as long as any shell at all remained, it generally covered their hearts and other important organs ; because it would there act as a special protection, even after it had ceased to be of any use for the defence of the animal's body as a whole. Exactly in the same way men specially protected their heads and breasts with helmets and cuirasses, before armour was used for the whole body, because these were the places where a wound would be most dangerous; and they continued to cover these vulnerable spots in the same manner even when the use of armour had been generally abandoned. My poor mutilated slug, who is just now crawling off contentedly enough towards the hedge, would have been cut in two outright by my hoe had it not been for that solid calcareous plate of his, which saved his life as surely as any coat of mail. 
How does it come, though, that slugs and snails now live together in the self-same districts? Why, because they each live in their own way. Slugs belong by origin to very damp and marshy spots; but in the fierce competition of modern life they spread themselves over comparatively dry places, provided there is long grass to hide in, or stones under which to creep, or juicy herbs like lettuce, among whose leaves are nice moist nooks wherein to lurk during the heat of the day. Moreover, some kinds of slugs are quite as well protected from birds (such as ducks) by their nauseous taste as snails are by their shells. Thus it happens that at present both races may be discovered in many hedges and thickets side by side. But the real home of each is quite different. The truest and most snail-like snails are found in greatest abundance upon high chalk-downs, heathy limestone hills, and other comparatively dry places; while the truest and most slug-like slugs are found in greatest abund- 
ance among low water-logged meadows, or under the damp fallen leaves of moist copses. The intermediate kinds inhabit the intermediate places. Yet to the last even the most thorough-going snails retain a final trace of their original water-haunting life, in their universal habit of seeking out the coolest and moistest spots of their respective habitats. The soft-fleshed mollusks are all by nature aquatic animals, and nothing can induce them wholly to forget the old tradition of their marine or fresh-water existence. 


\section{VI.}

A STUDY OF BONES.

ON the top of this bleak chalk down, where I am wandering on a dull afternoon, I light upon the blanched skeleton of a crow, which I need not fear to handle, as its bones have been first picked clean by carrion birds, and then finally purified by hungry ants, time, and stormy weather. I pick a piece of it up in my hands, and find that I have got hold of its clumped tail-bone. A strange fragment truly, with a strange history, which I may well spell out as I sit to rest a minute upon the neighbouring stile. For this dry tail-bone consists, as I can see at a glance, of several separate vertebræ, all firmly 
welded together into a single piece. They must once upon a time have been real disconnected jointed vertebræ, like those of the dog's or lizard's tail ; and the way in which they have become fixed fast into a solid mass sheds a world of light upon the true nature and origin of birds, as well as upon many analogous cases elsewhere.

When I say that these bones were once separate, I am indulging in no mere hypothetical Darwinian speculation. I refer, not to the race, but to the particular crow in person. These very pieces themselves, in their embryonic condition, were as distinct as the individual bones of the bird's neck or of our own spines. If you were to examine the chick in the egg you would find them quite divided. But as the young crow grows more and more into the typical bird-pattern, this lizard-like peculiarity fades away, and the separate pieces unite by 'anastomosis' into a single 'coccygean bone,' as the osteologists call it. In all our modern birds, as in this 
crow, the vertebræ composing the tail-bone are few in number, and are soldered together immovably in the adult form. It was not always so, however, with ancestral birds. The earliest known member of the class the famous fossil bird of the Solenhofen lithographic stone-retained throughout its whole life a long flexible tail, composed of twenty unwelded vertebræ, each of which bore a single pair of quill-feathers, the predecessors of our modern pigeon's train. There are many other marked reptilian peculiarities in this primitive oolitic bird; and it apparently possessed true teeth in its jaws, as its later cretaceous kinsmen discovered by Professor Marsh undoubtedly did. When we compare side by side those real flying dragons, the Pterodactyls, together with the very birdlike Deinosaurians, on the one hand, and these early toothed and lizard-tailed birds on the other, we can have no reasonable doubt in deciding that our own sparrows and swallows are the remote feathered descendants 
of an original reptilian or half-reptilian ancestor.

Why modern birds have lost their long flexible tails it is not difficult to see. The tail descends to all higher vertebrates as an heirloom from the fishes, the amphibia, and their other aquatic predecessors. With these it is a necessary organ of locomotion in swimming, and it remains almost equally useful to the lithe and gliding lizard on land. Indeed, the snake is but a lizard who has substituted this wriggling motion for the use of legs altogether; and we can trace a gradual succession from the four-legged true lizards, through snake-like forms with two legs and wholly rudimentary legs, to the absolutely limbless serpents themselves. But to flying birds, on the contrary, a long bony tail is only an inconvenience. All that they need is a little muscular knob for the support of the tail-feathers, which they employ as a rudder in guiding their flight upward or downward, to right or left. The elongated 
waving tail of the Solenhofen bird, with its single pair of quills, must have been a comparatively ineffectual and clumsy piece of mechanism for steering an aërial creature through its novel domain. Accordingly; the bones soon grew fewer in number and shorter in length, while the feathers simultaneously arranged themselves side by side upon the terminal hump. As early as the time when our chalk was deposited, the bird's tail had become what it is at the present daya single united bone, consisting of a few scarcely distinguishable crowded rings. This is the form it assumes in the toothed fossil birds of Western America. But, as if to preserve the memory of their reptilian origin, birds in their embryo stage still go on producing separate caudal vertebræ, only to unite them together at a later point of their development into the typical coccygean bone.

Much the same sort of process has taken place in the higher apes, and, as Mr. Darwin would assure us, in man himself. There the 
long prehensile tail of the monkeys has grown gradually shorter, and, being at last coiled up under the haunches, has finally degenerated into an insignificant and wholly embedded terminal joint. But, indeed, we can find traces of a similar adaptation to circumstances everywhere. Take, for instance, the common English amphibians. The newt passes all its life in the water, and therefore always retains its serviceable tail as a swimming organ. The frog in its tadpole state is also aquatic, and it swims wholly by means of its broad and flat rudder-like appendage. But as its legs bud out, and it begins to fit itself for a terrestrial existence, the tail undergoes a rapid atrophy, and finally fades away altogether. To a hopping frog on land, such a long train would be a useless drag, while in the water its webbed feet and muscular legs make a satisfactory substitute for the lost organ. Last of all, the tree-frog, leading a specially terrestrial life, has no tadpole at all, but emerges from the egg in the full frog. 
like shape. As he never lives in the water, he never feels the need of a tail.

The edible crab and lobster show us an exactly parallel case amongst crustaceans. Everybody has noticed that a crab's body is practically identical with a lobster's, only that in the crab the body-segments are broad and compact, while the tail, so conspicuous in its kinsman, is here relatively small and tucked away unobtrusively behind the legs. This difference in construction depends entirely upon the habits and manners of the two races. The lobster lives among rocks and ledges; he uses his small legs but little for locomotion, but he springs surprisingly fast and far through the water by a single effort of his powerful muscular tail. As to his big fore-claws, those, we all know, are organs of prehension and weapons of offence, not pieces of locomotive mechanism. Hence the edible and muscular part of a lobster is chiefly to be found in the claws and tail, the latter having naturally the firmest and 
strongest flesh. The crab, on the other hand, lives on the sandy bottom, and walks about on its lesser legs, instead of swimming or darting through the water by blows of its tail, like the lobster or the still more active prawn and shrimp. Hence the crab's tail has dwindled away to a mere useless historical relic, while the most important muscles in its body are those seated in the network of shell just above its locomotive legs. In this case, again, it is clear that the appendage has disappeared because the owner had no further use for it. Indeed, if one looks through all nature, one will find the philosophy of tails eminently simple and utilitarian. Those animals that need them evolve them; those animals that do not need them never develop them; and those animals that have once had them, but no longer use them for practical purposes, retain a mere shrivelled rudiment as a lingering reminiscence of their original habits. 


\section{VII.}

BLUE MUD.

After last night's rain, the cliffs that bound the bay have come out in all their most brilliant colours; so this morning I am turning my steps seaward, and wandering along the great ridge of pebbles which here breaks the force of the Channel waves as they beat against the long line of the Dorset downs. Our cliffs just at this point are composed of blue lias beneath, with a capping of yellow sandstone on their summits, above which in a few places the layer of chalk that once topped the whole country-side has still resisted the slow wear and tear of unnumbered centuries. These three elements give a variety to the bold and broken bluffs which 
is rare along the monotonous southern escarpment of the English coast. After rain, especially, the changes of colour on their sides are often quite startling in their vividness and intensity. To-day, for example, the yellow sandstone is tinged in parts with a deep russet red, contrasting admirably with the bright green of the fields above and the sombre steel-blue of the lias belt below. Besides, we have had so many landslips along this bit of shore, that the various layers of rock have in more than one place got mixed up with one another into inextricable confusion. The little town nestling in the hollow behind me has long been famous as the head-quarters of early geologists; and not a small proportion of the people earn their livelihood to the present day by 'goin' a fossiling.' Every child about the place recognises ammonites as 'snake-stones;' while even the rarer vertebræ of extinct saurians have acquired a local designation as 'verterberries.' So, whether in search of science or the pictur- 
esque, I often clamber down in this direction for my daily stroll, particularly when, as is the case to-day, the rain has had time to trickle through the yellow rock, and the sun then shines full against its face; to light it up with a rich flood of golden splendour.

The base of the cliffs consists entirely of a very soft and plastic blue lias mud. This mud contains large numbers of fossils, chiefly chambered shells, but mixed with not a few relics of the great swimming and flying lizards that swarmed among the shallow flats or low islands of the lias sea. When the blue mud was slowly accumulating in the hollows of the ancient bottom, these huge saurians formed practically the highest race of animals then existing upon earth. There were, it is true, a few primæval kangaroo-mice and wombats among the rank brushwood of the mainland; and there may even have been a species or two of reptilian birds, with murderouslooking teeth and long lizard-like tailsdescendants of those problematical creatures 
which printed their footmarks on the American trias, and wincestors of the later toothed bird whose tail-feathers have been naturally lithographed for us on the Solenhofen slate. But in spite of such rare precursors of higher modern types, the saurian was in fact the real lord of earth in the lias ocean.

For him did his high sun flame, and his river billowing ran, And he felt himself in his pride to be nature's crowning race.

We have adopted an easy and slovenly way of dividing all rocks into primary, secondary, and tertiary, which veils from us the real chronological relations of evolving life in the different periods. The lias is ranked by geologists among the earliest secondary formations: but if we were to distribute all the sedimentary rocks into ten great epochs, each representing about equal duration in time, the lias would really fall in the tenth and latest of all. So very misleading to the ordinary mind is our accepted geological nomenclature. Nay, even commonplace geologists themselves 
often overlook the real implications of many facts and figures which they have learned to quote glibly enough in a certain off-hand way. Let mejust briefly reconstruct the chief features of this scarcely recognised world's chronology as I sit on this piece of fallen chalk at the foot of the mouldering cliff, where the stream from the meadow above brought down the newest landslip during the hard frosts of last December. First of all, there is the vast lapse of time represented by the Laurentian rocks of Canada. These Laurentian rocks, the oldest in the world, are at least 30,000 feet in thickness, and it must be allowed that it takes a reasonable number of years to accumulate such a mass of solid limestone or clay as that at the bottom of even the widest primæval ocean. In these rocks there are no fossils, except a single very doubtful member of the very lowest animal type. But there are indirect traces of life in the shape of limestone probably derived from shells, and of black lead probably derived from plants. All 
these early deposits have been terribly twisted and contorted by subsequent convulsions of the earth, and most of them have been melted down by volcanic action; so that we can tell very little about their original state. Thus the history of life opens for us, like most other histories, with a period of uncertainty : its origin is lost in the distant vistas of time. Still, we know that there was such an early period; and from the thickness of the rocks which represent it we may conjecture that it spread over three out of the ten great æons into which I have roughly divided geological time. Next comes the period known as the Cambrian, and to it we may similarly assign about two and a half æons on like grounds. The Cambrian epoch begins with a fair sprinkling of the lower animals and plants, presumably developed during the preceding age; but it shows no remains of fish or any other vertebrates. To the Silurian, Devonian, and Carboniferous periods we may roughly allow an æon and a fraction each : 
while to the whole group of secondary and tertiary strata, comprising almost all the bestknown English formations-red marl, lias, oolite, greensand, chalk, eocene, miocene, pliocene, and drift-we can only give a single æon to be divided between them. Such facts will sufficiently suggest how comparatively modern are all these rocks when viewed by the light of an absolute chronology. Now, the first fishes do not occur till the Silurianthat is to say, in or about the seventh æon after the beginning of geological time. The first mammals are found in the trias, at the beginning of the tenth æon. And the first known bird only makes its appearance in the oolite, about half-way through that latest period. This will show that there was plenty of time for their development in the earlier ages. True, we must reckon the interval between ourselves and the date of this blue mud at many millions of years; but then we must reckon the interval between the lias and the earliest Cambrian strata at some six times 
as much, and between the lias and the lowest Laurentian beds at nearly ten times as much. Just the same sort of lessening perspective exists in geology as in ordinary history. Most people look upon the age before the Norman Conquest as a mere brief episode of the English annals; yet six whole centuries elapsed between the landing of the real or mythical Hengst at Ebbsfleet and the landing of William the Conqueror at Hastings ; while under eight centuries elapsed between the time of William the Conqueror and the accession of Queen Victoria. But, just as most English histories give far more space to the three centuries since Elizabeth than to the eleven centuries which preceded them, so most books on geology give far more space to the single æon (embracing the secondary and tertiary periods) which comes nearest our own time, than to the nine æons which spread from the Laurentian to the Carboniferous epoch. In the earliest period, records either geological or historical are wholly wanting; 
in the later periods they become both more numerous and more varied in proportion as they approach nearer and nearer to our own time.

So too, in the days when Mr. Darwin first took away the breath of scientific Europe by his startling theories, it used confidently to be said that geology had shown us no intermediate form between species and species. Even at the time when this assertion was originally made it was quite untenable. All early geological forms, of whatever race, belong to what we foolishly call 'generalised' types: that is to say, they present a mixture of features now found separately in several different animals. In other words, they represent early ancestors of all the modern forms, with peculiarities intermediate between those of their more highly differentiated descendants ; and hence we ought to call them 'unspecialised' rather than 'generalised 'types. For example, the earliest ancestral horse is partly a horse and partly a tapir: we may regard 
him as a tertium quid, a middle term, from which the horse has varied in one direction and the tapir in another, each of them exaggerating certain special peculiarities of the common ancestor and losing others, in accordance with the circumstances in which they have been placed. Science is now perpetually discovering intermediate forms, many of which compose an unbroken series between the unspecialised ancestral type and the familiar modern creatures. Thus, in this very case of the horse, Professor Marsh has unearthed a long line of fossil animals which lead in direct descent from the extremely unhorse-like eocene type to the developed Arab of our own times. Similarly with birds, Professor Huxley has shown that there is hardly any gap between the very bird-like lizards of the lias and the very lizard-like birds of the oolite. Such links, discovered afresh every day, are perpetual denials, to the old parrot-like cry of ' No geological evidence for evolution.' 


\section{VIII.}

CUCKOO-PINT.

IN the bank which supports the hedge, beside this little hanger on the flank of Black Down, the glossy arrow-headed leaves of the common arum form at this moment beautiful masses of vivid green foliage. 'Cuckoopint' is the pretty poetical old English name for the plant; but village children know it better by the equally quaint and fanciful title of 'lords and ladies.' The arum is not now in flower: it blossomed much earlier in the season, and its queer clustered fruits are just at present swelling out into rather shapeless little light-green bulbs, preparatory to assuming the bright coral-red hue which makes them so conspicuous among the hedgerows 
during the autumn months. A cut-and-dry technical botanist would therefore have little to say to it in its present stage, because he cares only for the flowers and seeds which help him in his dreary classifications, and give him so splendid an opportunity for displaying the treasures of his Latinised terminology. But to me the plant itself is the central point of interest, not the names (mostly in bad Greek) by which this or that local orchidhunter has endeavoured to earn immortality.

This arum, for example, grows first from a small hard seed with a single lobe or seedleaf. In the seed there is a little store of starch and albumen laid up by the motherplant, on which the young arum feeds, just as truly as the growing chick feeds on the white which surrounds its native yolk, or as you and I feed on the similar starches and albumens laid by for the use of the young plant in the grain of wheat, or for the young fowl in the egg. Full-grown plants live by taking in food-stuffs from the air under the influence 
of sunlight: but a young seedling can no more feed itself than a human baby can; and so food is stored up for it beforehand by the parent stock. As, the kernel, swells with heat and moisture, its starches and albumens get oxidised and produce the motions and rearrangements of particles that result in the growth of a new plant. First a little head rises towards the sunlight and a little root pushes downward towards the moist soil beneath. The business of the root is to collect water for the circulating medium-the sap or blood of the plant-as well as a few mineral matters required for its stem and cells ; but the business of the head is to spread out into leaves, which are the real mouths and stomachs of the compound organism. For we must never forget that all plants mainly grow, not, as most people suppose, from the earth, but from the air. They are for the most part mere masses of carboncompounds, and the carbon in them comes from the carbonic acid diffused through the 
atmosphere around, and is separated by the sunlight acting in the leaves. There it mixes with small quantities of hydrogen and nitrogen brought by the roots from soil and water; and the starches or other bodies thus formed are then conveyed by the sap to the places where they will be required in the economy of the plant system. That is the all-important fact in vegetable physiology, just as the digestion and assimilation of food and the circulation of the blood are in our own bodies.

The arum, like the grain of wheat, has only a single seed-leaf; whereas the pea, as we all know, has two. This is the most fundamental difference among flowering plants, as it points back to an early and deep-seated mode of growth, about which they must have split off from one another millions of years ago. All the one-lobed plants grow with stems like grasses or bamboos, formed by single leaves enclosing another; all the double-lobed plants grow with stems like an oak, formed of concentric layers from within 
outward. As soon as the arum, with its sprouting head, has raised its first leaves far enough above the ground to reach the sunlight, it begins to form fresh starches and new leaves for itself, and ceases to be dependent upon the store laid up in its buried lobe. Most seeds accordingly contain just enough material to support the young seedling till it is in a position to shift for itself; and this, of course, varies greatly with the habits and manners of the particular species. Some plants, too, such as the potato, find their seeds insufficient to keep up the race by themselves, and so lay by abundant starches in underground branches or tubers, for the use of new shoots; and these rich starch receptacles we ourselves generally utilise as food-stuffs, to the manifest detriment of the young potato-plants, for whose benefit they were originally intended. Well, the arum has no such valuable reserve as that; it is early cast upon its own resources, and so it shifts for itself with resolution. Its big, 
glossy leaves grow apace, and soon fill out, not only with green chlorophyll, but also with a sharp and pungent essence which makes them burn the mouth like cayenne pepper. This acrid juice has been acquired by the plant as a defence against its enemies. Some early ancestor of the arums must have been liable to constant attacks from rabbits, goats, or other herbivorous animals, and it has adopted this means of repelling their advances. In other words, those arums which were most palatable to the rabbits got eaten up and destroyed, while those which were nastiest survived, and handed down their pungency to future generations. Just in the same way nettles have acquired their sting and thistles their prickles, which efficiently protect them against all herbivores except the patient, hungry donkey, who gratefully accepts them as a sort of sauce piquante to the succulent stems.

And now the arum begins its great preparations for the act of flowering. Everybody knows the general shape of the arum blossom 
-if not in our own purple cuckoo-pint, at least in the big white 'Æthiopian lilies' which form such frequent, ornaments of cottage windows. Clearly, this is a flower which the plant cannot produce without laying up a good stock of material beforehand. So it sets to work accumulating starch in its root. This starch it manufactures in its leaves, and then buries deep underground in a tuber, by means of the sap, so as to secure it from the attacks of rodents, who too frequently appropriate to themselves the food intended by plants for other purposes. If you examine the tuber before the arum has blossomed, you will find it large and solid; but if you dig it up in the autumn after the seeds have ripened, you will see that it is flaccid and drained; all its starches and other contents have gone to make up the flower, the fruit, and the stalk which bore them. But the tuber has a further protection against enemies besides its deep underground position. It contains an acrid juice like that of the leaves, 
which sufficiently guards it against fourfooted depredators. Man, however, that most persistent of persecutars, has found out a way to separate the juice from the starch; and in St. Helena the big white arum is cultivated as a food-plant, and yields the meal in common use among the inhabitants.

When the arum has laid by enough starch to make a flower it begins to send up a tall stalk, on the top of which grows the curious hooded blossom known to be one of the earliest forms still surviving upon earth. But now its object is to attract, not to repel, the animal world; for it is an insect-fertilised flower, and it requires the aid of small flies to carry the pollen from blossom to blossom. For this purpose it has a purple sheath around its head of flowers and a tall spike on which they are arranged in two clusters, the male blossoms above and the female below. This spike is bright yellow in the cultivated species. The fertilisation is one of the most interesting episodes in all nature, but it would take too 
long to describe here in full. The flies go from one arum to another, attracted by the colour, in search of pollen; and the pistils, or female flowers, ripen first. Then the pollen falls from the stamens or male flowers on the bodies of the flies, and dusts them all over with yellow powder. The insects, when once they have entered, are imprisoned until the pollen is ready to drop, by means of several little hairs, pointing downwards, and preventing their exit on the principle of an eel-trap or lobster-pot. But as soon as the pollen is discharged the hairs wither away, and then the flies are free to visit a second arum. Here they carry the fertilising dust with which they are covered to the ripe pistils, and so enable them to set their seed; but, instead of getting away again as soon as they have eaten their fill, they are once more imprisoned by the lobster-pot hairs, and dusted with a second dose of pollen, which they carry away in turn to a third blossom.

As soon as the pistils have been impreg- 
nated, the fruits begin to set. Here they are, on their tall spike, whose enclosing sheath has now withered away, while the top is at this moment slowly dwindling, so that only the cluster of berries at its base will finally remain. The berries will swell and grow soft, till in autumn they become a beautiful scarlet cluster of living coral. Then once more their object will be to attract the animal world, this time in the shape of field-mice, squirrels, and small birds; but with a more treacherous intent. For though the berries are beautiful and palatable enough they are deadly poison. The robins or small rodents which eat them, attracted by their bright colours and pleasant taste, not only aid in dispersing them, but also die after swallowing them, and become huge manure heaps for the growth of the young plant. So the whole cycle of arum existence begins afresh, and there is hardly a plant in the field around me which has not a history as strange as this one. 


\section{IX.}

BERRIES AND BERRIES.

This little chine, opening toward the sea through the blue lias cliffs, has been worn to its present pretty gorge-like depth by the slow action of its tiny stream - a mere thread of water in fine weather, that trickles down its centre in a series of mossy cascades to the shingly beach below. Its sides are overgrown by brambles and other prickly brushwood, which form in places a matted and impenetrable mass : for it is the habit of all plants protected by the defensive armour of spines or thorns to cluster together in serried ranks, through which cattle or other intrusive animals cannot break. Amongst them, near the down above, I have just lighted upon a rare 
plant for Southern Britain - a wild raspberrybush in full fruit. Raspberries are common enough in Scotland among heaps of stones on the windiest hillsides; but the south of England is too warm and sickly for their robust tastes, and they can only be found here in a few bleak spots like the stony edges of this weather-beaten down above the chine. The fruit itself is quite as good as the garden variety, for cultivation has added little to the native virtues of the raspberry. Good old Izaac Walton is not ashamed to quote a certain quaint saying of one Dr. Boteler concerning strawberries, and so I suppose I need not be afraid to quote it after him. 'Doubtless,' said the Doctor, 'God could have made a better berry, but doubtless also God never did.' Nevertheless, if you try the raspberry, picked fresh, with plenty of good country cream, you must allow that it runs its sister fruit a neck-and-neck race.

To compare the structure of a raspberry with that of a strawberry is a very instructive 
botanical study. It shows how similar causes may produce the same gross result in singularly different ways. Both are roses by family, and both have flowers essentially similar to that of the common dog-rose. But even in plants where the flowers are alike, the fruits often differ conspicuously, because fresh principles come into play for the dispersion and safe germination of the seed. This makes the study of fruits the most complicated part in the unravelling of plant life. After the strawberry has blossomed, the pulpy receptacle on which it bore its green fruitlets begins to swell and redden, till at length it grows into an edible berry, dotted with little yellow nuts, containing each a single seed. But in the raspberry it is the separate fruitlets themselves which grow soft and bright-coloured, while the receptacle remains white and tasteless, forming the 'hull' which we pull off from the berry when we are going to eat it. Thus the part of the raspberry which we throw away answers to the part of the straw- 
berry which we eat. Only, in the raspberry the separate fruitlets are all crowded close together into a single united mass, while in the strawberry they are scattered about loosely, and embedded in the soft flesh of the receptacle. The blackberry is another close relative; but in its fruit the little pulpy fruitlets cling to the receptacle, so that we pick and eat them both together; whereas in the raspberry the receptacle pulls out easily, and leaves a thimble-shaped hollow in the middle of the berry. Each of these little peculiarities has a special meaning of its own in the history of the different plants.

Yet the main object attained by all is in the end precisely similar. Strawberries, raspberries, and blackberries all belong to the class of attractive fruits. They survive in virtue of the attention paid to them by birds and small animals. Just as the wild strawberry which I picked in the hedgerow the other day procures the dispersion of its hard and indigestible fruitlets by getting them 
eaten together with the pulpy receptacle, so does the raspberry procure the dispersion of its soft and sugary fruitlets by getting them eaten all by themselves. While the strawberry fruitlets retain throughout their dry outer coating, in those of the raspberry the external covering becomes fleshy and red, but the inner seed has, notwithstanding, a still harder shell than the tiny nuts of the strawberry. Now, this is the secret of nine fruits out of ten. They are really nuts, which clothe themselves in an outer tunic of sweet and beautifully coloured pulp. The pulp, as it were, the plant gives in, as an inducement to the friendly bird to swallow its seed; but the seed itself it protects by a hard stone or shell, and often by poisonous or bitter juices within. We see this arrangement very conspicuously in a plum, or still better in a mango; though it is really just as evident in the raspberry, where the smaller size renders it less conspicuous to human sight. 
It is a curious fact about the rose family that they have a very marked tendency to produce such fleshy fruits, instead of the mere dry seed-vessels of ordinary plants, which are named fruits only by botanical courtesy. For example, we owe to this single family the peach, plum, apricot, cherry, damson, pear, apple, medlar, and quince, all of them cultivated in gardens or orchards for their fruits. The minor group known by the poetical name of Dryads, alone supplies us with the strawberry, raspberry, blackberry, and dewberry. Even the wilder kinds, refused as food by man, produce berries well known to our winter birds-the haw, rose-hip, sloe, bird-cherry, and rowan. On the other hand, the whole tribe numbers but a single thoroughgoing nut-the almond; and even this nut, always somewhat soft-shelled and inclined to pulpiness, has produced by a 'sport' the wholly fruit-like nectarine. The odd thing about the rose tribe, however, is this: that the pulpy tendency shows itself in very dif- 
ferent parts among the various species. In the plum it is the outer covering of the true fruit which grows soft and coloured : in the apple it is a swollen mass of the fruit-stalk surrounding the ovules : in the rose-hip it is the hollowed receptacle: and in the strawberry it is the same receptacle, bulging out in the opposite direction. Such a general tendency to display colour and collect sugary juices in so many diverse parts may be compared to the general bulbous tendency of the tiger-lily or the onion, and to the general succulent tendency of the cactus or the houseleek. In each case, the plant benefits by it in one form or another; and whichever form happens to get the start in any particular instance is increased and developed by natural selection, just as favourable varieties of fruits or flowers are increased and developed in cultivated species by our own gardeners.

Sweet juices and bright colours, however, could be of no use to a plant till there were eyes to see and tongues to taste them. A 
pulpy fruit is in itself a mere waste of productive energy to its mother, unless the pulpiness aids in the dispersion and promotes the welfare of the young seedlings. Accordingly, we might naturally expect that there would be no fruit-bearers on the earth until the time when fruit-eaters, actual or potential, arrived upon the scene: or, to put it more correctly, both must inevitably have developed simultaneously and in mutual dependence upon one another. So we find no traces of succulent fruits even in so late a formation as that of these lias or cretaceous cliffs. The birds of that day were fierce-toothed carnivores, devouring the lizards and saurians of the rank low-lying sea-marshes: the mammals were mostly primæval kangaroos or low ancestral wombats, gentle herbivores, or savage marsupial wolves, like the Tasmanian devil of our own times. It is only in the very modern tertiary period, whose soft muddy deposits have not yet had time to harden under superincumbent pressure into solid 
stone, that we find the earliest traces of the rose family, the greatest fruit-bearing tribe of our present world. And side by side with them we find their clever arboreal allies, the ancestral monkeys and squirrels, the primitive robins, and the yet shadowy forefathers of our modern fruit-eating parrots. Just as bees and butterflies necessarily trace back their geological history only to the time of the first honey-bearing flowers, and just as the honey-bearing flowers in turn trace back their pedigree only to the date of the rudest and most unspecialised honey-sucking insects, so are fruits and fruit-eaters linked together in origin by the inevitable bond of a mutual dependence. No bee, no honey; and no honey, no bee : so, too, no fruit, no fruit-bird; and no fruit-bird, no fruit. 


\section{$\mathrm{X}$.}

DISTANT RELATIONS.

BEHIND the old mill, whose overshot wheel,. backed by a wall thickly covered with the young creeping fronds of hart's-tongue ferns, forms such a picturesque foreground for the view of our little valley, the millstream expands into a small shallow pond, overhung at its edges by thick-set hazelbushes and clambering honeysuckle. Of course it is only dammed back by a mud wall, with sluices for the miller's waterpower; but it has a certain rustic simplicity of its own, which makes it beautiful to our eyes for all that, in spite of its utilitarian origin. At the bottom of this shallow pond you may now see a miracle daily taking 
place, which but for its commonness : we should regard as an almost incredible marvel. You may there behold evolution actually illustrating the transformation of life under your very eyes: you may watch a low type of gill-breathing gristlyboned fish developing into the highest form of lung-breathing terrestrial amphibian. Nay, more-you may almost discover the earliest known ancestor of the whole vertebrate kind, the first cousin of that once famous ascidian larva, passing through all the upward stages of existence which finally lead it to assume the shape of a relatively perfect four-legged animal. For the pond is swarming with fat black tadpoles, which are just at this moment losing their tails and developing their legs, on the way to becoming fully formed frogs.

The tadpole and the ascidian larva divide between them the honour of preserving for us in all its native simplicity the primitive aspect of the vertebrate type. Beasts, birds, reptiles, and fishes have all descended from 
an animal whose shape closely resembled that of these wriggling little black creatures which dart up and down like imps through the clear water, and raise a cloud of mud above their heads each time that they bury themselves comfortably in the soft mud of the bottom. But while the birds and beasts, on the one hand, have gone on bettering themselves out of all knowledge, and while the ascidian, on the other hand, in his adult form has dropped back into an obscure and sedentary life-sans eyes, sans teeth, sans taste, sans everything-the tadpole alone, at least during its early days, remains true to the ancestral traditions of the vertebrate family. When first it emerges from its egg it represents the very most rudimentary animal with a backbone known to our scientific teachers. It has a big hammer-looking head, and a set of branching outside gills, and a short distinct body, and a long semi-transparent tail. Its backbone is a mere gristly channel, in which lies its spinal cord. As it grows, it resembles 
in every particular the ascidian larva, with which, indeed, Kowalewsky and Professor Ray Lankester have demonstrated its essential identity. But since a great many people seem wrongly to imagine that Professor Lankester's opinion on this matter is in some way at variance with Mr. Darwin's and Dr. Haeckel's, it may be well to consider what the degeneracy of the ascidian really means. The fact is, both larval forms-that of the frog and that of the ascidian-completely agree in the position of their brains, their gill-slits, their very rudimentary backbones, and their spinal cords. Moreover, we ourselves and the tadpole agree with the ascidian in a further most important point, which no invertebrate animal shares with us; and that is that our eyes grow out of our brains, instead of being part of our skin, as in insects and cuttle-fish. This would seem $\grave{a}$ priori a most inconvenient place for an eye -inside the brain; but then, as Professor Lankester cleverly suggests, our common 
original ancestor, the very earliest vertebrate of all, must have been a transparent creature, and therefore comparatively indifferent as to the part of his body in which his eye happened to be placed. In after ages, however, as vertebrates generally got to have thicker skulls and tougher skins, the eye-bearing part of the brain had to grow outward, and so reach the light on the surface of the body : a thing which actually happens to all birds, beasts, and reptiles in the course of their embryonic development. So that in this respect the ascidian larva is nearer to the original type than the tadpole or any other existing animal.

The ascidian, however, in mature life, has grown degraded and fallen from his high estate, owing to his bad habit of rooting himself to a rock and there settling down into a mere sedentary swallower of passing morsels-a blind, handless, footless, and degenerate thing. In his later shape he is but a sack fixed to a stone, and with all his 
limbs and higher sense-organs so completely atrophied that only his earlier history allows us to recognise him as a vertebrate by descent at all. He is in fact a representative of retrogressive development. The tadpole, on the contrary, goes on swimming about freely, and keeping the use of its eyes, till at last a pair of hind legs and then a pair of fore legs begin to bud out from its side, and its tail fades away, and its gills disappear, and air-breathing lungs take their place, and it boldly hops on shore a fully evolved tailless amphibian.

There is, however, one interesting question about these two larvæ which I should much like to solve. The ascidian has only one eye inside its useless brain, while the tadpole and all other vertebrates have two from the very first. Now which of us most nearly represents the old mud-loving vertebrate ancestor in this respect? Have two original organs coalesced in the young ascidian, or has one organ split up into a couple with the rest of the class? I think the latter is the true 
supposition, and for this reason: In our heads, and those of all vertebrates, there is a curious cross-connection between the eyes and the brain, so that the right optic nerve goes to the left side of the brain and the left optic nerve goes to the right side. In higher animals, this 'decussation,' as anatomists call it, affects all the sense-organs except those of smell ; but in fishes it only affects the eyes. Now, as the young ascidian has retained the ancestral position of his almost useless eye so steadily, it is reasonable to suppose that he has retained its other peculiarities as well. May we not conclude, therefore, that the primitive vertebrate had only one brain-eye ; but that afterwards, as this brain-eye grew outward to the surface, it split up into two, because of the elongated and flattened form of the head in swimming animals, while its two halves still kept up a memory of their former union in the cross-connection with the opposite halves of the brain? If this be so, then we might suppose that the other organs 
followed suit, so as to prevent confusion in the brain between the two sides of the body; while the nose, which stands in the centre of the face, was under no liability to such error, and therefore still keeps up its primitive direct arrangement.

It is worth noting, too, that these tadpoles, like all other very low vertebrates, are mud-haunters ; and the most primitive among adult vertebrates are still cartilaginous mudfish. Not much is known geologically about the predecessors of frogs; the tailless amphibians are late arrivals upon earth, and it may seem curious, therefore, that they should recall in so many ways the earliest ancestral type. The reason doubtless is because they are so much given to larval development. Some ancestors of theirs-primæval newts or salamanders - must have gone on for countless centuries improving themselves in their adult shape from age to age, yet bringing all their young into the world from the egg, as mere mud-fish still, in much the same state 
as their unimproved forefathers had done millions of xons before. Similarly, caterpillars are still all but exact patterns of the primæval insect, while butterflies are totally different and far higher creatures. Thus, in spite of adult degeneracy in the ascidian and adult progress in the frog, both tadpoles preserve for us very nearly the original form of their earliest backboned ancestor. Each individual recapitulates in its own person the whole history of evolution in its race. This is a very lucky thing for biology; since without these recapitulatory phases we could never have traced the true lines of descent in many cases. It would be a real misfortune for science if every frog had been born a typical amphibian, as some tree-toads actually are, and if every insect had emerged a fully formed adult, as some aphides very nearly do. Larvæ and embryos show us the original types of each race; adults show us the total amount of change produced by progressive or retrogressive development. 


\section{XI.}

AMONG THE HEATHER.

THIs is the worst year for butterflies that I can remember. Entomologists all over England are in despair at the total failure of the insect crop, and have taken to botanising, angling, and other bad habits, in default of means for pursuing their natural avocation as beetle-stickers. Last year's heavy rains killed all the mothers as they emerged from the chrysalis; and so only a few stray eggs have survived till this summer, when the butterflies they produce will all be needed to keep up next season's supply. Nevertheless, I have climbed the highest down in this part of the country to-day, and come out for an airing among the heather, in the vague hope 
that I may be lucky enough to catch a glimpse of one or two old lepidopterous favourites. I am not a butterfly-hunter myself. I have not the heart to drive pins through the pretty creatures' downy bodies, or to stifle them with reeking chemicals; though I recognise the necessity for a hardened class who will perform that useful office on behalf of science and society, just as I recognise the necessity for slaughtermen and knackers. But I prefer personally to lie on the ground at my ease and learn as much about the insect nature as I can discover from simple inspection of the living subject as it flits airily from bunch to bunch of bright-coloured flowers.

I suppose even that apocryphal person, the general reader, would be insulted at being told at this hour of the day that all brightcoloured flowers are fertilised by the visits of insects, whose attentions they are specially designed to solicit. Everybody has heard over and over again that roses, orchids, and columbines have acquired their honey to 
allure the friendly bee, their gaudy petals to advertise the honey, and their divers shapes to ensure the proper fertilisation by the correct type of insect. But everybody does not know how specifically certain blossoms have laid themselves out for a particular species of fly, beetle, or tiny moth. Here on the higher downs, for instance, most flowers are exceptionally large and brilliant; while all Alpine climbers must have noticed that the most gorgeous masses of bloom in Switzerland occur just below the snow-line. The reason is, that such blossoms must be fertilised by butterflies alone. Bees, their great rivals in honey-sucking, frequent only the lower meadows and slopes, where flowers are many and small: they seldom venture far from the hive or the nest among the high peaks and chilly nooks where we find those great patches of blue gentian or purple anemone, which hang like monstrous breadths of tapestry upon the mountain sides. This heather here, now fully opening in the warmer 
sun of the southern counties-it is still but in the bud among the Scotch hills, I doubt not-specially lays itself out for the humblebee, and its masses form about his highest pasture-grounds ; but the butterflies-insect vagrants that they are-have no fixed home, and they therefore stray far above the level at which bee-blossoms altogether cease to grow. Now, the butterfly differs greatly from the bee in his mode of honey-hunting ; he does not bustle about in a business-like manner from one buttercup or dead-nettle to its nearest fellow; but he flits joyously, like a sauntering straggler that he is, from a great patch of colour here to another great patch at a distance, whose gleam happens to strike his roving eye by its size and brilliancy. Hence, as that indefatigable observer, Dr. Hermann Müller, has noticed, all Alpine or hill-top flowers have very large and conspicuous blossoms, generally grouped together in big clusters so as to catch a passing glance of the butterfly's eye. As soon as the 
insect spies such a cluster, the colour, seems to act as a stimulant to his broad wings, just as the candle-light does to those of his cousin the moth. Off he sails at once, as if by automatic action, towards the distant patch, and there both robs the plant of its honey and at the same time carries to it on his legs and head fertilising pollen from the last of its congeners which he favoured with a call. For of course both bees and butterflies stick on the whole to a single species at a time; or else the flowers would only get uselessly hybridised instead of being impregnated with pollen from other plants of their own kind. For this purpose it is that most plants lay themselves out to secure the attention of only two or three varieties among their insect allies, while they make their nectaries either too deep or too shallow for the convenience of all other kinds. Nature, though eager for cross-fertilisation, abhors 'miscegenation' with all the bitterness of an American politician. 
Insects, however, differ much from one another in their æsthetic tastes, and flowers are adapted accordingly to the varying fancies of the different kinds. Here, for example, is a spray of common white galium, which attracts and is fertilised by small flies, who generally frequent white blossoms. But here, again, not far off, I find a luxuriant mass of the yellow species, known by the quaint name of 'lady's bedstraw'-a legacy from the old legend which represents it as having formed Our Lady's bed in the manger at Bethlehem. Now why has this kind of galium yellow flowers, while its near kinsman yonder has them snowy white? The reason is that lady's bedstraw is fertilised by small beetles; and beetles are known to be one among the most colour-loving races of insects. You may often find one of their number, the lovely bronze and golden-mailed rose-chafer, buried deeply in the very centre of a red garden rose, and reeling about when touched as if drunk with pollen and honey. Almost 
all the flowers which beetles frequent are consequently brightly decked in scarlet or yellow. On the other hand, the whole family of the umbellates, those tall plants with level bunches of tiny blossoms, like the fool's parsley, have all but universally white petals ; and Müller, the most statistical of naturalists, took the trouble to count the number of insects which paid them a visit. He found that only I4 per cent. were bees, while the remainder consisted mainly of miscellaneous small flies and other arthropodous riff-raff; whereas in the brilliant class of composites, including the asters, sunflowers, daisies, dandelions, and thistles, nearly 75 per cent. of the visitors were steady, industrious bees. Certain dingy blossoms which lay themselves out to attract wasps are obviously adapted, as Müller quaintly remarks, ' to a less æsthetically cultivated circle of visitors.' But the most brilliant among all insect-fertilised flowers are those which specially affect the society of butterflies; and they are only sur- 
passed in this respect throughout all nature by the still larger and more magnificent tropical species which owe their fertilisation to humming-birds and brush-tongued lories.

Is it not a curious, yet a comprehensible circumstance, that the tastes which thus show themselves in the development, by natural selection, of lovely flowers, should also show themselves in the marked preference for beautiful mates? Poised on yonder sprig of harebell stands a little purple-winged butterfly, one of the most exquisite among our British kinds. That little butterfly owes its own rich and delicately shaded tints to the long selective action of a million generations among its ancestors. So we find throughout that the most beautifully coloured birds and insects are always those which have had most to do with the production of bright-coloured fruits and flowers. The butterflies and rosebeetles are the most gorgeous among insects : the humming-birds and parrots are the most gorgeous among birds. Nay more, exactly 
like effects have been produced in two hemispheres on different tribes by the same causes. The plain brown swifts of the North have developed among tropical West Indian and South American orchids the metallic gorgets and crimson crests of the humming-bird : while a totally unlike group of Asiatic birds have developed among the rich flora of India and the Malay Archipelago the exactly similar plumage of the exquisite sun-birds. Just as bees depend upon flowers, and flowers upon bees, so the colour-sense of animals has created the bright petals of blossoms; and the bright petals have reacted upon the tastes of the animals themselves, and through their tastes upon their own appearance. 
IT is a piece of the common vanity of anglers to suppose that they know something about speckled trout. A fox might almost as well pretend that he was intimately acquainted with the domestic habits of poultry, or an Iroquois describe the customs of the Algonquins from observations made upon the specimens who had come under his scalping-knife. I will allow that anglers are well versed in the necessity for fishing up-stream rather than in the opposite direction; and I grant that they have attained an empirical knowledge of the æsthetic preferences of trout in the matter of blue duns and red palmers; but that as a body they are familiar with the speckled trout 
at home I deny. If you wish to learn all about the race in its own life you must abjure rod and line, and creep quietly to the side of the pools in an unfished brooklet, like this on whose bank I am now seated; and then, if you have taken care not to let your shadow fall upon the water, you may sit and watch the live fish themselves for an hour together, as they bask lazily in the sunlight, or rise now and then at cloudy moments with a sudden dart at a May-fly who is trying in vain to lay her eggs unmolested on the surface of the stream. The trout in my little beck are fortunately too small even for poachers to care for tickling them: so I am able entirely to preserve them as objects for philosophical contemplation, without any danger of their being scared away from their accustomed haunts by intrusive anglers.

Trout always have a recognised home of their own, inhabited by a pretty fixed number of individuals. But if you catch the two sole denizens of a particular scour, you will find 
another pair installed in their place tomorrow. Young fry seem always ready to fill up the vacancies caused by the involuntary retirement of their elders. Their size depends almost entirely upon the quantity of food they can get; for an adult fish may weigh anything at any time of his life, and there is no limit to the dimensions they may theoretically attain. Mr. Herbert Spencer, who is an angler as well as a philosopher, well observes that where the trout are many they are generally small; and where they are large they are generally few. In the mill-stream down the valley they measure only six inches, though you may fill a basket easily enough on a cloudy day ; but in the canal reservoir, where there are only half-a-dozen fish altogether, a magnificent eight-pounder has been taken more than once. In this way we can understand the origin of the great lake trout, which weigh sometimes forty pounds. They are common trout which have taken to living 
in broader waters, where large food is far more abundant, but where shoals of small fish would starve. The peculiarities thus impressed upon them have been handed down to their descendants, till at length they have become sufficiently marked to justify us in regarding them as a separate species. But it is difficult to say what makes a species in animals so very variable as fish. There are, in fact, no less than twrelve kinds of trout wholly peculiar to the British Islands, and some of these are found in very restricted areas. Thus, the Loch Stennis trout inhabits only the tarns of Orkney; the Galway sea trout lives nowhere but along the west coast of Ireland; the gillaroo never strays out of the Irish loughs; the Killin charr is confined to a single sheet of water in Mayo ; and other species belong exclusively to the Llanberis lakes, to Lough Melvin, or to a few mountain pools of Wales and Scotland. So great is the variety that may be produced by small changes of food and habitat. Even the 
salmon himself is only a river trout who has acquired the habit of going down to the sea, where he gets immensely increased quantities of food (for all the trout kind are almost omnivorous), and grows big in proportion. But he still retains many marks of his early existence as a river fish. In the first place, every salmon is hatched from the egg in fresh water, and grows up a mere trout. The young parr, as the salmon is called in this stage of its growth, is actually (as far as physiology goes) a mature fish, and is capable of producing milt, or male spawn, which long caused it to be looked upon as a separate species. It really represents, however, the early form of the salmon, before he took to his annual excursion to the sea. The ancestral fish, only a hundredth fraction in weight of his huge descendant, must have somehow acquired the habit of going seaward-possibly from a drying up of his native stream in seasons of drought. In the sea, he found himself suddenly supplied with an unwonted store of 
food, and grew, like all his kind under similar circumstances, to an extraordinary size. Thus he attains, as it were, to a second and final maturity. But salmon cannot lay their eggs in the sea ; or at least, if they did, the young parr would starve for want of their proper food, or else be choked by the salt water, to which the old fish have acclimatised themselves. Accordingly, with the return of the spawning season there comes back an instinctive desire to seek once more the native fresh water. So the salmon return up stream to spawn, and the young are hatched in the kind of surroundings which best suit their tender gills. This instinctive longing for the old home may probably have arisen during an intermediate stage, when the developing species still haunted only the brackish water near the river mouths; and as those fish alone which returned to the head waters could preserve their race, it would soon grow hardened into a habit engrained in the nervous system, like the migration of birds or the clustering 
of swarming bees around their queen. In like manner the Jamaican land-crabs, which themselves live on the mountain-tops, come down every year to lay their eggs in the Caribbean; because, like-all other crabs, they pass their first larval stage as swimming tadpoles, and afterwards take instinctively to the mountains, as the salmon takes to the sea. Such a habit could only have arisen by one generation after another venturing further and further inland, while always returning at the proper season to the native element for the deposition of the eggs.

These trout here, however, differ from the salmon in one important particular beside their relative size, and that is that they are beautifully speckled in their mature form, instead of being merely silvery like the larger species. The origin of the pretty speckles is probably to be found in the constant selection by the fish of the most beautiful among their number as mates. Just as singing-birds are in their fullest and clearest song at the nest- 
ing period, and just as many brilliant species only possess their gorgeous plumage while they are going through their courtship, and lose the decoration after the young brood is hatched, so the -trout are most brightly coloured at spawning time, and become lank and dingy after the eggs have been safely deposited. The parent fish ascend to the head-waters of their native river during the autumn season to spawn, and then, their glory dimmed, they return down-stream to the deep pools, where they pass the winter sulkily, as if ashamed to show themselves in their dull and dusky suits. But when spring comes round once more, and flies again become abundant, the trout begin to move up-stream afresh, and soon fatten out to their customary size and brilliant colours. It might seem at first sight that creatures so humble as these little fish could hardly have sufficiently developed æsthetic tastes to prefer one mate above another on the score of beauty. But we must remember that every 
species is very sensitive to small points of detail in its own kind, and that the choice would only be exerted between mates generally very like one another, so that extremely minute differences must necessarily turn the scale in favour of one particular suitor rather than his rivals. Anglers know that trout are attracted by bright colours, that they can distinguish the different flies upon which they feed, and that artificial flies must accordingly be made at least into a rough semblance of the original insects. Some scientific fishermen even insist that it is no use offering them a brown drake at the time of year or the hour of day when they are naturally expecting a red spinner. Of course their sight is by no means so perfect as our own, but it probably includes a fair idea of form, and an acute perception of colour, while there is every reason to believe that all the trout family have a decided love of metallic glitter, such as that of silver or of the salmon's scales. Mr. Darwin has shown that the 
little stickleback goes through an elaborate courtship, and I have myself watched trout which seemed to me as obviously lovemaking as any pair of turtle-doves I ever saw. In their early life salmon fry and young trout are almost quite indistinguishable, being both marked with blue patches (known as 'finger-marks') on their sides, which are remnants of the ancestral colouring once common to the whole race. But as they grow up, their later-acquired tastes begin to produce a divergence, due originally to this selective preference of certain beautiful mates ; and the adult salmon clothes himself from head to tail in sheeny silver, while the full-grown trout decks his sides with the beautiful speckles which have earned him his popular name. Countless generations of slight differences, selected from time to time by the strongest and handsomest fish, have sufficed at length to bring about these conspicuous variations from the primitive type, which the young of both races still preserve. 


\section{XIII.}

DODDER AND BROOMRAPE.

THis afternoon, strolling through the undercliff, I have come across two quaint and rather uncommon flowers among the straggling brushwood. One of them is growing like a creeper around the branches of this overblown gorse-bush. It is the lesser dodder, a pretty clustering mass of tiny pale pink convolvulus blossoms. The stem consists of a long red thread, twining round and round the gorse, and bursting out here and there into thick bundles of beautiful bell-shaped flowers. But where are the leaves? You may trace the red threads through their labyrinthine windings up and down the supporting gorse-branches all in vain : there is not a leaf to be seen. As a matter of fact, 
the dodder has none. It is one of the most thorough-going parasites in all nature. Ordinary green-leaved plants live by making starches for themselves out of the carbonic acid in the air, under the influence of sunlight; but the dodder simply fastens itself on to another plant, sends down rootlets or suckers into its veins, and drinks up sap stored with ready-made starches or other foodstuffs, originally destined by its host for the supply of its own growing leaves, branches, and blossoms. It lives upon the gorse just as parasitically as the little green aphides live upon our rose-bushes. The material which it uses up in pushing forth its long thread-like stem and clustered bells is so much dead loss to the unfortunate plant on which it has fixed itself.

Old-fashioned books tell us that the mistletoe is a perfect parasite, while the dodder is an imperfect one; and I believe almost all botanists will still repeat the foolish saying to the present day. But it really shows 
considerable haziness as to what a true parasite is. The mistletoe is a plant which has taken, it is true, to growing upon other trees. Its very viscid berries are useful for attaching the seeds to the trunk of the oak or the apple; and there it roots itself into the body of its host. But it soon produces real green leaves of its own, which contain the ordinary chlorophyll found in other leaves, and help it to manufacture starch, under the influence of sunlight, on its own account. It is not, therefore, a complete drag upon the tree which it infests; for though it takes sap and mineral food from the host, it supplies itself with carbon, which is after all the important thing for plant-life. Dodder, however, is a parasite pure and simple. Its seeds fall originally upon the ground, and there root themselves at first like those of any other plant. But, as it grows, its long twining stem begins to curl for support round some other and stouter stalk. If it stopped there, and then produced 
leaves of its own, like the honeysuckle and the clematis, there would be no great harm done: and the dodder would be but another climbing plant the more in our flora. However, it soon insidiously repays the support given it by sending down little bud-like suckers, through which it draws up nourishment from the gorse or clover on which it lives. Thus it has no need to develop leaves of its own; and it accordingly employs all its stolen material in sending forth matted thread-like stems and bunch after bunch of bright flowers. As these increase and multiply, they at last succeed in drawing away all the nutriment from the supporting plant, which finally dies under the constant drain, just as a horse might die under the attacks of a host of leeches. But this matters little to the dodder, which has had time to be visited and fertilised by insects, and to set and ripen its numerous seeds. One species, the greater dodder, is thus parasitic upon hops and nettles; a second kind twines 
round flax; and the third, which I have here under my eyes, mainly confines its dangerous attentions to gorse, clover, and thyme. All of them are, of course, deadly enemies to the plants they infest.

How the dodder acquired this curious mode of life it is not difficult to see. By descent it is a bind-weed, or wild convolvulus, and its blossoms are in the main miniature convolvulus blossoms still. Now, all bind-weeds, as everybody knows, are climbing plants, which twine themselves round stouter stems for mere physical support. This is in itself a half-parasitic habit, because it enables the plant to dispense with the trouble of making a thick and solid stem for its own use. But just suppose that any bind-weed, instead of merely twining, were to put forth here and there little tendrils, something like those of the ivy, which managed somehow to grow into the bark of the host, and so naturally graft themselves to its tissues. In that case the plant would 
derive nutriment from the stouter stem with no expense to itself, and it might naturally be expected to grow strong and healthy, and hand down its peculiarities to its descendants. As the leaves would thus be rendered needless, they would first become very much reduced in size, and would finally disappear altogether, according to the universal custom of unnecessary organs. So we should get at length a leafless plant, with numerous flowers and seeds, just like the dodder. Parasites, in fact, whether animal or vegetable, always end by becoming mere reproductive sacs, mechanisms for the simple elaboration of eggs or seeds. This is just what has happened to the dodder before me.

The other queer plant here is a broom rape. It consists of a tall, somewhat fadedlooking stem, upright instead of climbing, and covered with brown or purplish scales in the place of leaves. Its flowers resemble the scales in colour, and the dead-nettle in shape. It is, in fact, a parasitic dead- 
nettle, a trifle less degenerate as yet than the dodder. This broomrape has acquired somewhat the same habits as the other plant, only that it fixes itself on the roots of clover or broom, from which it sucks nutriment by its own root, as the dodder does by its stemsuckers. Of course it still retains in most particulars its original characteristics as a dead-nettle ; it grows with their upright stem and their curiously shaped flowers, so specially adapted for fertilisation by insect visitors. But it has naturally lost its leaves, for which it has no further use, and it possesses no chlorophyll, as the mistletoe does. Yet it has not probably been parasitic for as long a time as the dodder, since it still retains a dwindling trace of its leaves in the shape of dry purply scales, something like those of young asparagus shoots. These leaves are now, in all likelihood, actually undergoing a gradual atrophy, and we may fairly expect that in the course of a few thousand years they will disappear altogether. At present, 
however, they remain very conspicuous by their colour, which is not green, owing to the absence of chlorophyll, but is due to the same pigment as that of the blossoms. This generally happens with parasites, or with that other curious sort of plants known as saprophytes, which live upon decaying living matter in the mould of forests. As they need no green leaves, but have often inherited leafy structures of some sort, in a more or less degenerate condition, from their self-supporting ancestors, they usually display most beautiful colours in their stems and scales, and several of them rank amongst our handsomest hot-house plants. Even the dodder has red stalks. Their only work in life being to elaborate the materials stolen from their host into the brilliant pigments used in the petals for attracting insect fertilisers, they pour this same dye into the stems and scales, which thus render them still more conspicuous to the insects' eyes. Moreover, as they use their whole material 
in producing flowers, many of these are very large and handsome; one huge Sumatran species has a blossom which measures three feet across. On the other hand, their seeds are usually small and very numerous. Thousands of seeds must fall on unsuitable places, spring up, and waste all their tiny store of nourishment, find no host at hand on which to fasten themselves, and so die down for want of food. It is only by producing a few thousand young plants for every one destined ultimately to survive that dodders and broomrapes manage to preserve their types at all. 


\section{XIV.}

DOG'S MERCURY AND PLANTAIN.

THE hedge and bank in Haye Lane are now a perfect tangled mass of creeping plants, among which I have just picked out a queer little three-cornered flower, hardly known even to village children, but christened by our old herbalists 'dog's mercury.' It is an ancient trick of language to call coarser or larger plants by the specific title of some smaller or cultivated kind, with the addition of an animal's name. Thus we have radish and horse-radish, chestnut and horse-chestnut, rose and dog-rose, parsnip and cow-parsnip, thistle and sow-thistle. On the same principle, a somewhat similar plant being known as mercury, this perennial weed becomes dog's mercury. Both, of course, go back to 
some imaginary medicinal virtue in the herb which made it resemble the metal in the eyes of old-fashioned practitioners.

Dog's mercury is one of the oddest English flowers I know. Each blossom has three small green petals, and either several stamens, or else a pistil, in the centre. There is nothing particularly remarkable in the flower being green, for thousands of other flowers are green and we never notice them as in any way unusual. In fact, we never as a rule notice green blossoms at all. Yet anybody who picked a piece of dog's mercury could not fail to be struck by its curious appearance. It does not in the least resemble the inconspicuous green flowers of the stinging-nettle, or of most forest trees: it has a very distinct set of petals which at once impress one with the idea that they ought to be coloured. And so indeed they ought : for dog's mercury is a degenerate plant which once possessed a brilliant corolla and was fertilised by insects, but which has now 
fallen from its high estate and reverted to the less advanced mode of fertilisation by the intermediation of the wind. For some unknown reason or other this species and all its relations have discovered that they get on better by the latter and usually more wasteful plan than by the former and usually more economical one. Hence they have given up producing large bright petals, because they no longer need to attract the eyes of insects ; and they have also given up the manufacture of honey, which under their new circumstances would be a mere waste of substance to them. But the dog's mercury still retains a distinct mark of its earlier insect-attracting habits in these three diminutive petals. Others of its relations have lost even these, so that the original floral form is almost completely obscured in their case. The spurges are familiar English roadside examples, and their flowers are so completely degraded that even botanists for a long time mistook their nature and analogies. 
The male and female flowers of dog's mercury have taken to living upon separate plants. Why is this? Well, there was no doubt a time when every blossom had both stamens and pistil, as dog-roses and buttercups always have. But when the plant took to wind fertilisation it underwent a change of structure. The stamens on some blossoms became aborted, while the pistil became aborted on others. This was necessary in order to prevent self-fertilisation ; for otherwise the pollen of each blossom, hanging out as it does to the wind, would have been very liable to fall upon its own pistil. But the present arrangement obviates any such contingency, by making one plant bear all the male flowers and another plant all the female ones. Why, again, are the petals green ? I think because dog's mercury would be positively injured by the visits of insects. It has no honey to offer them, and if they came to it at all, they would only eat up the pollen itself. Hence I suspect that those flowers 
among the mercuries which showed any tendency to retain the original coloured petals would soon get weeded out, because insects would eat up all their pollen, thus preventing them from fertilising others; while those which had green petals would never be noticed and so would be permitted to fertilise one another after their new fashion. In fact, when a blossom which has once depended upon insects for its fertilisation is driven by circumstances to depend upon the wind, it seems to derive a positive advantage from losing all those attractive features by which its ancestors formerly allured the eyes of bees or beetles.

Here, again, on the roadside is a bit of plantain. Everybody knows its flat rosette of green leaves and its tall spike of grass-like blossom, with long stamens hanging out to catch the breeze. Now plantain is a case exactly analogous to dog's mercury. It is an example of a degraded blossom. Once upon a time it was a sort of distant cousin to the 
veronica, that pretty sky-blue speedwell which abounds among the meadows in June and July. But these particular speedwells gave up devoting themselves to insects and became adapted for fertilisation by the wind instead. So you must look close at them to see at all that the flowering spike is made up of a hundred separate little four-rayed blossoms, whose pale and faded petals are tucked away out of sight flat against the stem. Yet their shape and arrangement distinctly recall the beautiful veronica, and leave one in little doubt as to the origin of the plant. At the same time a curious device has sprung up which answers just the same purpose as the separation of the male and female flowers on the dog's mercury. Each plantain blossom has both stamens and pistils, but the pistils come to maturity first, and are fertilised by pollen blown to them from some neighbouring spike. Their feathery plumes are admirably adapted for catching and utilising any stray golden grain 
which happens to pass that way. After the pistils have faded, the stamens ripen, and hang out at the end of long waving filaments, so as to discharge all their pollen with effect. On each spike of blossoms the lower flowerets open first; and so, if you pick a half-blown spike, you will see that all the stamens are ripe below, and all the pistils above. Were the opposite arrangement to occur, the pollen would fall from the stamens to the lower flowers of the same stalk; but as the pistils below have always been fertilised and withered before the stamens ripen, there is no chance of any such accident and its consequent evil results. Thus one can see clearly that the plantain has become wholly adapted to wind-fertilisation, and as a natural effect has all but lost its brightcoloured corolla.

Common groundsel is also a case of the same kind; but here the degradation has not gone nearly so far. I venture to conjecture, therefore, that groundsel has been embarked 
for a shorter time upon its downward course. For evolution is not, as most people seem to fancy, a thing which used once to take place; it is a process taking place around us every day, and it must necessarily continue to take place to the end of all time. By family the groundsel is a daisy; but it has acquired the strange and somewhat abnormal habit of self-fertilisation, which in all probability will ultimately lead to its total extinction. Hence it does not need the assistance of insects; and it has accordingly never developed or else got rid of the bright outer ray-florets which may once have attracted them. Its tiny bell-shaped blossoms still retain their divarf yellow corollas; but they are almost hidden by the green cup-like investment of the flower-head, and they are not conspicuous enough to arrest the attention of the passing flies. Here, then, we have an example of a plant just beginning to start on the retrograde path already traversed by the plantain and the spurges. If we could meet prophetically 
with a groundsel of some remote future century, I have little doubt we should find its bell-shaped petals as completely degraded as those of the plantain in our own day.

The general principle which these cases illustrate is that when flowers have always been fertilised by the wind, they never have brilliant corollas; when they acquire the habit of impregnating their kind by the intervention of insects, they almost always acquire at the same time alluring colours, perfumes, and honey; and when they have once been so impregnated, and then revert once more to wind-fertilisation, or become self-fertilisers, they generally retain some symptoms of their earlier habits, in the presence of dwarfed and useless petals, somerimes green, or if not green at least devoid of their former attractive colouring. Thus every plant bears upon its very face the history of its whole previous development. 


\section{XV.}

BUTTERFLY PSYCHOLOGY.

A SMALL red-and-black butterfly poises statuesque above the purple blossom of this tall field-thistle. With its long sucker it probes industriously floret after floret of the crowded head, and extracts from each its wee drop of buried nectar. As it stands just at present, the dull outer sides of its four wings are alone displayed, so that it does not form a conspicuous mark for passing birds; but when it has drunk up the last drop of honey from the thistle flower, and flits joyously away to seek another purple mass of the same sort, it will open its red-spotted vans in the sunlight, and will then show itself off as one among the prettiest of our native insects. 
Each thistle-head consists of some two hundred separate little bell-shaped blossoms, crowded together for the sake of conspicuousness into a single group, just as the blossoms of the lilac or the syringa are crowded into larger though less dense clusters; and, as each separate floret has a nectary of its own, the bee or butterfly who lights upon the compound flower-group can busy himself for a minute or two in getting at the various drops of honey without the necessity for any further change of position than that of revolving upon his own axis. Hence these composite flowers are great favourites with all insects whose suckers are long enough to reach the bottom of their slender tubes.

The butterfly's view of life is doubtless on the whole a cheerful one. Yet his existence must be something so nearly mechanical that we probably overrate the amount of enjoyment which he derives from flitting about so airily among the flowers, and passing his days in the unbroken amusement of 
sucking liquid honey. Subjectively viewed, the butterfly is not a high order of insect ; his nervous system does not show that provision for comparatively spontaneous thought and action which we find in the more intelligent orders, like the flies, bees, ants, and wasps. His nerves are all frittered away in little separate ganglia distributed among the various segments of his body, instead of being governed by a single great central organ, or brain, whose business it always is to correlate and co-ordinate complex external impressions. This shows that the butterfly's movements are almost all automatic, or simply dependent upon immediate external stimulants : he has not even that small capacity for deliberation and spontaneous initiative which belongs to his relation the bee. The freedom of the will is nothing to him, or extends at best to the amount claimed on behalf of Buridan's ass : he can just choose which of two equidistant flowers shall first have the benefit of his attention, and nothing 
else. Whatever view we take on the abstract metaphysical question, it is at least certain that the higher animals can do much more than this. Their brain is able to correlate a vast number of external impressions, and to bring them under the influence of endless ideas or experiences, so as finally to evolve conduct which differs very widely with different circumstances and different characters. Even though it be true, as determinists believe (and I reckon myself among them), that such conduct is the necessary result of a given character and given circumstances-or, if you will, of a particular set of nervous structures and a particular set of external stimuli-yet we all know that it is capable of varying so indefinitely, owing to the complexity of the structures, as to be practically incalculable. But it is not so with the butterfly. His whole life is cut out for him beforehand; his nervous connections are so simple, and correspond so directly with external stimuli, that we can almost 
predict with certainty what line of action he will pursue under any given circumstances. $\mathrm{He}$ is, as it were, but a piece of half-conscious mechanism, answering immediately to impulses from without, just as the thermometer answers to variations of temperature, and as the telegraphic indicator answers to each making and breaking of the electric current.

In early life the future butterfly emerges from the egg as a caterpillar. At once his many legs begin to move, and the caterpillar moves forward by their motion. But the mechanism which set them moving was the nervous system, with its ganglia working the separate legs of each segment. This movement is probably quite as automatic as the act of sucking in the new-born infant. The caterpillar walks, it knows not why, but simply because it has to walk. When it reaches a fit place for feeding, which differs according to the nature of the particular larva, it feeds automatically. Certain special 
external stimulants of sight, smell, or touch set up the appropriate actions in the mandibles, just as contact of the lips with an external body sets up sucking in the infant. All these movements depend upon what we call instinct-that is to say, organic habits registered in the nervous system of the race. They have arisen by natural selection alone, because those insects which duly performed them survived, and those which did not duly perform them died out. After a considerable span of life spent in feeding and walking about in search of more food, the caterpillar one day found itself compelled by an inner monitor to alter its habits. Why, it knew not; but, just as a tired child sinks to sleep, the gorged and full-fed caterpillar sank peacefully into a dormant state. Then its tissues melted one by one into a kind of organic pap, and its outer skin hardened into a chrysalis. Within that solid case new limbs and organs began to grow by hereditary impulses. At the same time the form of the nervous system altered, 
to suit the higher and freer life for which the insect was unconscinusly preparing itself. Fewer and smaller ganglia now appeared in the tail segments (since no legs would any longer be needed there), while more important ones sprang up to govern the motions of the four wings. But it was in the head that the greatest changes took place. There, a rudimentary brain made its appearance, with large optic centres, answering to the far more perfect and important eyes of the future butterfly. For the flying insect will have to steer its way through open space, instead of creeping over leaves and stones; and it will have to suck the honey of flowers, as well as to choose its fitting mate, all of which demands from it higher and keener senses than those of the purblind caterpillar. At length one day the chrysalis bursts asunder, and the insect emerges to view on a summer morning as a full-fledged and beautiful butterfly.

For a minute or two it stands and waits till the air it breathes has filled out its wings, 
and till the warmth and sunlight have given it strength. For the wings are by origin a part of the breathing apparatus, and they require to be plimmed by the air before the insect can take to flight. Then, as it grows more accustomed to its new life, the hereditary impulse causes it to spread its vans abroad, and it flies. Soon a flower catches its eye, and the bright mass of colour attracts it irresistibly, as the candle-light attracts the eye of a child a few weeks old. It sets off towards the patch of red or yellow, probably not knowing beforehand that this is the visible symbol of food for it, but merely guided by the blind habit of its race, imprinted with binding force in the very constitution of its body. Thus the moths, which fly by night and visit only white flowers whose corollas still shine out in the twilight, are so irresistibly led on by the external stimulus of light from a candle falling upon their eyes that they cannot choose but move their wings rapidly in that direction; 
and though singed and blinded twice or three times by the flame, must still wheel and eddy into it, till at last they perish in the scorching blaze. Their instincts, or, to put it more clearly, their simple nervous mechanism, though admirably aảapted to their natural circumstances, cannot be equally adapted to such artificial objects as wax candles. The butterfly in like manner is attracted automatically by the colour of his proper flowers, and settling upon them, sucks up their honey instinctively. But feeding is not now his only object in life: he has to find and pair with a suitable mate. That, indeed, is the great end of his winged existence. Here, again, his simple nervous system stands him in good stead. The picture of his kind is, as it were, imprinted on his little brain, and he knows his own mates the moment he sees them, just as intuitively as he knows the flowers upon which he must feed. Now we see the reason for the butterfly's large optic centres: they have to guide 
it in all its movements. In like manner, and by a like mechanism, the female butterfly or moth selects the right spot for laying her eggs, which of course depends entirely upon the nature of the young caterpillars' proper food. Each great group of insects has its own habits in this respect, may-flies laying their eggs on the water, many beetles on wood, flies on decaying animal matter, and butterflies mostly on special plants. Thus throughout its whole life the butterfly's activity is entirely governed by a rigid law, registered and fixed for ever in the constitution of its ganglia and motor nerves. Certain definite objects outside it invariably produce certain definite movements on the insect's part. No doubt it is vaguely conscious of all that it does : no doubt it derives a faint pleasure from due exercise of all its vital functions, and a faint pain when they are injured or thwarted; but on the whole its range of action is narrowed and bounded by its hereditary instincts and their nervous 
correlatives. It may light on one flower rather than another; it may choose a fresher and brighter mate rather than a battered and dingy one; but its little subjectivity is a mere shadow compared with ours, and it hardly deserves, to be considered as more than a semi-conscious automatic machine. 


\section{XVI.}

BUTTERFLY AESTHETICS:

THE other day, when I was watching that little red-spotted butterfly whose psychology I found so interesting, I hardly took enough account, perhaps, of the insect's own subjective feelings of pleasure and pain. The first great point to understand about these minute creatures is that they are, after all, mainly pieces of automatic mechanism: the second great point is to understand that they are probably something more than that as well. To-day I have found another exactly similar butterfly, and I am going to work out with myself the other half of the problem about him. Granted that the insect is, viewed intellectually, a cunning bit of nervous 
machinery, may it not be true at the same time that he is, viewed emotionally, a faint copy of ourselves?

Here he stands on a purple thistle again, true, as usual, to the plant on which I last found him. There can be no doubt that he distinguishes one colour from another, for you can artificially attract him by putting a piece of purple paper on a green leaf, just as the flower naturally attracts him with its native hue. Numerous observations and experiments have proved with all but absolute certainty that his discrimination of colour is essentially identical with our own ; and I think, if we run our eye up and down nature, observing how universally all animals are attracted by pure and bright colours, we can hardly doubt that he appreciates and admires colour as well as discriminates it. Mr. Darwin certainly judges that butterflies can show an æsthetic preference of the sort, for he sets down their own lovely hues to the constant sexual selection of the handsomest 
mates. We must not, however, take too human a measure of their capacities in this respect. It is sufficient to believe that the insect derives some direct enjoyment from the stimulation of pure colour, and is hereditarily attracted by it wherever it may show itself. This pleasure draws it on, on the one hand, towards the gay flowers which form its natural food; and, on the other hand, towards its own brilliant mates. Imprinted on its nervous system is a certain blank form answering to its own specific type ; and when the object corresponding to this blank form occurs in its neighbourhood, the insect blindly obeys its hereditary instinct. But out of two or three such possible mates it naturally selects that which is most brightly spotted, and in other ways most perfectly fulfils the specific ideal. We need not suppose that the insect is conscious of making a selection or of the reasons which guide it in its choice : it is enough to believe that it follows the strongest stimulus, just as the child picks out 
the biggest and reddest apple from a row of ten. Yet such unconscious selections, made from time to time in generation after generation, have sufficed to produce at last all the beautiful spots and metallic eyelets of our loveliest English or tropical butterflies. Insects always accustomed to exercising their colour-sense upon flowers and mates, may easily acquire a high standard of taste in that direction, while still remaining comparatively in a low stage as regards their intellectual condition. But the fact I wish especially to emphasise is this - that the flowers produced by the colour-sense of butterflies and their allies are just those objects which we ourselves consider most lovely in nature; and that the marks and shades upon their own wings, produced by the long selective action of their mates, are just the things which we ourselves consider most beautiful in the animal world. In this respect, then, there seems to be a close community of taste and feeling between the butterfly and ourselves. 
Let me note, too, just in passing, that while the upper half of the butterfly's wing is generally beautiful in colour, so as to attract his fastidious mate, the under half, displayed while he is at rest, is almost always dull, and often resembles the plant upon which he habitually alights. The first set of colours is obviously due to sexual selection, and has for its object the making an effective courtship; but the second set is obviously due to natural selection, and has been produced by the fact that all those insects whose bright colours show through too vividly when they are at rest fall a prey to birds or other enemies, leaving only the best protected to continue the life of the species.

But sight is not the only important sense to the butterfly. He is largely moved and guided by smell as well. Both bees and butterflies seem largely to select the flowers they visit by means of smell, though colour also aids them greatly. When we remember that in ants scent alone does duty instead of 
eyes, ears, or any other sense, it would hardly be possible to doubt that other allied insects possessed the same faculty in a high degree ; and, as Dr. Bastian says, there seems good reason for believing that all the higher insects are guided almost as much by smell as by sight. Now it is noteworthy that most of those flowers which lay themselves out to attract bees and butterflies are not only coloured but sweetly scented; and it is to this cause that we owe the perfumes of the rose, the lily-of-the-valley, the heliotrope, the jasmine, the violet, and the stephanotis. Nightflowering plants, which depend entirely for their fertilisation upon moths, are almost always white, and have usually very powerful perfumes. Is it not a striking fact that these various scents are exactly those which human beings most admire, and which they artificially extract for essences? Here, again, we see that the æsthetic tastes of butterflies and men decidedly agree; and that the thyme or lavender whose perfume pleases the bee is the very 
thing which we ourselves choose to sweeten our rooms.

Finally, if we look at the sense of taste, we find an equally curious agreement between men and insects; for the honey which is stored by the flower for the bee, and by the bee for its own use, is stolen and eaten up by man instead. Hence, when I consider the general continuity of nervous structure throughout the whole animal race, and the exact similarity of the stimulus in each instance, I can hardly doubt that the butterfly really enjoys life somewhat as we enjoy it, though far less vividly. I cannot but think that he finds honey sweet, and perfumes pleasant, and colour attractive; that he feels a lightsome gladness as he flits in the sunshine from flower to flower, and that he knows a faint thrill of pleasure at the sight of his chosen mate. Still more is this belief forced upon me when I recollect that, so far as I can judge, throughout the whole animal world, save only in a few aberrant types, sugar 
is sweet to taste, and thyme to smell, and song to hear, and sunshine to bask in. Therefore, on the whole, while I admit that the butterfly is mainly an animated puppet, I must qualify my opinion by adding that it is a puppet which, after its vague little fashion, thinks and feels very much as we do. 


\section{XVII.}

THE ORIGIN OF WALNUTS.

MR. DARWIN has devoted no small portion of his valuable life to tracing, in two bulky volumes, the Descent of Man. Yet I suppose it is probable that in our narrow anthropinism we should have refused to listen to him had he given us two volumes instead on the Descent of Walnuts. Viewed as a question merely of biological science, the one subject is just as important as the other. But the old Greek doctrine that ' man is the measure of all things' is strong in us still. We form for ourselves a sort of pre-Copernican universe, in which the world occupies the central point of space, and man occupies the central point of the world. What touches 
man interests us deeply: what concerns him but slightly we pass over as of no consequence. Nevertheless, even the origin and development of walnuts is a subject upon which we may profitably reflect, not wholly without gratification and interest.

This kiln-dried walnut on my plate, which has suggested such abstract cogitations to my mind, is shown by its very name to be a foreign production; for the word contains the same root as Wales and Welsh, the old Teutonic name for men of a different race, which the Germans still apply to the Italians, and we ourselves to the last relics of the old Keltic population in Southern Britain. It means 'the foreign nut,' and it comes for the most part from the south of Europe. As a nut, it represents a very different type of fruit from the strawberry and raspberry, with their bright colours, sweet juices, and nutritious pulp. Those fruits which alone bear the name in common parlance are attractive in their object; the nuts are deterrent. An 
orange or a plum is brightly tinted with hues which contrast strongly with the surrounding foliage; its pleasant taste and soft pulp all advertise it for the notice of birds or monkeys, as a means for assisting in the dispersion of its seed. But a nut, on the contrary, is a fruit whose actual seed contains an abundance of oils and other pleasant foodstuffs, which must be carefully guarded against the depredations of possible foes. In the plum or the orange we do not eat the seed itself: we only eat the surrounding pulp. But in the walnut the part which we utilise is the embryo plant itself ; and so the walnut's great object in life is to avoid being eaten. Accordingly, that part of the fruit which in the plum is stored with sweet juices is, in the walnut, filled with a bitter and very nauseous essence. We seldom see this bitter covering in our over-civilised life, because it is, of course, removed before the nuts come to table. The walnut has but a thin shell, and is poorly protected in comparison with some of 
its relations, such as the American butternut, which can only be cracked by a sharp blow from a hammer-or even the hickory, whose hard covering has done more to destroy the teeth of New Englanders than all other causes put together, and New England teeth are universally admitted to be the very worst in the world. Now, all nuts have to guard against squirrels and birds ; and therefore their peculiarities are exactly opposite to those of succulent fruits. Instead of attracting attention by being brightly coloured, they are invariably green like the leaves while they remain on the tree, and brown or dusky like the soil when they fall upon the ground beneath; instead of being enclosed in sweet coats, they are provided with bitter, acrid, or stinging husks; and, instead of being soft in texture, they are surrounded by hard shells, like the coco-nut, or have'a perfectly solid kernel, like the vegetable ivory.

The origin of nuts is thus exactly the reverse side of the origin of fruits. Certain 
seeds, richly stored with oils and starches for aiding the growth of the young plant, are exposed to the attacks of squirrels, monkeys, parrots, and other arboreal animals. The greater part of them are eaten and completely destroyed by these their enemies, and so never hand down their peculiarities to any descendants. But all fruits vary a little in sweetness and bitterness, pulpy or stringy tendencies. Thus a few among them happen to be protected from destruction by their originally accidental possession of a bitter husk, a hard shell, or a few awkward spines and bristles. These the monkeys and squirrels reject; and they alone survive as the parents of future generations. The more persistent and the hungrier their foes become, the less will a small degree of bitterness or hardness serve to protect them. Hence, from generation to generation, the bitterness and the hardness will go on increasing, because only those nuts which are the nastiest and the most difficult to crack will escape destruc- 
tion from the teeth or bills of the growing and pressing population of rodents and birds. The nut which best survives on the average is that which is least conspicuous in colour, has a rind of the most objectionable taste, and is enclosed in the most solid shell. But the extent to which such precautions become necessary will depend much upon the particular animals to whose attacks the nuts of each country are exposed. The European walnut has only to defy a few small woodland animals, who are sufficiently deterred by its acrid husk ; the American butter-nut has to withstand the long teeth of much more formidable forestine rodents, whom it sets at nought with its stony and wrinkled shell; and the tropical cocos and Brazil nuts have to escape the monkey, who pounds them with stones, or flings them with all his might from the tree-top so as to smash them in their fall against the ground below.

Our own hazel-nut supplies an excellent illustration of the general tactics adopted 
by the nuts at large. The little red tufted blossoms which everybody knows so well in early spring are each surrounded by a bunch of three bracts ; and as the nut grows bigger, these bracts form a green leaf-like covering, which causes it to look very much like the ordinary foliage of the hazel-tree. Besides, they are thickly set with small prickly hairs, which are extremely annoying to the fingers, and must prove far more unpleasant to the delicate lips and noses of lower animals. Just at present the nuts have reached this stage in our copses; but as soon as autumn sets in, and the seeds are ripe, they will turn brown, fall out of their withered investment, and easily escape notice on the soil beneath, where the dead leaves will soon cover them up in a mass of shrivelled brown, indistinguishable in shade from the nuts themselves. Take, as an example of the more carefully protected tropical kinds, the coco-nut. Growing on a very tall palm-tree, it has to fall a considerable distance toward the earth; and 
so it is wrapped round in a mass of loose knotted fibre, which breaks the fall just as a lot of soft wool would do. Then, being a large nut, fully stored with an abundance of meat, it offers special attractions to animals, and consequently requires special means of defence. Accordingly, its shell is extravagantly thick, only one small soft spot being left at the blunter end, through which the young plant may push its head. Once upon a time, to be sure, the coco-nut contained three kernels, and had three such soft spots or holes; but now two of them are aborted, and the two holes remain only in the form of hard scars. The Brazil nut is even a better illustration. Probably few people know that the irregular angular nuts which appear at dessert by that name are originally contained inside a single round shell, where they fit tightly together, and acquire their queer indefinite shapes by mutual pressure. So the South American monkey has first to crack the thick external 
common shell against a stone or otherwise; and, if he is successful in this process, he must afterwards break the separate sharpedged inner nuts with his teeth-a performance which is always painful and often ineffectual.

Yet it is curious that nuts and fruits are really produced by the very slightest variations on a common type, so much so that the technical botanist does not recognise the popular distinction between them at all. In his eyes, the walnut and the coco-nut are not nuts, but 'drupaceous fruits,' just like the plum and the cherry. All four alike contain a kernel within, a hard shell outside it, and a fibrous mass outside that again, bounded by a thin external layer. Only, while in the plum and cherry this fibrous mass becomes succulent and fills with sugary juice, in the walnut its juice is bitter, and in the coco-nut it has no juice at all, but remains a mere matted layer of dry fibres. And while the thin external skin becomes purple in the 
plum and red in the cherry as the fruits ripen, it remains green and brown in the walnut and coco-nut all their time. Nevertheless, Darwinism shows us both here and elsewhere that the popular distinction answers to a real difference of origin and function. When a seed-vessel, whatever its botanical structure, survives by dint of attracting animals, it always acquires a bright-coloured envelope and a sweet pulp; while it usually possesses a hard seed-shell, and often infuses bitter essences into its kernel. On the other hand, when a seed-vessel survives by escaping the notice of animals, it generally has a sweet and pleasant kernel, which it protects by a hard shell and an inconspicuous and nauseous envelope. If the kernel itself is bitter, as with the horse-chestnut, the need for disguise and external protection is much lessened. But the best illustration of all is seen in the West Indian cashew-nut, which is what Alice in Wonderland would have called a portmanteau seed-vessel-a fruit and 
a nut rolled into one. In this curious case, the stalk swells out into a bright-coloured and juicy mass, looking something like a pear, but of course containing no seeds; while the nut grows out from its end, secured from intrusion by a covering with a pungent juice, which burns and blisters the skin at a touch. No animal except man can ever successfully tackle the cashew-nut itself; but by eating the pear-like stalk other animals ultimately aid in distributing the seed. The cashew thus vicariously sacrifices its fruitstem for the sake of preserving its nut.

All nature is a continuous game of crosspurposes. Animals perpetually outwit plants, and plants in return once more outwit animals. Or, to drop the metaphor, those animals alone survive which manage to get a living in spite of the protections adopted by plants; and those plants alone survive whose peculiarities happen successfully to defy the attack of animals. There you have the Darwinian Iliad in a nutshell. 


\section{XVIII.}

A PRETTY LAND-SHELL.

THE heavy rains which have done so much harm to the standing corn have at least had the effect of making the country look greener and lovelier than I have seen it look for many seasons. There is now a fresh verdure about the upland pastures and pine woods which almost reminds one of the deep valleys of the Bernese Oberland in early spring. Last year's continuous wet weather gave the trees and grass a miserable draggled appearance; but this summer's rain, coming after a dry spring, has brought out all the foliage in unwonted luxuriance; and everybody (except the British farmer) agrees that we have never seen the country look more 
beautiful. Though the year is now so far advanced, the trees are still as green as in springtide; and the meadows, with their rich aftermath springing up apace, look almost as lush and fresh as they did in early June. Londoners who get away to the country or the seaside this month will enjoy an unexpected treat in seeing the fields as they ought to be seen a couple of months sooner in the season.

Here, on the edge of the down, where I have come up to get a good blowing from the clear south-west breeze, I have just sat down to rest myself awhile and to admire the view, and have reverted for a moment to my old habit of snail-hunting. Years ago, when evolution was an infant-an infant much troubled by the complaints inseparable from infancy, but still a sturdy and vigorous child, destined to outlive and outgrow its early attacks-I used to collect slugs and snails, from an evolutionist standpoint, and put their remains into a cabinet; and to this day I 
seldom go out for a walk without a few pillboxes in my pocket, in case I should happen to hit upon any remarkable specimen. Now here in the tall moss which straggles over an old heap of stones I have this moment lighted upon a beautifully marked shell of our prettiest English snail. How beautiful it is I could hardly make you believe, unless I had you here and could show it to you; for most people only know the two or three ugly brown or banded snails that prey upon their cabbages and lettuces, and have no notion of the lovely shells to be found by hunting among English copses and under the dead leaves of Scotch hill-sides. This cyclostoma, however,-I must trouble you with a Latin name for once-is so remarkably pretty, with its graceful clongated spiral whorls, and its delicately chiselled fretwork tracery, that even naturalists (who have perhaps, on the whole, less sense of beauty than any class of men I know) have recognised its loveliness by giving it the specific epithet 
of elegans. It is big enough for anybody to notice it, being about the size of a periwinkle; and its exquisite stippled chasing is strongly marked enough to be perfectly visible to the naked eye. But besides its beauty, the cyclostoma has a strong claim upon our attention because of its curious history.

Long ago, in the infantile days of evolutionism, I often wondered why people made collections on such an irrational plan. They always try to get what they call the most typical specimens, and reject all those which are doubtful or intermediate. Hence the dogma of the fixity of species becomes all the more firmly settled in their minds, because they never attend to the existing links which still so largely bridge over the artificial gaps created by our nomenclature between kind and kind. I went to work on the opposite plan, collecting all those aberrant individuals which most diverged from the specific type. In this way I managed to make some series 
so continuous that one might pass over specimens of three or four different kinds, arranged in rows, without ever being able to say quite clearly, by the eye alone, where one group ended and the next group began. Among the snails such an arrangement is peculiarly easy; for some of the species are very indefinite, and the varieties are numerous under each species. Nothing can give one so good a notion of the plasticity of organic forms as such a method. The endless varieties and intermediate links which exist amongst dogs is the nearest example to it with which ordinary observers are familiar.

But the cyclostoma is a snail which introduces one to still deeper questions. It belongs in all our scientific classifications to the group of lung-breathing mollusks, like the common garden snail. Yet it has one remarkable peculiarity: it possesses an operculum, or door to its shell, like that of the periwinkle. This operculum represents among the univalves the under-shell of the 
oyster or other bivalves; but it has completely disappeared in most land and freshwater snails, as well as among many marine species. The fact of its occurrence in the cyclostoma would thus be quite inexplicable if we were compelled to regard it as a descendant of the other lung-breathing mollusks. So far as I know, all naturalists have till lately always so regarded it; but there can be very little doubt, with the new light cast upon the question by Darwinism, that they are wrong. There exists in all our ponds and rivers another snail, not breathing by means of lungs, but provided with gills, known as paludina. This paludina has a door to its shell, like the cyclostoma ; and so, indeed, have all its allies. Now, strange as it sounds to say so, it is pretty certain that we must really class this lung-breathing cyclostoma among the gill-breathers, because of its close resemblance to the paludina. It is, in fact, one of these gill-breathing pondsnails which has taken to living on dry land, 
and so has acquired the habit of producing lungs. All molluscan lungs are very simple: they consist merely of a small sac or hollow behind the head, lined with blood-vessels; and every now and then the snail opens this sac, allowing the air to get in and out by natural change, exactly as when we air a room by opening the windows. So primitive a mechanism as this could be easily acquired by any soft-bodied animal like a snail. Besides, we have many intermediate links between the pond-snails and my cyclostoma here. There are some species which live in moist moss, or the beds of trickling streams. There are others which go further from the water, and spend their days in damp grass. And there are yet others which have taken to a wholly terrestrial existence in woods or meadows and under heaps of stones. All of them agree with the pond-snails in having an operculum, and so differ from the ordinary land and river-snails, the mouths of whose shells are quite unprotected. Thus land- 
snails have two separate origins-one large group (including the garden-snail) being derived from the common fresh-water mollusks, while another much smaller group (including the cyclostoma) is derived from the operculated pond-snails.

How is it, then, that naturalists had so long overlooked this distinction? Simply because their artificial classification is based entirely upon the nature of the breathing apparatus. But, as Mr. Wallace has well pointed out, obvious and important functional differences are of far less value in tracing relationship than insignificant and unimportant structural details. Any water-snail may have to take to a terrestrial life if the ponds in which it lives are liable to dry up during warm weather. Those individuals alone will then survive which display a tendency to oxygenise their blood by some rudimentary form of lung. Hence the possession of lungs is not the mark of a real genealogical class, but a mere necessary result of a terrestrial 
existence. On the other hand, the possession of an operculum, unimportant as it may be to the life of the animal, is a good test of relationship by descent. All snails which take to living on land, whatever their original form, will acquire lungs : but an operculated snail will retain its operculum, and so bear witness to its ancestry; while a snail which is not operculated will of course show no tendency to develop such a structure, and so will equally give a true testimony as to its origin. In short, the less functionally useful any organ is, the higher is its value as a gauge of its owner's pedigree, like a Bourbon* nose or an Austrian lip. 


\section{XIX.}

DOGS AND MASTERS.

Probably the most forlorn and abject creature to be seen on the face of the earth is a masterless dog. Slouching and slinking along, cringing to every human being it chances to meet, running away with its tail between its legs from smaller dogs whom under other circumstances it would accost with a gruff who-the-dickens-are-you sort of growl,-it forms the very picture of utter humiliation and self-abasement. Grip and I have just come across such a lost specimen of stray doghood, trying to find his way back to his home across the fields-I fancy he belongs to a travelling show which left the village yesterday-and it is quite refreshing to watch 
the air of superior wisdom and calm but mute compassionateness with which Grip casts his eye sidelong upon that wretched masterless vagrant, and passes him by without even a nod. He looks up to me complacently as he trots along by my side, and seems to say with his eye, 'Poor fellow! he's lost his master, you know-careless dog that he is!' I believe the lesson has had a good moral effect upon Grip's own conduct, too; for he has now spent ten whole minutes well within my sight, and has resisted the most tempting solicitations to ratting and rabbiting held out by half-a-dozen holes and burrows in the hedge-wall as we go along.

This total dependence of dogs upon a master is a very interesting example of the growth of inherited instincts. The original dog, who was a wolf or something very like it, could not have had any such artificial feeling. He was an independent, self-reliant animal, quite well able to look after himself on the boundless plains of Central Europe or 
High Asia. But at least as early as the days of the Danish shell-mounds, perhaps thousands of years earlier, man had learned to tame the dog and to employ him as a friend or servant for his own purposes. Those dogs which best served the ends of man were preserved and increased; those which followed too much their own original instincts were destroyed or at least discouraged. The savage hunter would be very apt to fling his stone axe at the skull of a hound which tried to eat the game he had brought down with his flint-tipped arrow, instead of retrieving it : he would be most likely to keep carefully and feed well on the refuse of his own meals the hound which aided him most in surprising, killing, and securing his quarry. Thus there sprang up between man and the dog a mutual and ever increasing sympathy which on the part of the dependent creature has at last become organised into an inherited instinct. If we could only thread the labyrinth of a dog's brain, we should find somewhere in it a group 
of correlated nerve-connections answering to this universal habit of his race; and the group in question would be quite without any analogous mechanism in the brain of the ancestral wolf. As truly as the wing of the bird is adapted to its ccngenital instinct of flying, as truly as the nervous system of the bee is adapted to its congenital instinct of honeycomb building, just so truly is the brain of the dog adapted to its now congenital instinct of following and obeying a master. The habit of attaching itself to a particular human being is nowadays engrained in the nerves of the modern dog just as really, though not quite so deeply, as the habit of running or biting is engrained in its bones and muscles. Every dog is born into the world with a certain inherited structure of limbs, sense-organs, and brain: and this inherited structure governs all its future actions, both bodily and mental. It seeks a master because it is endowed with master-seeking brain organs; it is dissatisfied until it finds 
one, because its native functions can have free play in no other way. Among a few dogs, like those of Constantinople, the instinct may have died out by disuse, as the eyes of cave animals have atrophied for want of light; but when a dog has once been brought up from puppyhood under a master, the instinct is fully and freely developed, and the masterless condition is thenceforth for him a thwarting and disappointing of all his natural feelings and affections.

Not only have dogs as a class acquired a special instinct with regard to humanity generally, but particular breeds of dogs have acquired particular instincts with regard to certain individual acts. Nobody doubts that the muscles of a greyhound are specially correlated to the acts of running and leaping ; or that the muscles of a bull-dog are specially correlated to the act of fighting. The whole external form of these creatures has been modified by man's selective action for a deliberate purpose : we breed, as we say, from the dog with the best 
points. But besides being able to modify the visible and outer structure of the animal, we are also able to modify, by indirect indications, the hidden and inner structure of the brain. We choose the best ratter among our terriers, the best pointer, retriever, or setter among other breeds, to become the parents of our future stock. We thus half unconsciously select particular types of nervous system in preference to others. Once upon a time we used even to rear a race of dozs with a strange instinct for turning the spit in our kitchens; and to this day the Cubans rear blood-hounds with a natural taste for hunting down the trail of runaway negroes. Now, everybody knows that you cannot teach one sort of dog the kind of tricks which come by instinct to a different sort. No amount of instruction will induce a well-bred terrier to retrieve your handkerchief : he insists upon worrying it instead. So no amount of instruction will induce a well-bred retriever to worry a rat: he brings it gingerly to your feet, as if it 
was a dead partridge. The reason is obvious, because no one would breed from a retriever which worried or from a terrier which treated its natural prey as if it were a stick. Thus the brain of each kind is hereditarily supplied with certain nervous connections wanting in the brain of other kinds. We need no more doubt the reality of the material distinction in the brain than we need doubt it in the limbs and jaws of the greyhound and the bull-dog. Those who have watched closely the different races of men can hardly hesitate to believe that something analogous exists in our own case. While the highest types are, as $\mathrm{Mr}$. Herbert Spencer well puts it, to some extent 'organically moral' and structurally intelligent, the lowest types are congenitally deficient. A European child learns to read almost by nature (for Dogberry was essentially right after all), while a Negro child learns to read by painful personal experience. And savages brought to Europe and 'civilised' for years often return at last with joy to their native 
home, cast off their clothes and their outer veneering, and take once more to the only life for which their nervous organisation naturally fits them. "What is bred in the bone,' says the wise old proverb, ' will out in the blood.' 


\section{XX.}

BLACKCOCK.

JusT at the present moment the poor black grouse are generally having a hot time of it. After their quiet spring and summer they suddenly find their heath-clad wastes invaded by a strange epidemic of men, dogs, and hideous shooting implements; and being as yet but young and inexperienced, they are falling victims by the thousand to their youthful habit of clinging closely for protection to the treacherous reed-beds. A little later in the season, those of them that survive will have learned more wary ways : they will pack among the juniper thickets, and become as cautious on the approach of perfidious man as their cunning cousins, the red grouse of 
the Scottish moors, But so far youthful innocence prevails; no sentinels as yet are set to watch for the distant gleam of metal, and no foreshadowing of man's evil intent disturbs their minds as they feed in fancied security upon the dry seeds of the marsh plants in their favourite sedges.

The great families of the pheasants and partridges, in which the blackcock must be included, may be roughly divided into two main divisions so far as regards their appearance and general habits. The first class consists of splendidly coloured and conspicuous birds, such as the peacock, the golden pheasant, and the tragopan ; and these are, almost without exception, originally jungle-birds of tropical or sub-tropical lands, though a few of them have been acclimatised or domesticated in temperate countries. They live in regions where they have few natural enemies, and where they are little exposed to the attacks of man. Most of them feed more or less upon fruits and bright-coloured food- 
stuffs, and they are probably every one of them polygamous in their habits. Thus we can hardly doubt that the male birds, which alone possess the brilliant plumage of their kind, owe their beauty to the selective preference of their mates; and that the taste thus displayed has been aroused by their relation to their specially gay and bright natural surroundings. The most lovely species of pheasants are found among the forests of the Himalayas and the Malay Archipelago, with their gorgeous fruits and flowers and their exquisite insects. Even in England our naturalised Oriental pheasants still delight in feeding upon blackberries, sloes, haws, and the pretty fruit of the honeysuckle and the holly; while our dingier partridges and grouse subsist rather upon heather, grain, and small seeds. Since there must always be originally nearly as many cocks as hens in each brood, it will follow that only the handsomest or most attractive in the polygamous species will succeed in attracting to 
them a harem; and as beauty and strength usually go hand in hand, they will also be the conquerors in those battles which are universal with all polygamists in the animal world. Thus we account for the striking and conspicuous difference between the peacock and the peahen, or between the two sexes in the pheasant, the turkey, and the domestic fowl.

On the other hand, the second class consists of those birds which are exposed to the hostility of many wild animals, and more especially of man. These kinds, typified by the red grouse, partridges, quails, and guineafowls, are generally dingy in hue, with a tendency to pepper-and-salt in their plumage ; and they usually display very little difference between the sexes, both cocks and hens being coloured and feathered much alike. In short, they are protectively designed, while the first class are attractive. Their plumage resembles as nearly as possible the ground on which they sit or the covert in 
which they skulk. They are thus enabled to escape the notice of their natural enemies, the birds of prey, from whose ravages they suffer far more in a state of nature than from any other cause. We may take the ptarmigans as the most typical example of this class of birds; for in summer their zigzagged black-and-brown attire harmonises admirably with the patches of faded heath and soil upon the mountain-side, as every sportsman well knows; while in the winter their pure white plumage can scarcely be distinguished from the snow in which they lie huddled and crouching during the colder months. Even in the brilliant species, Mr. Darwin and $\mathrm{Mr}$. Wallace have pointed out that the ornamental colours and crest are never handed down to female descendants when the habits of nesting are such that the mothers would be exposed to danger by their conspicuousness during incubation. Speaking broadly, only those female birds which build in hollow trees or make covered nests have bright hues 
at all equal to those of the males. A female bird nesting in the open would be cut off if it showed any tendency to reproduce the brilliant colouring of its male relations.

Now the blackcock occupies to some extent an intermediate position between these two types of pheasant life, though it inclines on the whole to that first described. It is a polygamous bird, and it differs most conspicuously in plumage from its consort, the grey-hen, as may be seen from the very names by which they are each familiarly known. Yet, though the blackcock is handsome enough and shows evident marks of selective preference on the part of his ancestral hens, this preference has not exerted itself largely in the direction of bright colour, and that for two reasons. In the first place the blackcock does not feed upon brilliant foodstuffs, but upon small bog-berries, hard seeds, and young shoots of heather, and it is probable that an æsthetic taste for pure and dazzling hues is almost confined to those 
creatures which, like butterflies, hummingbirds, and parrots, seek their livelihood amongst beautiful fruits or flowers. In the second place, red, yellow, or orange ornaments would render the blackcock too con spicuous a mark for the hawk, the falcon, or the weapons of man; for we must remember that only those blackcocks survive from year to year and hand down their peculiarities to descendants which succeed in evading the talons of birds of prey or the small-shot of sportsmen. Feeding as they do on the open, they are not protected, like jungle-birds, by the shade of trees. Thus any bird which showed any marked tendency to develop brighter or more conspicuous plumage would almost infallibly fall a victim to one or other of his many foes; and however much his beauty might possibly charm his mates (supposing them for the moment to possess a taste for colour), he would have no chance of transmitting it to a future generation. Accordingly, the decoration of the blackcock is 
confined to glossy plumage and a few ornamental tail-feathers. The grey-hen herself still retains the dull and imitative colouring of the grouse race genera!ly; and as for the cocks, even if a fair percentage of them is annually cut off through their comparative conspicuousness as marks, their loss is less felt than it would be in a monogamous community. Every spring the blackcock hold a sort of assembly or court of love, at which the pairing for the year takes place. The cocks resort to certain open and recognised spots, and there invite the grey-hens by their calls, a little duelling going on meanwhile. During these meetings they show off their beauty with great emulation, after the fashion with which we are all familiar in the case of the peacock; and when they have gained the approbation of their mates and maimed or driven away their rivals, they retire with their respective families. Unfortunately, like most polygamists, they make bad fathers, leaving the care of their young almost en- 
tirely to the hens. According to the veracious account of Artemus Ward, the great Brigham Young himself pathetically descanted upon the difficulty of extending his parental affections to $\mathrm{I} 3 \mathrm{I}$ children. The imperious blackcock seems to labour under the same sentimental disadvantage. 


\section{XXI.}

BINDWEED.

Not the least beautiful among our native wild flowers are many of those which grow, too often unheeded, along the wayside of every country road. The hedge-bordered highway on which I am walking to-day, to take my letters to the village post, is bordered on either side with such a profusion of colour as one may never see equalled during many years' experience of tropical or sub-tropical lands. Jamaica and Ceylon could produce nothing so brilliant as this tangled mass of gorse, and thistle, and St. John's-wort, and centaury, intermingled with the lithe and whitening sprays of half-opened clematis. And here, on the very edge of 
the road, half-smothered in its grey dust, I have picked a pretty little convolvulus blossom, with a fly buried head-foremost in its pink bell; and I am carrying them both along with me as I go, for contemplation and study. For this little flower, the lesser bindweed, is rich in hints as to the strange ways in which Nature decks herself with so much waste loveliness, whose meaning can only be fully read by the eyes of man, the latest comer among her children. The old school of thinkers imagined that beauty was given to flowers and insects for the sake of man alone: it would not, perhaps, be too much to say that, if the new school be right, the beauty is not in the flowers and insects themselves at all, but is read into them by the fancy of the human race. To the butterfly the world is a little beautiful; to the farm-labourer it is only a trifle more beautiful: but to the cultivated man or the artist it is lovely in every cloud and shadow, in every tiny blossom and passing bird. 
The outer face of the bindweed, the exterior of the cup, so to speak, is prettily marked with five dark russet-red bands, between which the remainder of the corolla is a pale pinky-white in hue. Nothing could be simpler and prettier than this alternation of dark and light belts; but how is it produced ? Merely thus. The convolvulus blossom in the bud is twisted or contorted round and round, part of the cup being folded inside, while the five joints of the corolla are folded outside, much after the fashion of an umbrella when rolled up. And just as the bits of the umbrella which are exposed when it is folded become faded in colour, so the bits of the bindweed blossom which are outermost in the bud become more deeply oxidised than the other parts, and acquire a russet-red hue. The belted appearance which thus results is really as accidental, if I may use that unphilosophical expression, as the belted appearance of the old umbrella, or the wrinkles caused by the 
waves on the sea-sands. The flower happened to be folded so, and got coloured, or discoloured, accordingly. But when a man comes to look at it, he recognises in the alternation of colours and the symmetrical arrangement one of those elements of beauty with which he is familiar in the handicraft of his own kind. He reads an intention into this result of natural causes, and personifies Nature as though she worked with an æsthetic design in view, just as a decorative artist works when he similarly alternates colours or arranges symmetrical and radial figures on a cup or other piece of human pottery. The beauty is not in the flower itself; it is in the eye which sees and the brain which recognises the intellectual order and perfection of the work.

I turn the bindweed blossom mouth upward, and there I see that these russet marks, though paler on the inner surface, still show faintly through the pinky white corolla. This produces an effect not unlike 
that of a delicate shell cameo, with its dainty gradations of semi-transparent white and interfusing pink. But the inner effect can be no more designed with an eye to beauty than the outer one was; and the very terms in which I think of it clearly show that my sense of its loveliness is largely derived from comparison with human handicraft. A farmer would see in the convolvulus nothing but a useless weed; a cultivated eye sees in it just as much as its nature permits it to see. I look closer, and observe that there are also thin lines running from the circumference to the centre, midway between the dark belts. These lines, which add greatly to the beauty of the flower, by marking it out into zones, are also due to the folding in the bud; they are the inner angles of the folds, just as the dark belts are the overlapping edges of the outer angles. But, in addition to the minor beauty of these little details, there is the general beauty of the cup as a whole, which also calls for explana- 
tion. Its shape is as graceful as that of any Greek or Etruscan vase, as swelling and as simply beautiful as any beaker. Can I account for these peculiarities on mere natural grounds as well as for the others? I somehow fancy I can.

The bindweed is descended from some earlier ancestors which had five separate petals, instead of a single fused and circular cup. But in the convolvulus family, as in many others, these five petals have joined into a continuous rim or bowl, and the marks on the blossom where it was folded in the bud still answer to the five petals. In many plants you can see the pointed edges of the former distinct flower-rays as five projections, though their lower parts have coalesced into a bell-shaped or tubular blossom, as in the common harebell. How this comes to pass we can easily understand if we watch an unopened fuchsia; for there the four brightcoloured sepals remain joined together till the bud is ready to open, and then split 
along a line marked out from the very first. In the plastic bud condition it is very easy for parts usually separate so to grow out in union with one another. I do not mean that separate pieces actually grow together, but that pieces which usually grow distinct sometimes grow united from the very first. Now, four or five petals, radially arranged, in themselves produce that kind of symmetry which man, with his intellectual love for order and definite patterns, always finds beautiful But the symmetry in the flower simply results from the fact that a single whorl of leaves has grown into this particular shape, while the outer and inner whorls have grown into other shapes; and every such whorl always and necessarily presents us with an example of the kind of symmetry which we so much admire. Again, when the petals forming a whorl coalesce, they must, of course, produce a more or less regular circle. If the points of the petals remain as projections, then we get a circle with vandyked 
edges, as in the lily of the valley; if they do not project, then we get a simple circular rim, as in the bindweed. All the lovely shapes of bell-blossoms are simply due to the natural coalescence of four, five, or six petals; and this coalescence is again due to an increased certainty of fertilisation secured for the plant by the better adaptation to insect visits. Similarly, we know that the colours of the corolla have been acquired as a means of rendering the flower conspicuous to the eyes of bees or butterflies; and the hues which so prove attractive to insects are of the same sort which arouse pleasurable stimulation in our own nerves. Thus the whole loveliness of flowers is in the last resort dependent upon all kinds of accidental causes-causes, that is to say, into which the deliberate design of the production of beautiful effects did not enter as a distinct factor. Those parts of nature which are of such a sort as to arouse in us certain feelings we call beautiful; and those parts which are of 
such a sort as to arouse in us the opposite feelings we call ugly. But the beauty and the ugliness are not parts of the things; they are merely human modes of regarding some among their attributes. Wherever in nature we find pure colour, symmetrical form, and intricate variety of pattern, we imagine to ourselves that nature designs the object to be beautiful. When we trace these peculiarities to their origin, however, we find that each of them owes its occurrence to some special fact in the history of the object ; and we are forced to conclude that the notion of intentional design has been read into it by human analogies. All nature is beautiful, and most beautiful for those in whom the sense of beauty is most highly developed; but it is not beautiful at all except to those whose own eyes and emotions are fitted to perceive its beauty. 


\section{XXII.}

ON CORNISH CLIFFS.

I AM lying on my back in the sunshine, close to the edge of a great broken precipice, beside a clambering Cornish fishing village. In front of me is the sea, bluer than I have seen it since last I lay in like fashion a few months ago on the schistose slopes of the Maurettes at Hyères, and looked away across the plain to the unrippled Mediterranean and the Stæchades of the old Phocæan merchantmen. On either hand rise dark cliffs of hornblende and serpentine, weathered above by wind and rain, and smoothed below by the ceaseless dashing of the winter waves. $\mathrm{Up}$ to the limit of the breakers the hard rock is polished like Egyptian syenite; but beyond 
that point it is fissured by disintegration and richly covered with a dappled coat of grey and yellow lichen. The slow action of the water, always beating against the solid wall of crystalline rock, has eaten out a thousand such little bays all along this coast, each bounded by long headlands, whose points have been worn into fantastic pinnacles, or severed from the main mass as precipitous islets, the favourite resting-place of gulls and cormorants. No grander coast scenery can be found anywhere in the southern half of Great Britain.

Yet when I turn inland I see that all this beauty has been produced by the mere interaction of the sea and the barren moors of the interior. Nothing could be flatter or more desolate than the country whose scaward escarpment gives rise to these romantic coves and pyramidal rocky islets. It stretches away for miles in a level upland waste, only redeemed from complete barrenness by the low straggling bushes of the dwarf furze, 
whose golden blossom is now interspersed with purple patches of ling or the paler pink flowers of the Cornish heath. Here, then, I can see beauty in nature actually beginning to be. I can trace the origin of all these little bays from small rills which have worn themselves gorge-like valleys through the hard igneous rock, or else from fissures finally giving rise to sea-caves, like the one into which I rowed this morning for my early swim. The waves penetrate for a couple of hundred yards into the bowels of the rock, hemmed in by walls and roof of dark serpentine, with its interlacing veins of green and red bearing witness still to its once molten condition; and at length in most cases they produce a blow-hole at the top, communicating with the open air above, either because the fissure there crops up to the surface, or else through the agency of percolation. At last, the roof falls in; the boulders are carried away by the waves; and we get a long and narrow cove, still bounded on either 
side by tall cliffs, whose summits the air and rainfall slowly wear away into jagged and exquisite shapes. Yet in all this we see nothing but the natural play of cause and effect; we attribute the beauty of the scene merely to the accidental result of inevitable laws; we feel no necessity for calling in the aid of any underlying rsthetic intention on the part of the sea, or the rock, or the creeping lichen, in order to account for the loveliness which we find in the finished picture. The winds and the waves carved the coast into these varied shapes by force of blind currents working on hidden veins of harder or softer crystal : and we happen to find the result beautiful, just as we happen to find the inland level dull and ugly. The endless variety of the one charms us, while the unbroken monotony of the other wearies and repelś us.

Here on the cliff I pick up a pretty fern and a blossoming head of the autumn squill - though so sweet a flower deserves a better 
name. This fern, too, is lovely in its way, with its branching leaflets and its rich glossygreen hue. Yet it owes its shape just as truly to the balance of external and internal forces acting upon it as does the Cornish coast-line. How comes it then that in the one case we instinctively regard the beauty as accidental, while in the other we set it down to a deliberate esthetic intent? I think because, in the first case, we can actually see the forces at work, while in the second they are so minute and so gradual in their action as to escape the notice of all but trained observers. This fern grows in the shape that I see, because its ancestors have been slowly moulded into such a form by the whole group of circumstances directly or indirectly affecting them in all their past life; and the germ of the complex form thus produced was impressed by the parent plant upon the spore from which this individual fern took its birth. Over yonder I see a great dock-leaf; it grows tall and rank above 
all other plants, and is able to spread itself boldly to the light on every side. It has abundance of sunshine as a motive-power of growth, and abundance of air from which to extract the carbon that it needs. Hence it and all its ancestors have spread their leaves equally on every side, and formed large flat undivided blades. Leaves such as these are common enough ; but nobody thinks of calling them pretty. Their want of minute subdivision, their monotonous outline, their dull surface, all make them ugly in our eyes, just as the flatness of the Cornish plain makes it also ugly to us. Where symmetry is slightly marked and variety wanting, as in the cabbage leaf, the mullein, and the burdock, we see little or nothing to admire. On the other hand, ferns generally grow in hedge-rows or thickets, where sunlight is much interrupted by other plants, and where air is scanty, most of its carbon being extracted by neighbouring plants which leave but little for one another's needs. Hence you may notice that most 
plants growing under such circumstances have leaves minutely sub-divided, so as to catch such stray gleams of sunlight and such floating particles of carbonic acid as happen to pass their way. Look into the next tangled and overgrown hedge-row which you happen to pass, and you will see that almost all its leaves are of this character; and when they are otherwise the anomaly usually admits of an easy explanation. Of course the shapes of plants are mostly due to their normal and usual circumstances, and are comparatively little influenced by the accidental surroundings of individuals; and so, when a fern of such a sort happens to grow like this one on the open, it still retains the form impressed upon it by the life of its ancestors. Now, it is the striking combination of symmetry and variety in the fern, together with vivid green colouring, which makes us admire it so much. Not only is the frond as a whole symmetrical, but each frondlet and each division of the frondlet is separately symmetrical as well. 
This delicate minuteness of workmanship, as we call it, reminds us of similar human products-of fine lace, of delicate tracery, of skilful filagree or engraving. Almost all the green leaves which we admire are noticeable, more or less, for the same effects, as in the case of maple, parsley, horse-chestnut, and vine. It is true, mere glossy greenness may, and often does, make up for the want of variety, as we see in the arum, holly, laurel, and hart's-tongue fern ; but the leaves which we admire most of all are those which, like maidenhair, are both exquisitely green and delicately designed in shape. So that, in the last resort, the beauty of leaves, like the beauty of coast scenery, is really due to the constant interaction of a vast number of natural laws, not to any distinct æsthetic intention on the part of Nature.

On the other hand, the pretty pink squill reminds me that semi-conscious æsthetic design in animals has something to do with the production of beauty in nature-at least, 
in a few cases. Just as a flower garden has been intentionally produced by man, so flowers have been unconsciously produced by insects. As a rule, all bright red, blue, or orange in nature (except in the rare case of gems) is due to animal selection, either of flowers, fruits, or mates. Thus we may say that beauty in the inorganic world is always accidental; but in the organic world it is sometimes accidental and sometimes designed. A waterfall is a mere result of geological and geographical causes, but a bluebell or a butterfly is partly the result of a more or less deliberate $æ$ sthetic choice. 



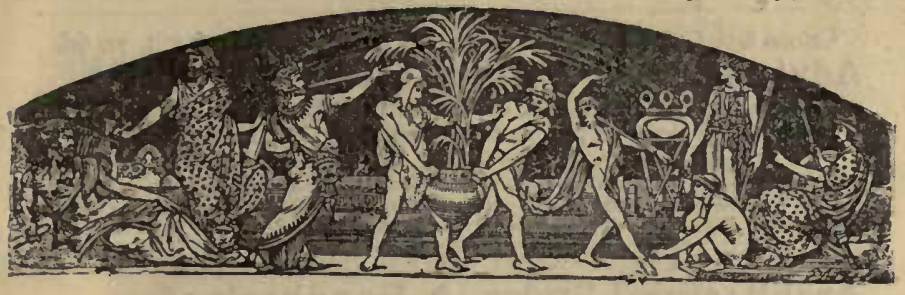

\section{CHATTO $\mathcal{E}$ WINDUS'S LIST OF BOOKS.}

Imperial 8vo, with ${ }_{4} 47$ fine Engravings, half-morocco, $3^{6 s}$.

\section{THE EARLY TEUTONIC, ITALIAN, AND FRENCH MASTFRS.}

Translated and Edited from the Dohme Series by A. H. KEANE, M.A.I. With numerous Illustrations.

"Cannot fail to be of the utmost use to students of art history."-Times.

Second Edition, Revised, Crown 8vo, I, 200 pages, half-roxburghe, I2s. $6 d$.

\section{THE READER'S HANDBOOK} OF ALLUSIONS, REFERENCES, PLOTS, AND STORIES.

By the Rev. Dr. BrewER.

"Dr. Brewer has produced a wonderfully comprehensive dictionary of references to matters which are always cropping wp in conversation and in cveryday life, and suriters generally will have reason to feel grateful to the author for a most handy volume, supplententing in a hundred zuays their onun knowledge or ignorance, is the case may be. . . . It is something more than a mere dictionaly of guota. tions, though a most useful companion to any work of that kind, being a dictionary' of most of the allusions, references, plots, stories, and characters which occur in the classical poems, plays, novels, ronzances, $\mathcal{S}^{\circ} \mathrm{c}$., not only of our own country, but of most rations, arcient and modern." -TiMrs.

"A welcome addition to the list of what may be termed the really handy refer. ence-books, combining as it does a dictionary of literature with a condensed ency. clopadia, interspersed with itens one usually looks for in commonplace books. The appendices contain the dates of celebrated and well-known dramas, operas, poems, and novels, with the names of their authors." - SPRCTATOR.

"There seems to be scarcely anything concerning which one may not "overhanl" Dr. Brewer's book with profit. It is a most laborious and patient compilation, and, considering the magnitude of the work, successfully performed. . . Many queries which appear in our pages conld be satisfactoril answered by a reference to 'The Reader's Handbook:' no mean testimony to the value of Dr. Brewer's book." -NOTES AND QURRIRS.

A HANDBOOK FOR POTTERY-PAINTERS.

Crown 8 vo, cloth extra, $6 s$.

\section{Practical Keramics for Students.}

By Cirakles A. JANVier. 
Crown 8vo, Coloured Frontispiece and Illustrations, cloth gilt, 7s. 6d. Advertising, A History of.

From the Earliest Times. Illustrated by Anecdotes, Curious Specimens, and Notes of Successful Advertisers. By HenRY SAMPSON.

"We have here a book to be thankful for. We recommend the present volume, which takes ws through antiguity, the middle ages, and the present time, illustrat. ing all in turn by advertisements-seriows, comic, roguish, or downright rascally. The volume is full of entertainment from the first page to the last." -A А THRN

Crown 8vo, cloth extra, with 639 Illustrations, 75. 6d.

\section{Architectural Styles, A Handbook of.}

Translated from the German of A. ROSENGARTEN by W. COLLETTSANDARS. With 639 Illustrations.

Crown 8vo, with Portrait and Facsimile, cloth extra, 7s. 6d.

Artemus Ward's Works:

The Works of ChARLES FARRER BROWNE, better known as ARTEMUS

WARD. With Portrait, Facsimile of Handwriting, \&c.

Second Edition, demy $8 \mathrm{vo}$, cloth extra, with Map and Illustrations, 18 s.

Baker's Clouds in the Elast:

Travels and Adventures on the Perso-Turcoman Frontier. By

VALENTINE BAKER. Second Edition, revised and corrected.

Crown 8vo, cloth extra, 6s.

Balzac. - The Comédie Humaine and its

Author. With Translations from Balzac. By H. H. WALKER.

Crown 8vo, cloth extra, 7s. $6 d$.

Bankers, A Handbook of London;

With some Aocount of their Predecessors, the Early Goldsmiths: together with Lists of Bankers from 1677 to 1876 . By F. G. HnLTON PRICE.

Bardsley (Rev. C. W.), Works by:

Fnglish Surnames: Their Sources and Significations, By ChARLES WAREING BARDSLEY, M.A. Second Edition, revised throughout and considerably Enlarged. Crown 8vo, cloth extra, 7s, 6d.

"Mr. Bardsley has faith fully consulted the original medietoal documents and works from which the orig in and develotement of surnames can alone be satisfactorily traced. He has funished a valuable contribution to the literature of surnames, and we hope to hear more of him in this field." -Tises.

Curiosities of Puritan Nomenclature. By CHARLES W.

BARDSLEY. Crown 8vo, cloth extra, 7s. $6 d$.

"The book is full of interest; in fact, it is just the thorough and scholarly work we should expect from the author of 'English Surnames.' "-GRAPuic.

Small 4to, green and gold, $6 s .6 d$; ; gilt edges, $75.6 d$.

\section{Bechstein's As Pretty as Seven,}

And other German Stories. Collected by LUDWIG BECHSTErN. With Additional Tales by the Brothers Grrmm, and 100 Illustrations by RICHTER. 
A New Edition, crown 8vo, cloth extra, 7s. $6 d$.

\section{Bartholomew Fair, Memoirs of.}

By Henry MORlex. New Edition, with One Hundred Illustrations.

Imperial 4 to, cloth extra, gilt and gilt edges, 2 rs. per volume.

Beautiful Pictures by British Artists :

A Gathering of Favourites from our Picture Galleries. In Two Series. The FIRST SERIEs including Examples by WiLKIE, CONSTABLE,

Turner, Mulready, Landseer, Maclise, E. M. WARd, Frith,

Sir John Gilbert, Leslie, Ansdell, Marcus Stone, Sir Noel,

Paton, Faed, Eyre Crowe, Gavin O'Neil, and Madox Brown.

The Second Series containing Pictures by ARmitage, Faed,

GoOdall, HeMSLEY, HORSLEY, MARKS, Nicholls, Sir NOEL Paton, Pickersgill, G, Smith, Marcus Stone, Solomon, STRAIGHT, E. M. WARD, and WARREN.

All engraved on Steel in the highest style of Art. Edited, with

Notices of the Artists, by Sydney ARmytaGe, M.A.

"This book is well got up, and good engravings by Feens, Lwmb Stocks, and others, bring back to ws Royal Academy Exhibitions of past years."-Times.

NEW NOVEL BY THE AUTHOR OF "THE NE WV REPUBLIC." Belgravia for January, 1881,

Price One Slilling, contains the First Parts of Three New Serials, viz. :-

x. A Romance of the Nineteenth Century, by W. H. Mallock, Author of "The New Republic."

2. Joseph's CoAt, by D. Christie MURray, Author of "A Life's Atonement." With Illustrations by F.BARNARD.

3. Round ABout Eton axd Harrow, by AlFred Riniser. With numerous Illustrations.

* The FORTY-SECOND Volume of BELGRA VIA, elegantly bound in crimson cloth, full gilt side and back, gilt edges, price $75.6 d$., is now ready. - Handsome Cases for binding volumes can be had at 2 s, each.

\section{Blackburn's Art Handbooks:}

Demy 8 vo, Illustrated, uniform in size for binding.

Academy Notes, 1875. With 40 Illustrations. Is.

Academy Notes, 1876. With Io7 Illustrations. Is.

Academy Notes, 1877. With 143 Illustrations. Is.

Academy Notes, 1878. With 150 Illustrations. Is.

Academy Notes, 1879. With 146 Illustrations, Is.

Academy Notes, 1880. With 126 Illustrations.

Grosvenor Notes, 1878. With 68 Illustrations. Is.

Grosvenor Notes, 1879. With 60 Illustrations. Is.

Grosvenor Notes, 1880 . With 48 Illustrations.

Pictures at the Paris Exhibition, 1878. 8o Illustrations.

Pletures at South Kensington. (The Raphael Cartoons, Sheep. shanks Collection, \&c.) With yo Illustrations. Is.

The English Plctures at the National Gallerg. With II4 Illustrations. Is. 
ART HANDBOOKS-continued.

The Old Masters at the National Gallery. 128 Illusts. 1s, 6 . Academy Notes, 1875-79. Complete in One Volume, with nearly 600 Illustrations in Facsimile. Demy 8vo, cloth limp, 6s.

A Complete Illustrated Catalogue to the National Gallery. With Notes by HenkY Blıckaures, and 242 Illustrations. Demy 8vo, cloth limp, $3 s$. UNIFORM WITH "ACADEMY NOTES."

Royal Scottish Academy Notes, 1878. 117 Illustrations. Is. Royal Scottish Academy Notes, 1879. I25 Illustrations. Is. Royal Scottish Academy Notes, 1880. II 4 Illustrations. Is. Glasgow Institute of Fine Arts Notes, 1878. 95 Illusts. Is. Glasgow Institute of Fine Arts Notes, 1879. ID Illusts. Is. Glasgow Institute of Fine Arts Notes, 1880. I20 Illusts. Is. Walker Art Gallery Notes, Liverpool, 1878. 112 Illusts. Is. Walker Art Gallery Notes, Liverpool, 1879. Ioo Illusts. Is. Walker Art Gallery Notes, Liverpool, 1880. Ioo Illusts. Is's. Royal Manchester Institution Notes, 1878. 88 Illustrations. Is. Society of Artists Notes, Birmingham, 1878. 95 Illusts. 1s. Children of the Great City. By F. W. LAwson. With Facsimile Sketches bv the Artist. Demy $8 \mathrm{vo}$, rs.

Blake (William):

Folio, half-bound boards, India Proofs, 21s.

Etchings from his Works, By W. B. ScoTr. With descriptive Text.

"The best side of Blake's work is given here, and makes a really attractive volume, which all can enjoy. . . The etching is of the best kind, more refined and delicate than the oripinal work."-SATURDAY REVIEW.

Crown 8vo, cloth extra, gilt, with Illustrations, 7s. $6 d$.

Boccaccio's Decameron;

or, Ten Days' Entertainment. Translated into English, with an Introduction by Thomas WRIGHT, Esq., M.A., F.S.A. With Portrait, and STOTHARD's beautiful Copperplates.

\section{Bowers' (G.) Hunting Sketches:}

Canters in Crampshire. By G. Bowers. I. Gallops from Gorseborough. II. Scrambles with Scratch Packs. III. Studies with Stag Hounds. Oblong 4to, half-bound boards, $21 s$.

Leaves from a Hunting Journal. By G. Bowers. Coloured in facsimile of the originals. Obiong 4 to, half-hound, ats.

Crown 8vo, cloth extra, gilt, $75.6 d$.

Brand's Observations on Popular Antiquaties, chiefly Illustrating the Origin of our Vulgar Customs, Ceremonies, and Superstitions. With the Additions of Sir HENry ElLis. An entirely New and Revised Edition, with fine full-page Illustrations.

Small crown 8vo, cloth extra, gilt, with full-page Portraits, 4s. 6d. Brewster's (Sir David) Martyrs of Science.

Small crown 8vo, cloth extra, gilt, with Astronomical Plates, 4s. 6d. Brewster's (Sir D.) More Worlds than One, the Creed of the Philosopher and the Hope of the Christian. 


\section{Bret Harte, Works by :}

Bret Harte's Collected Works. Arranged and Revised by the

Author. Complete in Five Vols., cr. 8vo, cl. ex., 6s. each.

Vol. I. Cumplete Poetical ana Dramatic Works. Wilh Steel Plate Portrait, and an Introduction by the Author.

Vol. II. Eartiek PApriss-Luck of Roaring CAMp, and other Sketches - BOHEMIAN PAPERS-SYANish and A MERICAN LEGENDS.

Vol. III. TALes of the ARgonauts-EAStern SkBtches.

Vol. IV. GABRIRL CONROY.

Vol. V. StORles-CONDENSEd NovrLs, \&c.

The Select Works of Bret Harte, in Prose and Poetry. With Introductory Essay by J. M. BeLlew, Portrait of the Author, and 50 Illustrations. Crown 8vo, cloth extra, 7s. $6 d$.

An Heiress of Red Dog, and other Stories. By BRET HARTE. Poss $8 \mathrm{vo}$, illustrased boards, $2 s$, ; cloth limp, $2 s .6 d$.

The Twins of Table Mountain. By BRET HARTE. Fcap. $8 \mathrm{vo}$, picture cover, Is.; crown $8 \mathrm{vo}$, cloth extra, 3s. $6 d$.

The Luck of Roaring Camp, and other Sketches. By BRET HARTE. Post $8 \mathrm{vo}$, illustrated boards, 2s.

Jeff Briggs's Love Story. By BRET HARTE. Fcap. 8vo, picture cover, 1s. ; cloth extra, 2s. 6 d.

\section{British Flora Medica:}

\section{Demy $8 \mathrm{vo}$, profusely Illustrated in Colours, 30 s.}

A History of the Medicinal Plants of Great Britain. Illustrated by a Figure of each Plant, COLOURED BY HAND. By BENJAMIN H. Barton, F.L.S., and Thomas Castle, M.D., F.R.S. A New Edition, revised and partly re-written by JoHN R. JACrson, A.L.S., Curator of the Museums of Economic Botany, Royal Gardens, Kew.

THE STOTHARD BUNYAN.-Crown 8vo, cloth extra, gilt, 7s. $6 d$.

Bunyan's Pilgrim's Progress.

Edited by Rev. T. ScOTT. With 17 beautiful Stecl Plates by STOTHARD, engraved by GOODALL ; and numerous Woodcuts.

Crown 8vo, cloth extra, gilt, with Illustrations, $7 s .6 d$.

Byron's Letters and Journals.

With Notices of his Life. By THOMAS MOORE. A Reprint of the Original Edition, newly revised, with Twelve full-page Plates.

\section{Campbell's (Sir G.) White and Black :}

The Outcome of a Visit to the United States. By Sir GEORge CAMPBELL, M.P.

"Few persons are likelv to take it up withou: finishing it." -NonCon roRMisT. :

Crown 8vo, cloth extra, Is. $6 d$.

Carlyle (Thomas) On the Choice of Books. With Portrait and Memoir.

Small 4to, cloth gilt, with Coloured Illustrations, 10s. 6 d. Chaucer for Children:

A Golden Key. By Mrs. H. R. HAwers. With Eight Coloured Pictures and numerous Woodcuts by the Author. 


\section{Chaucer for Schools.}

Demy 8vo, cloth limp, 2s. $6 d$.

By Mrs. Hawers, Author of "Chaucer for Children."

This is a copious and judicious selection from Chaucer's Tales, with fall wotes on the history, manners, customs, and language of the fourtecnth century, with marginal glossary and'a literal poetical version in modern English in parallel columns with the original postry. Six of the Canterbury Tales are thus presented, in sections of from 10 to 200 lines, mingled with prose narrative. "Chaucer for Schools" is issued to meet a widely-expresed want, and is especially adapted for class instruction. It may be profitably studied in connection with the maps and illustrations of " Chaucer for Children."

Crown 8vo, cloth limp, with Map and Illustrations, 2s. $6 d$. Cleopatra's Needle:

Its Acquisition and Removal to England. By Sir J. E. ALexAnder,

\section{Crown 8vo, cloth extra, gilt, $7 s .6 d$.}

\section{Colman's Humorous Works:}

"Broad Grins," " My Nightgown and Slippers," and other Humorous

Works, Prose and Poetical, of George Colman. With Life by G.

B. BUCKSTONE, and Frontispiece by HOGARTH.

\section{Conway (Moncure D.), Works by :}

Demonology and Devil-Lore. By Moncure D. Conway, M.A. Two Vols, royal 8vo, with 65 Illustrations, 28s.

"A valuable contribution to mythological literature. ... There is muck good writing, a vast fund of humanity, undeniable earnestness, and a delicate sense of hamowr, all set forth in pure English." - CONTEMPORARY REvIEWe

A Necklace of Stories. By Moncure D. Conway, M.A. Illustrated by W. J. Hesnessy. Square $8 \mathrm{vo}$, cloth extra, 6s.

"This delightful 'Necklace of Stories" is inspired with lovely and lofiy sentiments."-ILLUSTRATED LONDON NEWS.

Demy 8vo, cloth extra, with Coloured Illustrations and Maps, 24 s.

Cope's History of the Rifle Brigade

(The Prince Consort's Own), formerly the 95th. By Sir William

H. COPE, formerly Lieutenant, Rifle Brigade.

Crown $8 \mathrm{vo}$, cloth extra, gilt, with $\mathrm{r}_{3}$ Portraits, $7 s .6 d$.

Creasy's Memoirs of Eminent Etonians;

with Notices of the Early History of Eton College. By Sir EDWARD

CREASY, Author of "The Fifteen Decisive Battles of the World."

Crown 8vo, cloth extra, with Etched Frontispiece, $75.6 d$.

Credulities, Past and Present.

By William Jones, F.S.A., Author of "Finger-Ring Lore," \&c.

NEW WORK by the AUTHOR OF "PRIMITIVE MANNERS

AND CUSTOMS."-Crown 8vo, cloth extra, 6 s.

\section{Crimes and Punishments.}

Including a New Translation of Beccaria's "Dei Delitti e delle Pene." By JAMES ANSON FARRER. 
Crown 8 vo, cloth gilt, Two very thick Volumes, 7s. 6d. each.

\section{Cruikshank's Comic Almanack.}

Complete in Two SERIES : The FIRST from 1835 to 1843 ; the SECOND from 1844 to 1853 . A Gathering of the BEST HUMOUR of Thackeray, Hood, Mayhew, Albert SMith, A'Becket, ROBERT BROUGH, \&c. With 2,000 Woodcuts and Steel Engravings by CRUIKSHANK, HINE, LANDELLS, \&C.

\section{Parts I. to XIV. now ready, 2Is. each.}

\section{Cussans' History of Hertfordshire.}

By JoHn E. Cussans. Illustrated with full-page Plates on Copper and Stone, and a profusion of small Woodcuts.

* Parts XV. and XVI., completing the work, are just ready.

"Mr. Cussans has, from sources not accessible to Clutzerouck, made most valisable additions to the manorial history of the county from the earliest period downwards, cleared up many doubtful points, and given original details concerning various subjects untouched or imperfectly treated by that writer." ACADRMV.

Two Vols., demy 4to, handsomely bound in half-morocco, gilt. profusely Illustrated with Coloured and Plain Plates and Woodcuts, price 6775.

\section{Cyclopædia of Costume ;}

or, A Dictionary of Dress-Regal, Ecclesiastical, Civil, and Militaryfrom the Earliest Period in England to the reign of George the Third. Including Notices of Contemporaneous Fashions on the Continent, and a General History of the Costumes of the Principal Countries of Europe. By J. R. PLANCHÊ, Somerset Herald.

The Volumes may also be had scparately (each Complete in itself) at $\delta_{3} \times 3$ s. 6d. each :

V01. I. THE DICTIONARY.

Vol. II. A GENERAL HISTORY OF COSTUME IN EOROPE.

Also in 25 Parts, at 5s. each. Cases for binding, 5s. each.

"A comprehensive and highly valuable book of reference. . . We have y arely failed to find in this book an account of an article of dress, while in most of the entries curious and instructive details are given. . . Mr. Planche's snormous labour of love, the production of a text which, whether in its dictionary form or in that of the 'General History,' is within its intended scope immeasurably the best and rickest work on Costume in English. . . This book is not only one of the most readable works of the kind, but intrinsically attractive and a mosing." - ATHENAUM.

"A most readable and interesting work-and it can scarcely be consulted in eain, whether the reader is in search for information as to military. court, ecclesiastical, legal, or professional costume. . . All the chromolithograpks, and most of the woodcut illustrations - the latter amounting to several thousands - are very elaborately executed; and the work forms a livre de luxe which renders it equally suited to the library and the ladies' drawing-room." -TiMrs.

Square 8vo, cloth gilt, profusely Illustrated.

\section{Dickens.-About England with Dickens.}

By AlfRed RIMMER. With Illustrations by the Author and CHARLES A. VANDERHOOF. 
Second Edition, revised and enlarged, demy 8vo, cloth extra, with Illustrations, 24 s.

Dodge's (Colonel) The Hunting Grounds of the Great West : A Description of the Plains, Game, and Indians of the Great North American Desert. By Richard IRving DoDgE, Lieutenant-Colonel of the United States Army. With an Introduction by Wrlliam BlACKMORE; Map, and numerous Illustrations drawn by ERNEST GRISET.

Demy 8vo, cloth extra, r2s, $6 d$.

Doran's Memories of our Great Towns.

With Anecdotic Gleanings concerning their Worthies and their Oddities. By Dr. John Doran, F.S.A.

Second Edition, demy $8 \mathrm{vo}$, cloth gilt, with Illustrations, 18 s.

\section{Dunraven's The Great Divide:}

A Narrative of Travels in the Upper Yellowstone in the Summer of 1874. By the EARL of DUNRAVEN. With Maps and numerous striking full-page Illustrations by VALENTINE W. BROMLEY.

"There has not for a long time appeared a better book of travel than Lord Dusinaven's 'The Great Divide.' . . . The book is full of cletver observation, and both namative and illustrations are thoroughly good." - ATHEN EUM.

Two Vols., crown 8vo, cloth extra, 2rs.

Drury Lane (Old):

Fifty Years' Recollections of Author, Actor, and Manager. By EDWARD STIRLING.

Demy 8vo, cloth, x6s.

\section{Dutt's India, Past and Present;}

with Minor Essays on Cognate Subjects. By SHOSHEE CHUNDER DuTr, Rái Báhádoor.

Crown 8ve, cloth extra, gilt, with Illustrations, $6 \mathrm{~s}$.

Emanuel On Diamonds and Precious

Stones ; their History, Value, and Properties; with Simple Tests for ascertaining their Reality. By HARRY EMANUEL, F.R.G.S. With numerous Illustrations, Tinted and Plain.

Demy 4 to, cloth extra, with Illustrations, $3^{6 s}$.

Emanuel and Grego.-A History of the Goldsmith's and Jeweller's Art in all Ages and in all Countries. By E. EMANUEL and JOSEPH GREgo. With numerous fine Engravings.

[In preparation.

Crown 8vo, cloth extra, with Illustrations, 7s.6d.

Englishman's House, The:

A Practical Guide to all interested in Selecting or Building a House, with fuil Estimates of Cost, Quantities, \&c. By C. J. RICHARDSON. Third Edition. With nearly 600 Illustrations. 
Early English Poets.

Crown 8 vo, cloth boards, 6 s. per Volume.

Edited, with Introductions and Annotations, by Rev. A. B. GRosART.

"Mr. Grosart has spent the most laborious and the most enthusiostic care on the perfect restoration and preservation of the text. . . From MIr. Grosart we always expect and always receive the final results of most patient and competckt scholarship."-EXAMINER.

1. Fletcher's(Giles, B.D.) Com. plete Poems: Christ's Victorie in Heaven, Christ's Victorie on Earth Christ's Triumph over Death, and Minor Poems. With Memorial-Introduction and Notes. One Vol.

2. Davies' (Sir John) Complete Poetical Works, including Psalms I. to $L$. in Verse, and other hitherto Unpublished MSS., for the first time Collected and Edited. MemorialIntroduction and Notes. Two Vols.
3. Herrick's (Robert) Hesperides, Noble Numbers, and Complete Collected Poems. With MemorialIntroduction and Notes, Steel Portrait, Index of First Lines, and Glossarial Index, \&c. Three Vols.

4. Sidney's (Sir Philip) Complete Poetical Works, including all those in "Arcadia." With Portrait, Memorial-Introduction, Essay on the Poetry of Sidney, and Notes. Three Vols.

\section{Evolution (Chapters on);}

A Popular History of the Darwinian and Allied Theories of Development. By ANDREW WILSON, Ph.D., F.R.S. Edin. \&c. [In preparation. Abstract of Contents :-The Problem Stated-Sketch of the Rise and Progress of Evolution-What Evolution is and what it is not-The Evidence for EvolutionThe Evidence from Development-The Evidence from Rudimentary Organs-The Evidence from Geographical Distribution-The Evidence from Geology-Evolution and Environments-Flowers and their Fertilisation and Development-Evolution and Degeneration-Evolution and Ethics-The Relations of Evolution to Ethics and Theology, \&c. \&c.

\section{Evolutionist (The) At Large. \\ Crown 8 vo, cloth extra, $6 s$.}

\section{By GRANT ALLEN.}

\section{Two Vols., crown 8vo, cloth extra, 2 Is.}

Ewald.-Stories from the State Papers.

By Alex. Charles Ewald.

In preparation.

\section{Folio, cloth extra, $\&$ I IIs. $6 d$.}

\section{Examples of Contemporary Art.}

Etchings from Representative Works by living English and Forefgn

Artists. Edited, with Critical Notes, by J. CoMYNS CARR.

"It would not be easy to meet with a more sumptuous, and at the same time a more tasteful and irstructive drawing-room book." - NONCONFORMIST.

\section{Fairholt's Tobacco :}

Crown 8 vo, cloth extra, with Illustrations, $6 s$.

Its History and Associations; with an Account of the Plant and its.

Manufacture, and its Modes of Use in all Ages and Countries. By F.

W. FAIRHolt, F.S.A. With Coloured Frontispiece and upwards of Ioo Illustrations by the Author.

\section{Crown 8vo, cloth extra, with Illustrations, 4s. 6d.}

Faraday's Chemical History of a Candle.

Lectures delivered to a Juvenile Audience. A New Edition. Edited by W. CROOKEs, F.C.S. With numerous Mlustrations. 
Crown 8vo, cloth extra, with Illustrations, 4 s. $6 d$.

Faraday's Various Forces of Nature.

New Edition. Edited by W. CrookES, F.C.S. Numerous Illustrations,

Finger-Ring Lore:

Crown 8vo, cloth extra, with Illustrations, $75,6 d$.

Historical, Legendary, and Anecdotal. By WM.Jonss, F.S.A. With

Hundreds of Illustrations of Curious Rings of all Ages and Countries.

"One of those gossiping books which are as full of amusement as of instruction."-ATHENEUM.

\section{NEW NOVEL BY fUSTIN MCCARTHY.}

\section{Gentleman's Magazine for January, 1881,}

Price One Shilling, contains the First Chapters of 'a' New Novel, entitled "The Comet of a SEAson," by Justrn McCarthy, M.P., Author of "A History of Our Own Times," "Dear Lady Disdain," \&c. Science Notes, by W. Mattieu Williams, F.R.A.S., will also be continued Monthly.

* Now ready, the Volume for JuLY to DECEMBER, 1880, cloth extra, price 8 s. 6d.; and Cases for binding, price 25 . each.

\section{THE RUSKIN GRIMM.-Square 8vo, cloth extra, 6s, 6d, ; gilt edges, 7s. $6 d$.}

\section{German Popular Stories.}

Collected by the Brothers Grrmm, and Translated by EDGAR TAYLOR.

Edited with an Introduction by JOHN RUSKrN. With 22 Illustrations after the inimitable designs of GEORGE CRUIKshank. Both Series Complete.

"The illustrations of this volume ... are of quite sterling and adminable art, of a class precisely parallel in elevation to the character of the tales which they illustrate; and the original etchings, as I have before said in the Appendix to my 'Elements of Drawing' were unrivalled in masterfulness of tosch since Rembrandt (in some qualities of delineation, surrivalled even by him). . . . To make sometwhat enlarged copies of them, looking at them through a magnifying glass, and never putting two lines where Cruikshank has put only one, would be an exer: cise in decision and severe drawing which would leave afterwards lintle to be learnt in schools." - Extract from Introduction by JoHs Ruskin.

\section{Glenny's A Year's Work in Garden and}

Greenhouse : Practical Advice to Amateur Gardeners as to the Management of the Flower. Fruit, and Frame Garden. By George GlennNy.

"A great deal of valuable information, conveyed in very simple language. The amatenr need not wish for a better guide."-LREDS MERcuRY.

New and Cheaper Edition, demy 8vo, cloth extra, with Illustrations, 7s.6d.

Greeks and Romans, The Life of the,

Described from Antique Monuments. By ERNST GuHL and W.

KONER. Translated from the Third German Edition, and Edited by Dr. F. HUEFFER. With 545 Illustrations.

\section{Crown 8vo, cloth extra, gilt, with Illustrations, $75,6 d$.}

\section{Greenwood's Low-Life Deeps :}

An Account of the Strange Fish to be found there. By JAMrs GrirnwOOD. With Illustrations in tint by ALFRED CONCANEN. 
Crown 8 vo, cloth extra, gilt, with Illustrations, $75.6 \%$.

\section{Greenwood's Wilds of London:}

Descriptive Sketches, from Personal Observations and Experience, of Remarkable Scenes, People, and Places in London. By J AMies GreenWOOD. With 12 Tinted Illustrations by ALFRED CONCANEN.

Square I6mo (Tauchnitz size), cloth extra, 2s. per volume.

Golden Library, The:

Ballad History of England. By W. C. BenNetT.

Bayard Taylor's Diversions of the Echo Club.

Byron's Don Juan.

Emerson's Letters and Social Aims.

Godwin's (William) Lives of the Necromancers.

Holmes's Autocrat of the Breakfast Table. With an Introduction by G. A. SAlA.

Holmes's Professor at the Breakfast Table.

Hood's Whims and Oddities. Complete. With all the original Illustrations.

Irving's (Washington) Tales of 2 Traveller.

Irving's (Washington) Tales of the Alhambra.

Jesse's (Edward) Scenes and Occupations of Country Life.

Lamb's Essays of Elia. Both Series Complete in One Vol.

Leigh Hunt's Essays: A Tale for a Chimney Corner, and other Pieces. With Portrait, and Introduction by EDMUND OlLIER.
Mallory's (Sir Thomas) Mort d'Arthur: The Stories of King Arthur and of the $\mathrm{K}$ nights of the Round Table. Edited by B. Montgomeria RANKING.

Pascal's Provincial Letters. A New Translation, with Historical Introduction and Notes, by T. M'Crin, D.D.

Pope's Pootical Works. Complete.

Rochefoucauld's Maxims and Moral Reflections. With Notes, and an Introductory Essay by SAINTzBauve.

St. Pierre's Paul and Virginia, and The Indian Cottage. Edited, with Life, by the Rev. E. Clarke.

Shelley's Farly Poems, and Queen Mab, with Essay by Lrigr HuNT.

Shelley's Later Poems : Laon and Cythna, \&c.

Shelley's Posthumous Poeras, the Shelley Papers, \&c.

Shelley's Prose Works, includ. ing A Refutation of Deism, Zastrozzi, St. Irvyne, \&sc.

White's Natural History of Selborne. Edited, with additions, by ThOMAS BROWN, F.L.S.

Crown $8 \mathrm{vo}$, cloth gilt and gilt edges, $75.6 d$.

\section{Golden Treasury of Thought, The:}

An ENCYCLOPADIA OF QUOTATIONS from Writers of all Times and Countries. Selected and Edited by THEODORE TAYLOR.

\footnotetext{
Crown 8vo, cloth extra, gilt, with Illustrations, 4 s. 6 d.

Guyot's Earth and Man;

or, Physical Geography in its Relation to the History of Mankind. With Additions by Professors Agassiz, PIERCE, and Gray; 12 Maps and Engravings on Steel, some Coloured, and copious Index.
} 


\section{Hake (Dr. Thomas Gordon), Poems by:}

Maiden Ecstasy. Small 4 to, cloth extra, 8 s.

New Symbols. Crown 8vo, cloth extra, 6 s.

Legends of the Morrow. Crown 8vo, cloth extra, $6 s$.

Medium 8vo, cloth extra, gilt, with Illustrations, 75. 6d.

Hall's(Mrs. S. C.) Sketches of Irish Character.

With numerous Illustrations on Steel and Wood by MACLISE, GrL. BERT, HARVEY, and G. CruikshaNK.

"The lrish Sketches of this lady resemble Miss Mitford's beantiful English sketches in 'Our Village,' but they are far more vigorous and picturespue and bright."-BLackwood's Magazine.

Post 8vo, cloth extra, 4s. 6d.; a few large-paper copies, half-Roxb., ros. $6 d$.

\section{Handwriting, The Philosophy of.}

By Don Felix dE Salamanca. With r34 Facsimiles of Signatures.

\section{Haweis (Mrs.), Works by:}

The Art of Dress. By Mrs. H. R. Hawers, Author of "The

Art of Beauty," \&c. Illustrated by the Author. Small 8vo, illustrated cover, 1s.; cloth limp, $1 s .6 d$.

"A well-considered attempt to afply canons of good taste to the costumes of ladies of our time. . . . Mrs. Hazveis writes frankly and to the point, she does not mince matters, but boldly remonstrates with her oun sex on the follies they indulge in. . . . . We may recommend the book to the ladies whom it concerns."-ATHENAUM.

The Art of Beauty. By Mrs. H. R. Hawers, Author of "Chaucer for Children," Square $8 \mathrm{vo}$, cloth extra, gilt, gilt edges, with Coloured Frontispiece and nearly roo Illustrations, xos. $6 d$.

** See also Chaucer, pp. 5 and 6 of this Catalogue.

Complete in Four Vols., demy 8vo, cloth extra, r2s, each.

History of Our Own Times, from the Accession of Queen Victoria to the General Election of r88o. By Justrn MCCARTHY, M.P.

"Criticism is disarmed before a composition which provokes little but approval. This is a really good book on a really interesting subject, and words piled on words conild say no more for it. . . . Such is the effect of its general fustice, its breadth of virw, and its sparkling buoyancy, that very few of its readers will close these solsmes without looking forward with interest to the two [since published] that are to follote."-SATURDAY REVIEW.

\section{Crown 8vo, cloth extra, $5^{5}$.}

\section{Hobhouse's The Dead Hand :}

Addresses on the subject of Endowments and Settlements of Property. By Sir Arthur Hobhouse, Q.C., K.C.S.I.

Crown 8vo, cloth limp, with Illustrations, 2s. 6d.

Holmes's The Science of Voice Production and Voice Preservation: A Popular Manual for the Use of Speakers and Singers. By Gordon HoL.Mes, L.R.C.P.E. 
Crown 8 vo, cloth extra, 45. 6d.

\section{Hollingshead's (John) Plain English.}

"I anticipate immense entertainment fran the perusal of Mr. Hollingshead's 'Plain Enslish,' which I imagined to be a philolosical work, but which I find to be a series of essays, in the Hollingsheadinn or Sledse-Hammer style, on those maticrs theatrical with which he is so eminently conversant."-G. A. S. in the ILLUSTRATED LUNDON NEWS.

\section{Hood's (Thomas) Choice Works,}

In Prose and Verse. Including the Cream of THE Comic ANnUALs. With Life of the Author, Portrait, and Two Hundred Illustrations.

Square crown 8 vo, cloth extra, gilt edges, $6 s$.

Hood's (Tom) From Nowhere to the North

Pole: A Noah's Arkæological Narrative. With 25 Illustrations by

W. BRUNTON and E. C. BARNES.

"The amusing letterpress is profusely interspersed with the jingling rhymes which children love and learm so easily. Messrs. Brunton and Barnes do full justice to the writer's meaning, and a pleasanter result of the harmonious cooperation of author and artist could not be desired." - Times.

Crown 8 vo, cloth extra, gilt, $75.6 d$.

Hook's (Theodore) Choice Humorous Works,

including his Ludicrous Adventures, Bons-mots, Puns, and Hoaxes.

With a new Life of the Author, Portraits, Facsimiles, and Illustrations.

\section{Horne's Orion:}

Crown 8vo, cloth extra, 75 .

An Epic Poem in Three Books. By Richard Hengist Horne. With a brief Commentary by the Author. With Photographic Portrait from a Medallion br Summers. Tenth Edition.

Crown 8vo, cloth exira, 7 s. $6 d$.

\section{Howell's Conflicts of Capital and Labour}

Historically and Economically considered. Being a History and Review of the Trade Unions of Great Britain, showing their Origit. Progress, Constitution, and Objects, in their Political, Social, Econonical, and Industrial Aspects. By GEORGe Howell.

"This book is an attempt, and on the whole a successful attempt, to place the work of trade unions in the past, and their objects in the future, fairly before the public from the working man's point of view."-PALL MALL GAZRTTR.

\section{Hueffer's The Troubadours:}

Demy 8 vo, cloth extra, $12 s .6 d$.

A History of Provencal Life and Literature in the Middle Ages. By FRANCIS HUEFFER.

Two Vols. 8vo, with 52 Illustrations and Maps, cloth extra, gilt, 14s.

Josephus, The Complete Works of.

Translated by WHISTON. Containing both "The Antiquities of the Jews" and "The Wars of the Jews." 
A NEw EDITION, Revised and partly Re-written, with several New Chapters and Illustrations, crown 8vo, cloth extra, 7s. $6 d$.

\section{Jennings' The Rosicrucians:}

Their Rites and Mysteries. With Chapters on the Ancient Fire and Serpent Worshippers. By Hargrave Jennings. With Five fullpage Plates and upwards of 300 Illustrations.

Small 8vo, cloth, full gilt, gilt edges, with Illustrations, 6 s.

Kavanaghs' Pearl Fountain,

And other Fairy Stories. By Bridget and Julia Kavanagh. With

Thirty Illustrations by J. MOYR SMrTH.

" Genuine new fairy stories of the old type, some of them as delightful as the best of Grimm's 'German Popular Stories.'. . For the most part the stories are downright, thorough going fairy stories of the most admirable kind.

. . Mr. Moyr Smith's illustrations, too, are admirable."-Sprctator.

\section{Kitchen Garden (Our) :}

Fcap. 8vo, illustrated boards.

The Plants we Grow, and How we Cook Them. By Tom Jerrold, Author of "The Garden that Paid the Rent," \&c. In the press.

Crown $8 v 0$, illustrated boards, with numerous Plates, 2s. $6 d$.

Lace (Old Point), and How to Copy and Imitate it. By DAISY WATERHouse Hawkins. With i7 Illustrations by the Author.

\section{Crown 8vo, loth extra, with numerous Illustrations, ros, $6 d$. \\ Lamb (Mary and Charles):}

Their Poems, Letters, and Remains. With Reminiscences and Notes by W. CAREW HazlitT. With Hancock's Portrait of the Essayist, Facsimiles of the Title-pages of the rare First Editions of Lamb's and Coleridge's Works, and numerous Illustrations.

"Very many passages will delight those fond of literary trifies; hardly any portion will fail in interest for lovers of Charles Lamb and his sister."-STANDARD.

\section{Lamb's Poetry for Children, and Prince}

Dorus. Carefully Reprinted from unique copies.

"The quaint and delightful little book, over the recovery of which all the hearts of his lovers are yet warm with rejoicing."-A. C. SwINBURNB.

\section{Lamb's Complete Works,}

In Prose and Verse, reprinted from the Original Editions, with many

Pieces hitherto unpublished. Edited, with Notes and Introduction, by R. H. ShePHERD. With Two Portraits and Facsimile of a Page of the "Essay on Roast Pig."

"A complete edition of Lamb's suritings, in prose and verse, has long been wanted, and is now supplied. The editor applars to have taken great pains to bring together Lambs scattered contributions, and his collection contains a number of pieces which are now reproduced for the first time since their original affearance in various old periodicals." - SATURDAY REVIEW. 
Demy 8 vo, cloth extra, with Maps and Illustrations, $18 \mathrm{~s}$.

\section{Lamont's Yachting in the Arctic Seas;}

or, Notes of Five Voyages of Sport and Discovery in the Neighbourhood of Spitzbergen and Novaya Zemlya: By JAMES LAMONT, F.R.G.S. With numerous full-page Illustrations by Dr. LIVESAY.

"After wading through numberless volumes of icy fiction, concocted narrative, and spurious biography of Arctic voyagers, it is pleasant to meet with a real and sensine volume. . . He showes much tact in recounting his adventures, and they are so interspersed with anecdotes and information as to make them anythins but wearisome. . . The book, as a whole, is the most important addition made to our Arctic literature for a long time."-ATHENAUM.

Lares and Penates;

Crown $8 v o$, cloth extra, $6 s$.

Or, The Background of Life. By Florexce CADDY.

Latter-Day Lyrics:

Crown 8vo, cloth, full gilt, $75.6 d$.

Poems of Sentiment and Reflection by Living Writers; selected and arranged, with Notes, by W. DAvENPORT ADAMs. With a Note on some Foreign Forms of Verse, by Austin DOBSON.

\section{Leigh's A Town Garland.}

Crown 8 vo, cloth, full gilt, 6 s.

By HENRY S. LEIGH, Author of "Carols of Cockayne."

"If Mr. Leigh's verse survive to a future generation-and there is no reason why that honour should rot be accorded productions so delicate, so finished, and so full of humour-their author will probably be remembered as the Poet of the Strand." - ATHENEUA.

SECONd Edition.-Crown 8vo, cloth extra, with Illustrations, 6s.

\section{Leisure-Time Studies, chiefly Biological.}

By ANDREw WiLson, F.R.S.E., Lecturer on Zoology and Compara-

tive Anatomy in the Edinburgh Medical School.

"It is well when we can take up the work of a really qualified investigator, who in the intervals of his more serious professional labours sets himself to impart knowledge in such a simple and elementary form as may attract and instruct, with no danger of misleading the tyro in natural science. Such a wor.in is this little volume, made up of essays and addresses written and delivered by Dr. Andrew Wilson, lecturer and examiner in science at Edirburgh and Glasgow, at Leisure intervals in a busy professional life. . . Dr. Wilson's pages reem with matter stimulating to a healthy love of science and a reverence for the truths of nature." - SATURDAV REviEW.

\section{Life in London;}

Crown 8 vo, cloth extra, with Illustrations, 7 s. $6 d$.

or, The History of Jerry Hawthorn and Corinthian Tom. With the whole of CRUIKSHANK's Illustrations, in Colours, after the Originals.

\section{Lights on the Way:}

\section{Crown 8 vo, cloth extra, 6 s.}

Some Tales within a Tale. By the late J. H. AlexAnder, B.A. Edited, with an Explanatory Note, by H. A. PAGE, Author of "Thoreau: A Study." 


\section{Crown $8 v 0$, cloth extra, with Illustrations, $75.6 d$. Longfellow's Complete Prose Works.}

Including "Outre Mer," "Hyperion," " Kavanagh," "The Poets and Poetry of Europe," and "Driftwood." With Portrait and Illustrations by VALENTINE BROMLEY.

Crown 8vo, cloth extra, gilt, with Illustrations, $75.6 d$.

\section{Longfellow's Poetical Works.}

Carefully Reprinted from the Original Editions. With numerous fine Illustrations on Steel and Wood.

\section{Lunatic Asylum, My Experiences in a. \\ Crown $8 v 0$, cloth extra, $5^{5}$.}

By a SANE PATIEnt.

"The story is clever and interesting, sad beyond measure thoweh the subject be. There is no personal bitterness, and no violence or anger. Whatever may have been the evidence for our author's madness when he was consigned to an asylum, nothing can be clearer than his sanity when he wrote this book; it is brieht, calm, and to the point." -SPRCTATOR.

Demy $8 \mathrm{vo}$, with Fourteen full-page Plates, cloth boards, 18 s,

Lusiad (The) of Camoens.

Translated into English Spenserian verse by ROBERT FFrENCH DUFF, Knight Commander of the Portuguese Royal Order of Christ.

\section{Macquoid (Mrs.), Works by:}

In the Ardennes. By Katharine S. MAcquoID, With 5o fine Illastrations by ThомAs R. MAcQuorD. Uniform with "Pictures and Legends." Square 8vo, cloth extra, 1os. $6 d$.

Pictures and Legends from Normandy and Brittany. By KATHARINE S. Macquoid. With numerous Illustrations by Thosas $R$. MAcQuord. Square 8vo, cloth gilt, ros. $6 d$.

"Mr. and Mrs. Macquoid have been strolling in Normandy and Brittany, and the result of their observations and researches in that picturesgue land of romantic associations is an attractive volume, which is neither a work of travel nor a collection of stories, but a book partaking almost in equal degree of each of these characters. . . The illustrations, which are numerous, are drawn, as a rule, with remarkable delicacy as well as with true artistic feeling:"-DAILY NEws.

Through Normandy. By KATHarine S. Macquoid. With 90 Illustrations by T. R, M^cQuoId. Square $8 \mathrm{vo}$, cloth extra, 7s. $6 d$.

"One of the feev books which can be read as a piece of literature, whilst at the same time handy in the knapsack."-BRITISH QUARTERLY REVIEW.

Through Brittany. By Katharine S. Maceuord, With numerous Illustrations by THomAs R. MAcQuold. Square $8 \mathrm{vo}$, cloth extra, $7 s .6 d$.

"The pleasant companionship which Mrs. Macguoid offers, while wander. ing from one point of interest to another, seems to throw a reneaved charm around each oft-depicted scene."-MORNING POST.

Crown 8vo, cloth extra, with lllustrations, 2s. 6d.

Madre Natura v. The Moloch of Fashion.

By LUKE Lmener. With 32 Illustrations by the Author. Fourtu EDrTion, revised and enlarged. 
Magna Charta.

Handsomely printed in facsimile, price 5 s.

An exact Facsimile of the Original Document in the British Museum, printed on fine plate paper, nearly 3 feet long by 2 feet wide, with the Arms and Seals emblazoned in Gold and Colours.

\section{Small 8vo, is,; cloth extra, is. $6 d$. \\ Milton's The Hygiene of the Skin.}

A Concise Set of Rules for the Management of the Skin ; with Directions for Diet, Wines, Soaps, Baths, \&c. By J. L. Milton, Senior Surgeon to St. John's Hospital.

By the same Author.

The Bath in Diseases of the Skin. Sm. Svo, is.; cl, extra, is. $6 d^{2}$.

\section{IMallock's (W. H.) Works :}

Is Life Worth Living? By WilliaM HuRrell Mallock. New Edition, crown 8vo, cloth extra, $6 s$.

"This deeply interesting volume. . . . . It is the most powerful vin dication of religion, both nat ural and revealea, that has appeared since Bishop Butier wrote, and is much more useful than either the Analogy or the Sermons of that great divine, as a refutation of the peculiar form assumed by the infidelity of the present day. . . Deeply philosophical as the book is, there is not a heavy page in it. The writer is 'possessed' so to speak, with his great subject, has sounded its depths, surveyed it in all its cxtent, and brought to bear on it all the resources of a vivid, rich, and impassioned style, as zuell as an adequate acquaintance with the science, the philosophy, and the literature of the day."-IRISH DAILY Naws.

The New Republic; or, Culture, Faith, and Philosophy in an English Country House. By William Hurrell Mallock. Chray Edition, in the "Mayfair Library." Post 8vo, cloth limp, 2s.6d.

The New Paul and Virginia ; or, Positivism on an Island. By William Hurrell Mallock. Chrap Edition, in the "Mayfair Li. brary." Post 8vo, cloth limp, 2s. 6d.

Poems. By W. H. MALLOCK. Small 4 to, bound in parchment, 8 s.

\section{Mark Twain's Works:}

The Choice Works of Mark Twain. Revised and Corrected throughout by the Author. With Life, Portrait, and numerous Illustra. tions. Crown 8vo, cloth extra, $7 s .6 d$.

The Adventures of Tom Sawyer. By Mark TwaIn. With roo Illustrations. Small 8vo, cl.ex., 7s.6d. CHEAP EDition, illust, boards, 2s.

A Pleasure Trip on the Continent of Europe : The Innocents Abroad, and The New Pilgrim's Progress. By MARK Twain. Post 8vo, illustrated boards, $2 s$.

An Idle Excursion, and other sketches. By Mark TwaIs. Post 8vo, illustrated boards, $2 s$.

A Tramp Abroad. By MARK TwaIN. With 3 I4 Illustrations. Crown $8 v 0$, cloth extra, $7 s .6 d$.

"The finn and tenderness of the conception, of which no lizing man but Mark Twain is capable, its grace and fantasy and slyness, the wonderful feeling for animals that is manifest in every line, make of all this episodi of Fin Baker ard his jays a piece of work that is not only delightful as mere rending, but also of a high degree of merit as literature. . . . The book is full of good things, and contains passages and episodes thint are equal to the funiest of those that have gone before." - A THENAus. 
Post 8vo, cloth limp, 2s. 6d, per vol.

\section{Mayfair Library, The:}

The New Republic. By W. H. MaLLock.

The New Paul and Virginia. By W. H. MaLlock.

The True History of Joshua Davidson. By E. Lvas Lrsmon.

OldStories Re-told. By WaLter

THornaury.

Thoreau : His Life and Aims. By H. A. PAGR.

By Stream and Sea. By WIL. LIAM Sknior.

Jeux d'Esprit. Edited by HENRY S. LeIGH.

Puniana. By the Hon. HugH RowL.gy.

More Puniana. By the Hon. HUGH ROWLEY.

Puck on Pegasus. By $\mathrm{H}$. Cholmondeley-Pennel.

The Speeches of Charles Dickens. With Chapters on Dickens as a Letter-Writer, Poet, and Public Reader.
Muses of Mayfair. Edited by H. Cholmondrtegy-Pennezl.

Gastronomy as a Fine Art. By Brillat-Savaris.

[Begr.

Original Plays. By W. S. GrL. Carols of Cockayne. By Henry S. LetGH.

Literary Frivolities, Fancies, Follies, and Frolics. By Wrt.uns T. Dosson.

Pencil and Palette: Biographical Anecdotes chiefly of Contemporary Painters, with Gossip about Pictures Lost, Stolen, and Forged, also Great Picture Sales. By RoBerT Kestr.

The Agony Column of "The Times," from 1800 to 1870 . Edited, with an Introduction, by ALICE CLAy. Nearly, eady.

The Book of Clerical Anec. dotes: A Gathering of the Antiquities, Humours, and Eccentricities of "The Cloth." By JACOB LARwOOD.

[Nearly ready.

** Other Volumes are in freparation.

\section{New Novels.}

\section{OUIDA'S NEW WORK.}

A VILLAGE COMMUNE. By OUIDA. Two Vols., crown $8 \mathrm{vo}$, cloth extra.

[Fust ready.

TAMES PAYN'S NEW NOVEL.

A CONFIDENTIAL AGENT. By JAMES PAYN, With 12 Illustrations by ARTHUR Hopkiss. Three Vols., crown 8 vo. NEW NOVEL BY FULIAN HAWTHORNE.

ELLICE QUENTIN, and other Stories. By Julian Haw. THORNE. Two Vols., crown 8 vo.

$$
\text { MR. FRANCILLON'S NEW NOVEL. }
$$

QUEEN COPHETUA. By R. E. Francilion. Three Vols., crown 8vo.

$$
\text { MRS. HUNT'S NEW NOVEL. }
$$

THE LEADEN CASket. By Mrs. Alfred W. Hunt. Three Vols., crown 8 vo.

$$
\text { NEW NOVEL BY MRS. LINTON. }
$$

THE REBEL OF THE FAMILY. By E. LYNN LINTON. Three Vols., crown 8 vo.

NEW NOVEL by the AUTHORS OF "READY-MONEY MORTIBOY:"

THE TEN YEARS' TENANT, and other Stories. By Walter Besaxt and JAMes Rick. Three Vols, crown 8 vo. 
Small 8vo, cloth limp, with Illustrations, 2s. 6d.

\section{Miller's Physiology for the Young;}

Or, The House of Life: Human Physiology, with its Applications to the Preservation of Health. For use in Classes and Popular Reading. With numerous Illustrations. By Mrs. F. FENWICK MILLER.

"An admirable introduction to a subject which all who value health and enjoy life should have at their fingers' ends."-EcHO.

\section{Square 8vo, cloth extra, with numerous Illustrations, gs.}

North Italian Folk.

By Mrs. COMYns CARR. Illustrated by RANDOLPH CALDECOTT.

"A delightfulbook, of a kind which is far tow rare. If anyone wants to really know the North Italian folk, we can horestly advise him to omit the joumey, and sit down to read Mrs. Carr's pages instead. D. Description with Mrs. Carr is a real gift. . . . It is rarely that a book is so happily illustrated."-CoNTEMPORARY REVIEW.

Crown 8vo, cloth extra, with Vignette Portraits, price 6s. per Vol.

\section{Old Dramatists, The:}

Ben Jonson's Works.

With Notes, Critical and Explanatory, and a Biographical Memoir by WILLIAM GIFFORD. Edited by Colonel Cunningham. Three Vols.

\section{Chapman's Works.}

Now First Collected. Complete in Three Vols. Vol. I. contains the Plays complete, including the doubtful ones; Vol. II. the Poems and Minor Trans: Lations, with an Introductory Essay by AzgrRnon Charles SWInbuRnz. Vol. III. the Translations of the Iliad and Odyssey.

Marlowe's Works.

Including his Translations. Edited, with Notes and Introduction, by Col. Cunningham. One Vol.

Massinger's Plays.

From the Text of WilliaM Girford. With the addition of the Tragedy of "Believe as you List." Edited by Col. Cunningham. One Vol.

\section{Ouida's Novels.-Library Edition.}

\begin{tabular}{ll|ll} 
Held in Bondage. & By OUIDA. & Dog of Flanders. & By OUIDA. \\
Strathmore. & By OUIDA. & Pascarel. & By OUIDA. \\
Chandos. & By OUIDA. & Two Wooden Shoes. By OUIDA. \\
Under Two Flags. & By OUIDA. & Signa. & By OUIDA. \\
Idalia. & By OUIDA. & In a Winter City. & By OUIDA. \\
Cecil Castlemaine. & By OUIDA. & Ariadne. & By OUIDA. \\
Tricotrin. & By OUIDA. & Friendship. & By OUIDA. \\
Puck. & By OUIDA. & Moths. & By OUIDA. \\
Folle Fdrine. & By OUIDA. & & \\
$*$ * Also a Cheap Edition of all but the last, post 8vo, illustrated boards, \\
25. each.
\end{tabular}

Post 8vo, cloth limp, $x$. $6 d$.
Parliamentary Procedure, A Popular Handbook of. By HENRY W. LuCY. Crown 8vo, cloth extra, with Portrait and Illustrations, $7^{5.6 d .}$ Poe's Choice Prose and Poetical Works.

With BAudelaire's "Essay." 
Crown $8 \mathrm{vo}$, carefully printed on creamy paper, and tastefully bound in cloth for the Library, price $3^{s,} 6 d$. each.

\section{Piccadilly Novels, The.}

Fapular stories by the 3est Gutbors.

READY-MONEY MORTIBOY. By W. BESANT and JAMES Rick. MY LITTLE GIRL. By W. Besant and James Rice. THE CASE OF MR. LUCRAFT. By W. BesANT and JAMES Rice. THIS SON OF VULCAN. By W. BesANT and JAMrs Rice. WITH HARP AND CROWN. By W. BESANT and JAMES Rice. THE GOLDEN BUTTERFLY. By W. BesANT and JAMES Rice.

With a Frontispiece by F. S. WALKER.

BY CELIA'S ARBOUR. By W. Besant and James Rice. THE MONKS OF THELEMA. By W. BesANT and JAMES Ricr. 'TWAS IN TRAFALGAR'S BAY. By W. Besant \& JAMES Rice. THE SEAMY SIDE. By WALTER Besant and JAMES Rize.

ANTONINA. By Wilkie Collins, Illustrated by Sir J. Gilbert and Alfred Concanen.

BASIL. By Wilkie Colzins. Illustratcd by Sir JoHn 'Gilbert and J. MAHONEY.

EIDE AND SEEK. By WrLkie Collins. Illustrated by Sir JoHn GHsert and J. MAHONвY.

THE DEAD SECRET. By Wilkie Collins. Illustrated by Sir John GrLiert and H. Furasiss.

QUEEN OF HEARTS. By WILKIE Collins. Illustrated by Sir John Grzert and A. Concangs.

MY MISCELLANIES. By Wilkie Collins. With Steel Portrait, and Illustrations by A. Concusens.

THE WOMAN IN WHITE. By Wilkie Collins. Illustrated by Sir J. Gilbert and F. A. Fraser.

THE MOONSTONE. By Wilkie Collins. Illustrated by G. Du Maurier and F. A. Fraser.

MAN AND WIFE. By Wilkie Collins. Illust. by WM. Smal.t. POOR MISS FINCH. By Wilkie Collins. Illustrated by G. Du Maurirr and Edward Hughes.

MISS OR MRS. P By WILKIE Collins. Illustrated by S. L. Findes and Henry Woods.

THE NEW MAGDALEN. By WILKIE Collins. Illustrated by G. Du Maurirr and C. S. Reinhart.

THE FROZEN DEEP. By WrLkIE Collins. Illustrated by G. Du MaUrier and J. MAhonev.

THE LAW AND THE LADY. By WrLkir Collins. Illustrated by S. L. Fridis and Sydngy Hall.

THE TWO DESTINIES. By Wrlkiz Collins.

THE HAUNTED HOTEL. By WrLkIE Collins. Illustrated by ARTHUR Hopkins.

THE FALLEN LeAves. By Wilkie Colins. 
PicCadilly Novels-continued.

JEZEBEL'S DAUGETER. BY WILKIE COLLJNS.

DECEIVERS EVER. By Mrs. H. LovetT CameroN.

JULIET'S GUARDIAN. By Mrs. H. LovetT CaMERON. Illus. trated by VALRNTINE BROMLEY.

FElicia. By M. Betham-Edwards. Frontispiece by W. Bowle: OLYMPIA. BY R. E. FRANCILLON.

GaRTH. By JULiaN HAWTiloRne.

ROBIN GRAY. Hy Charles GibBon.

FOR IACK OF GOLD. BY CHARLES GIBBON.

IN LOVE AND WAR. By CHARLES GiBBON.

WHAT WILL THE WORLD SAY? BY CHARLES GIBBON,

FOR THE KING. By Charles GibBon.

IN HONOUR BOUND. By CHARLES GibBon.

QUEEN OF THE MEADOW. By Charles GibBox. Illustrated by ARTHUR HOpkiNs.

UNDER THE GREENWOOD TREE. By THOMAS HARDY,

THORNICROFT'S MODEL. By Mrs. A. W. HUNT.

FATED TO BE FREE. By JEAN INGELOW.

CONFIDENCE. By HEXRY JAMES, Jun.

THE QUEEN OF CONNAUGFT. BY HARRIETT JAY.

THE DARK COLLEEN. BY HARRIETT JAY.

NUMBER SEVENTEEN. By HENRY KINGSLEY.

OAKSHOTT CASTIE. By HENRY KINGSLEY. With a Frontis. piece by SHIRLEY HOOSON.

PATRICIA KEMBALL. By E. LyNN LiNTON, With a Frontispiece by G. Du MAURIRr.

THE ATONEMENT OF LEAM DUNDAS. By E. LYNN LINTON. With a Frontispiece by HRNRY WOODS.

THE WORLD WELL LOST. By E. LYNN LINTON. Illustrated by J. LAwSON and HENRY FRENCH.

UNDER WHICH LORD? BY E. LYNN LINTON.

WITH A SILKEN THREAD. BY E. LYNN LINTON.

THE WATERDALE NEIGHBOURS. By JUSTIN MCCARTHY. MY ENEMY'S DAUGHTER. By JUSTIN MCCARTHY. LINLEY ROCHFORD. BY JUSTIN MCCARTHY.

A FAIR SAXON. By JustiN MCCaRThy.

DEAR LADY DISDAIN. By JUSTIN MCCARTHY.

MISS MISANTHROPE. By JUSTIN MCCARTHY. Illustrated by ARTHUR HOPKINS.

DONNA QUIXOTE. By JUSTIN MCCARTIY. Illustrated by ARTHUR HOPKINS.

QUAKER COUSINS. By AGNES MACDONELL.

LOST ROSE. Hy Katharine S. Macquoid. 
Piccadilly Novels-continued.

THE EVIL EYE, and other Stories. By KATHARINE S. MACQuord. Illustrated by Tromas R. MAcQuord and Percy MAcQuord.

OPEn! SESAME! By Florence Marryat, Ilustrated by F. A. Fraser.

TOUCH AND GO. By JeAn Middlemass.

WHITELADIES. By Mrs. Oliphant. With Illustrations by A. HoPKINS and $\mathrm{H}$, Woods.

THE BEST OF HUSBANDS. By JAMES PAYN. Illustrated by J. Movr Sмттн.

FALLEN FORTUNES. BY JAMES PAYN.

haLVES. By James Payn. With a Frontispiece by J. MAhoney. WALTER'S WORD. By JAMES PAYN. Illust, by J. MOYR SMITH. WHAT HE COST HER. By JAMES PAYN.

LESS BLACK THAN WE'RE PAINTED., BY JAMES PAYN. BY PROXY. By JAMES PAYN. Illustrated by ARTHUR Hopkins. UNDER ONE ROOF. BY JAMES PAYN. HIGH SPIRITS. By JAMES PAYN.

HER MOTHER'S DARLING. By Mrs. J. H. RIDDELL. BOUND TO THE WHEEL. By JOHN SAUNDERS.

GUY WATERMAN. By JOHN SAUNDERS.

ONE AGAINST THE WORLD. BY JOHN SAUNDERS. THE LION IN THE PATH. By JOHN SAUNDERS.

THE WAY WE LIVE NOW. By ANTHONY Trollope Illust. THE AMERICAN SENATOR. BY ANTHONY TROLLOPE. DIAMOND CUT DIAMOND. By T. A. TROLLOPE.

\section{Post 8ro, illustrated boards, 2s, each. \\ Popular Novels, Cheap Editions of.

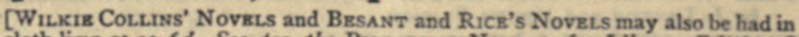
cloth limp at 2s. 6d. See, too, the Piccndru.y Novrus, for Library Editions.]

Maid, Wife, or Widow ? By Mrs. Alexander.

Ready-Money Mortiboy. By Walter Besant and JaMres Rick.

The Golden Butterfly. By Authors of "Ready-Money Mortiboy."

This Son of Vulcan. By the same. My Little Girl. By the same. The Case of Mr. Lucraft. By Authors of "Ready-MoneyMortiboy." With Elarp and Crown. By, Authors of "Ready-MoneyMortiboy." The Monks of Thelema. By Walter Besant and James Rice.
By Celia's Arbour. By WALter Besant and Jasmes Rice.

'Twas in Trafalgar's Bay. By WALTER BEsANt and JaMIES Rick. Jullet's Guardian. By Mrs. H. Lovett Cameron.

Surly Tim. By F.H. BurNeTT. The Cure of Souls. By MACLAREN COBBan.

The Woman in White. By WILKIE COLLINS.

Antonina. By WILKIE CoLlins. Basil. By Wilkie Collins. Hide and Seek. By the same. 
Popular Novels-continued.

The Queen of Hearts. By WILKIE CoLLINS.

The Dead Secret. By the same. My Miscellanies. By the same. The Moonstone. By the same. Man and Wife. By the same. Poor Miss Finch. By the same. Miss or Mrs.? By the same. TheNew Magdalen. By the same. The Frozen Deep. By the same. The Law and the Lady. By WILKIK ColLINS.

The Two Destinles. By WILkI Colliss.

The Haunted Hotel. ByWiLKIE Collins.

Roxy. By EdWARD EGgLeston. Folicia. M. BETHAM-EDWARDS. Filthy Lucre. By AzBANY DE FonblanquR.

Olympia. By R. E. Francillon. Robin Gray. By Crias. GrBbox. For Lack of Gold. By Charles Gibion.

What will the World Say? By Charles Gibbon.

In Love and War. By Charles Gibion.

For the King. By Charles Gibron.

In Honour Bound. Ey CiAs. Ginson.

Dick Temple. By Jaskes GRRRnwood.

Under the Greenwood Tree. By Tuomas Hardy.

An Heiress of Red Dog. By Bret Harte.

The Luck of Roaring Camp. By Brkt HARTr.

Gabriel Conroy. Bret Harte.

Fated to be Free. By JEAN INGBLOW.

Confldence. By IIEnRy James, Jun.
The Queen of Connaught. By HARRIETT JAY.

The Dark Colleen. By the same. Number Seventeen. by HENRY KINGSLKY.

Oakshott Castle. By the same. Patricia Kemball. By E. LYN LinTON.

TheA tonement of LeamDundas By E. Lynn Lintan.

The World Well Lost. By E. LYNN LinTon.

The Waterdale Neighbours. By Justin McCarthy.

My Enemy's Daughter. Do.

Linley Rochford. By the same. A Fair Saxon. By the same. DearLady Disdain. By the same. Miss Misanthrope. By JustiN MCCARTHY.

Lost Rose. By Katharine S. MacQuotD.

The Evil Eye. By the same.

Open! Sesame! By Florzace Marryat.

Whiteladiss. Mrs. Oliphant. Held in Bondage. By OUIDA. Strathmore. By OUIDA. Chandos. By OUIDA. Under Two Flags. By OUiDA. Idalia. By OUIDA. Cecil Castlemaine. By Ouida. Tricotrin. By Ourda.

Puck. By Ouida. Folle Farine. By OuIDA. Dog of Flanders. By OuIDA. Pascarel. By OuIda.

Two Little Wooden Shoes. By Ouida.

Signa. By Ouida.

In a Winter City. By Ou:DA. Ariadne. By OuIDA. Friendship. liy OUiDA. 
Popular Novels-continued. Fallen Fortunes. By J. PAYN. Halves. By JAMES PAYN. What He Cost Her. By ditto. By Proxy. By James Payn. Less Black than We're Painted. By James PAYN.

The Best of Husbands. Do. Walter's Word. By J. PAYN. The Mystery of Marie Roget. By Edgar A. Poz.

Her Mother's Darling. By Mrs. J. H. RIDDELL.

Gaslight and Daylight. By Grorge Augustus Sat.A.

Bound to the wheel. By JoHN SaUnders.

Guy Waterman. J. SAUNDERS.

One Against the World. By JoHn SAUnders.

The Lion in the Path. By JoHv and KATHERINg SAUNDERS.

Tales for the Marines. By W ALTER THORNBURY,

The Way we Live Now. By Anthony TroLLope.

The Amerioan Senator. By Anthony Trollope.

Diamond Cut Diamond. By T. A. Trollore.

An Idle Excursion. By MARK Twarn.

Adventures of Tom Sawyer. By MARk Twais.

A Pleasure Trip on the Cont1. nent of Europe. By Mark Twain.

Fcap. 8vo, picture covers, Is. each.

Jeff Briggs's Love Story. By BRET HARTE.

The Twins of Table Mountain. By Bret Harte.

Mrs. Gainsborough's Diamonds. By Julian HawthoRNE.

Kathleen Mavourneen. By the Author of "That Lass o' Lowrie's." Lindsay's Luok. By the Author of "That Lass o' Lowrie's." Pretty Polly Pemberton. By Author of "That Lass o' Lowrie's." Trooping with Crows. By Mrs. PIRKIS.

Crown 8vo, cloth extra, 6s.

Planché.-Songs and Poems, from 18 ig to 1879 . By J. R. Planche. 'Edited, with an Introduction, by his Daughter, MrS. MACKARNESS.

Two Vols. 8vo, cloth extra, with Illustrations, 10s, $6 d$.

Plutarch's Lives of Illustrious Men.

Translated from the Greek, with Notes, Critical and Historical, and a I.ife of Plutarch, by JoHN and William LANGHORNe, New Edition, with Medallion Portraits.

Crown 8vo, cloth extra, 7s, $6 d$.

\section{Primitive Manners and Customs.}

By JAMES A. FARRER.

"A book which is really both instructive and amusing, and which will open a nesv field of thowght to many readers." - ATHENAEU.

"An adminable example of the application of the scientific method and the working of the truly scientific spirit." - SATURDAY REVIEW. 
Small 8vo, cloth extra, with Illustrations, 3s. $6 d$.

Prince of Argolis, The:

A Story of the Old Greek Fairy Time. By J. MoYr SMrth. With I30 Illustrations by the Author.

\section{Proctor's (R. A.) Works:}

Easy Star Lessons for Young Learners. With Star Maps for Every Night in the Year, Drawings of the Constellations, \& c. By RICHARD A. Proctor. Crown 8vo, cloth extra, 6s. [In preparation.

Myths and Marvels of Astronomy. By Rich. A. Proctor, Author of "Other Worlds than Ours," \&c. Crown 8vo, cloth extra, $6 s$.

Pleasant Ways in Science. By Richard A. Proctor. Crown 8vo, cloth extra, 6s.

Rough Ways made Smooth: A Series of Familiar Essays on Scientific Subjects. By R. A. Proctor. Crown 8vo, cloth extra, 6s.

Our Place among Infinities: A Series of Essays contrasting our Little Abode in Space and Time with the Infinities Around us. By Kichard A. Proctor. Crown 8vo, cloth extra, $6 s$.

The Expanse of Heaven : A Series of Essays on the Wonders of the Firmament. By Richard A. Proctor. Crown 8vo, cloth, 6s.

Wages and Wants of Sclence Workers. By RICHARD A. Proctor. Crown Svo, 1s. 6d.

"Mr. Proctor, of all writers of our time, best conforms to Matthew Arnold's conception of a man of culture, in that he strives to humanise knowledge and divest it of whatever is harsh, crude, or technical, and so makes it a sontre of happiness and brightness for all."-WESTMINSTER REvizw.

\section{Pursuivant of Arms, The;}

or, Heraldry founded upon Facts. A Popular Guide to the Science of Heraldry. By J. R. Planche, Somerset Herald. With Coloured Frontispiece, Plates, and 200 Illustrations.

\section{Rabelais' Works.}

Crown 8vo, cloth extra, with Illustrations, 7s. 6d.

Faithfully Translated from the French, with variorum Notes, and numerous characteristic Illustrations by GUSTAVE DORE.

" $H$ is buffoonery was not merely Brutus's rough skin, which contained a rod of gold: it was necessary as an amulet against the monks and legates; and he must be classed with the greatest creative minds in the world-with Shake. speare, with Dante, and with Cervantes." - S. T. ColeriDGR.

Crown 8 vo, cloth gilt, with numerous Illustrations, and a beautifully executed Chart of the various Spectra, 7s. $6 d$.

Rambosson's Astronomy.

By J. RAMBossos, Laureate of the Institute of France. Transiated by C. B. PItMas. Profusely Illustrated. 
Crown 8vo, cloth extra, 6s.

Richardson's (Dr.) A Ministry of Health,

and other Papers. By Benjamin Ward Richardson, M.D., \&c.

"This highly interesting volume contains whuards of nise addresses, written in the asuthor's weall-known style, and full of great and good thoughts. . . . The werk is, like all those of the author, that of a man of genisus, of grvat power, of evperience, and noble independence of thought."-POPULAR SCIENCE REVIEw.

Square 8vo, cloth extra, gilt, 10s. $6 \mathrm{~d}$.

Rimmer's Our Old Country Towns.

With over 50 Illustrations. By ALFRED RIMMER. [Nearly ready.

\section{Roll of Battle Abbey, The;}

Handsomely printed, price 5 :

or, A List of the Principal Warriors who came over from Normandy with William the Conqueror, and Settled in this Country, A.D. ro66-7. Printed on fine plate paper, nearly three feet by two, with the principal Arms emblazoned in Gold and Colours.

Two Vols., large 4to, profusely Illustrated, half-morocco, $L_{2} 26 \mathrm{~s}$.

Rowlandson, the Caricaturist.

A Selection from his Works, with Anecdotal Descriptions of his Famous

Caricatures, and a Sketch of his Life, Times, and Contemporaries.

With nearly 400 Illustrations, mostly in Facsimile of the Originals. By

JOSEPH GREGO, Author of "James Gillray, the Caricaturist ; his Life, Works, and Times,"

"Mr. Grego's excellent accournt of the works of Thomas Rosulandson . . . illustrated with some 400 spirited, accurate, and clever trasscripts from his designs. . . The thanks of all who care for what is original and personal in art are diue to Mr. Grego for the pains he has been at, avd the time he has $\mathrm{ex}$ pended, in the preparation of this very pleasant, very carefwl, and adeguate memorial." - PALl Mall Gazettr.

\footnotetext{
Crown 8vo, cloth extra, profusely Illustrated, 4s, 6d, each,

" Secret Out" Series, The.

The Pyrotechnist's Treasury; or, Complete Art of Making Fireworks. By ThомAs Kentish, With numerous Illustrations.

The Art of Amusing :

A Collection of Graceful Arts, Games, Tricks, Puzzles, and Charades. By Fravk BeLLew. 300 Illustrations.

Hanky-Panky :

Very Easy Tricks, Very Difficult Tricks, White Magic, Sleight of Hand. Edited by W. H. CremER, 200 Illustrations.

The Merry Circle:

A Book of New Intellectual Games and Amusements. By Clara Bet.erw. Mary Illustrations.

Magiolan's Own Book :

Performances with Cups and Balls, Eggs, Hats, Handkerchiefs, \&c. AII from Actual Experience. Edited by W. H. Cresser. a 20 Illustrations.

Magio No Mystery : Tricks with Cards, Dice, Balls, \&c., with fully descriptive Directions; the Art of Secret Writing; Training of Performing Animals, \&c. Coloured Frontispiece and many Illustrations.

The Secret Out :

One Thousand Tricks with Cards, and other Recreatiors ; with Entertaining Experiments in Drawing-room or "White Magic." By W, H. Cramer. 700 Engravings.
} 
Crown 8vo, cloth extra, 6s.

\section{Senior's Travel and Trout in the Antipodes.}

An Angler's Sketches in Tasmania and New Zealand. By Willias SENIOR ("Red Spinner"), Author of "Stream and Sea."

"In every way a happy production. . . What Tumer effected in colour on canvas, Mr. Senior may be said to efect by the force of a practical mind, in lan. guage that is magnificently descriptive, on his subject. There is in both painter and suriter the same magical combination of idealism and realism, and the snme hearty appreciation for all that is sublime and pathetic in natural scenery. That there is an undue sliare of travel to the number of trout caught is certainly not Mr. Senior's foult; but the comparative scarcity of the prince of fishes is adeguately atoned for, in that the writer was led pretty well through all the glorious scenery of the antipodes in quest of him. . . So great is the charm and the freshness and the ability of the book, that it is hard 20 put it down when once taken up."-Номв Naws.

\section{Shakespeare :}

Shakespeare, The First Folio. Mr. William Shakespeare's Comedies, Histories, and Tragedies. Published according to the true Originall Copies. London, Printed by ISAAC IAGgARD and ED. BlounT, 1623. - A Reproduction of the extremely rare origial, in reduced facsimile by a photographic process-ensuring the strictest accuracy in every detail. Small 8vo, half-Roxburghe, ros. $6 d$.

"To Messrs. Chatto and Windus belongs the merit of having done more to facilitate the critical study of the text of our great dramatist than all the Shakespeare clubs and societies put together. A complete facsimile of the celebrated First Folio edition of 1623 for half-a-guinea is at once a miracle of cheapness and enterprise. Being in a reduced form, the type is necessarily rather diminutive, but it is as distinct as in a genuine copy of the original, and will be fourd to be as kseful and far more handy to the student than the latter."-ATHENAUM.

Shakespeare, The Lansdowne. Beautifully printed in red and black, in small but very clear type. With engraved facsimile of Drozshour's Portrait. Post 8vo, cloth extra, 7s. $6 d$.

Shakespeare for Children: Tales from Shakespeare. By CiARLeS and MARY LAMB. With numerous Illustrations, coloured and plain, by J. MoYr Sмrтн. Crown 4to, cloth gilt, ros. $6 d$.

Shakespeare Muslc, The Handbook of. Being an Account of Three Hundred and Fifty Pieces of Music, set to Words taken from the Play's and Poems of Shakespeare, the compositions ranging from the Elizabethan Age to the Present Time. By ALFRED Rofre. 4to, half-Roxburghe, 75

Shakespeare, A Study of. By Algernow Charles Swiv. EURNE. Crown 8 vo, cloth extra, 8 s.

Crown 8vo, cloth extra, gilt, with ro full-page Tinted Illustrations, 7s. 6d.

\section{Sheridan's Complete Works,}

with Life and Anecdotes. Including his Dramatic Writings, printed from the Original Editions, his Works in Prose and Poetry, Transla. tions, Speeches, Jokes, Puns, \&c. ; with a Collection of Sheridaniaza. 


\section{Signboards :}

Crown $8 \mathrm{vo}$, cloth extra, with Illustrations, $7 s .6 d$.

Their History. With Anecdotes of Famous Taverns and Remarkable Characters. By JACOB LARWOOD and JOHN CAMDEN HOTTEN. With nearly roo nlustratio:is.

"Even if we were ever so maliciously inclined, we could not pick out all Messrs. Larwood and Hotten's plums, because the good things are so numerous as to defy the most wholesale depredation."-TMES.

\section{Slang Dictionary, The:}

Crown 8vo, cloth extra, gilt, $6 s .6 d$.

Etymological, Historical, and Anecdotal. An ENTIRELY NEW

EDITION, revised throughout, and considerably Enlarged.

"We are glad to see the Slang Dictionary reprnsted and enlarged. Froma ki h scientific point of view this book is not to be despised. Of course it cannot fail to be amusing also. It contains the very vocabulary of wurestrained humour, and oddity, and grotesqueness. In a word, it provides valwable material both for the st udent of langwage and the student of human nature." - ACADEMY.

\section{Exquisitely printed in miniature, cloth extra, gilt edges, 2s, $6 d$. Smoker's Text-Book, The.}

By J. Hamer, F.R.S.L.

\section{Spalding's Elizabethan Demonology :}

An Essay in Illustration of the Belief in the Existence of Devils, and the Powers possessed by them, with Special Reference to Shakspere and his Works. By T. Alpred Spalding, LL.B.

"A very thoughtful and weighty book, which cannot bat be weelcome to every earnest student." -ACADEMY.

Crown 4to, uniform with "Chaucer for Children," with Coloured Illustrations, cloth gilt, 10s. $6 d$.

\section{Spenser for Children.}

By M. H. TOwRY. With Illustrations in Colours by WALTER J. MORGAN,

"Spenser has stmply been transferred into plain frest, with here and there a line or stanza quoted, where the meaning and the diction are within a child's comprehension, and additional point is thus given to the narrative without the cost of obscurity. . . . Altogether the work has been tevill and carefully dome." -THR TIMrs.

\section{Stories about Number Nip,}

\section{Post 8vo, cloth extra, 5 .}

The Spirit of the Giant Mountains. Retold for Children, by WALter

Grahame, With Illustrations by J. Morg Smith.

Demy 8vo, cloth extra, Illustrated, 21s.

\section{Sword, The Book of the:}

Being a History of the Sword, and its Use, in all Times and in all Countries. By Captain Richard BURTON, With numerous Illustrations. 
Crown 8vo, cloth extra, 9s.
Stedman's Victorian Poets:
Critical Essays. By EDMUND CrARENCE STEDMAN.
"We ought to be thankful to those who do critical work with conpetent siill
and wnderstanding. Mr. Stedman deserves the thanks of English scholars;
-. . - he is faith

Crown 8vo, cloth extra, with Illustrations, 7s. $6 d$.

Strutt's Sports and Pastimes of the People of England; including the Rural and Domestic Recreations, May Games, Mummeries, Shows, Processions, Pageants, and Pompous Spectacles, from the Earliest Period to the Present Time. With 140 Illustrations. Edited by WILLIAM HONE.

\section{Swift's Choice Works,}

Crown 8vo, cloth extra, with Illustrations, 7s. $6 d$.

In Prose and Verse. With Memoir, Portrait, and Facsimiles of the Maps in the Original Edition of "Gulliver's Travels."

\section{Swinburne's Works :}

The Queen Mother and Rosa. mond. Fcap. 8vo, 5 s.

Atalanta in Calydon.

A New Edition. Crown 8vo, 6s.

Chastelard.

A Tragedy. Crown 8vo, 75.

Poems and Ballads.

First Serigs. Fcap. 8vo, gs. Also in crown $8 \mathrm{vo}$, at same price.

Poems and Ballads.

Second Srrizs. Fcap. 8 vo, gs. Also in crown $8 \mathrm{vo}$, at same price.

Notes on "Poems and Ballads." 8vo, is.

William Blake :

A Critical Essay. With Facsimile Paintings. Demy 8vo, r6s.

Songs before Sunrise.

Crown 8vo, ros. $6 d$.

$$
\text { NEW VOLUME OF POEMS BY MR. SWIVBURNE. }
$$

Crown 8 ro, cloth extra, $7 s$.

Studies in Song. By Algernon CHarles Swinburne.

Contents:-Song for the Centenary of Walter Savage Landor-Ofi ShoreAfter Nine Years-For a Portrait of Felice Orsini-Evening on the Broads-The Emperor's Progress-The Resurrection of Alcilia-The Fourteenth of July-A Parting Song-By the North Sea.-\&c.

Medium 8vo, cloth extra, with Illustrations, 7s. $6 d$.

\section{Syntax's (Dr.) Three Tours,}

in Search of the Picturesque, in Search of Consolation, and in Search of a Wife. With the whole of RowLANDSON's droll page Illustrations, in Colours, and Life of the Author by J. C. HOTTEN. 
Four Vols. small 8vo, cloth boards, 3os.

\section{Taine's History of English Literature.}

Translated by Henry Van Laun.

$\because$ Also a Popular Edition, in Two Vols. crown 8vo, cloth extra, 15 s.

Tales of Old Thule.

Collected and Illustrated by J. MoYr SMrTH.

"It is not ofien that we meet with a volume of fairy tales possessing more fully the double recommendation of absorbing interest and purity of tone than does the one before us containing a collection of 'Tales of Old Thule.' These come, to say the least, near fulfilling the idea of perfect works of the kind; and the illustrations with which the volusne is embellished are equally excellent. . . We commend the book to parents and teachers as an admirable gift to their children and pupils."-LITERARY WORLD.

\section{One Vol. crown 8vo, cloth extra, 7s. $6 d$. \\ Taylor's (Tom) Historical Dramas: \\ " Clancarty," "Jeanne Darc," " "Twixt Axe and Crown," "The Fool's Revenge," " Arkwright's Wife," " Anne Boleyn," "' Plot and Passion." $\because *$ The Plays may also be had separately, at 1s. each.}

Crown 8vo, cloth extra, with Coloured Frontispiece and numerous Illustrations, $7 s .6 d$.

\section{Thackerayana:}

Notes and Anecdotes. Illustrated by a profusion of Sketches by WILLIAM MAKEPEACE THACKERAY, depicting Humorous Incidents in his School-life, and Favourite Characters in the books of his everyday reading. With Hundreds of Wood Engravings, facsimiled from Mr. Thackeray's Original Drawings.

"It would have been a real loss to bibliographical literature had cofyright difficulties deprived the general fublic of this very amusing collection. Ome of Thackeray's habits, from his schoolboy days, was to ornament the margins and blank pages of the books he had in wse with caricature illwstrations of their contents. This gave special valiue to the sale of his library, and is almost casuse for regret that it could not have been preserved in its integrity. Thackeray's place in literature is eminent enough to have made this an interest to future generations. The anonymous editor has done the best that he could to compen. sate for the lack of this. It is an admirable addendum, not only to his collected works, but also to any memoir of him that has been, or that is likely to be, written."-BRITISH QUARTRRLY REviRw.

Crown 8vo, cloth extra, with numerous Illustrations, 7s. 6d.

\section{Thornbury's (Walter) Haunted London.}

A New Edition, edited by EDWARD WALForD, M.A., with numerous Illustrations by F. W. FAIRHOLT, F.S.A.

"Mr. Thornbury knew and loved his London. . . . He had read much his. tory, and every by-lane and every court had associations for him, His memory and his note-books were stored with anecdote, and, as he had singular skill in the matter of narration, it will be readilv believed that when ke took to writing a set book about the places he knew and cared for, the said book woould be charming. Charming the volume before ys certainly is. It may be begun in the beginning, or middle, or end, it is all one: wherever one lights, there is some pleasant and curiows bit of gossip, some amusing fragment of allusion or guotation." $-V_{A N I T Y}$ FAIR, 
Crown 8vo, cloth extra, gilt edges, with Ill strations, 7s. $6 d$.

Thomson's Seasons and Castle of Indolence. With a Biographical and Critical Introduction by ALLAN CUNNINGHAM, and over 50 fine Illustrations on Steel and Wood.

Crown 8vo, cloth extra, with Illustrations, 7s. $6 d$.

Timbs' Clubs and Club Life in London.

With Anecdotes of its famous Coffee-houses, Hostelries, and Taverns. By JOHN TIMBS, F.S.A. With numerous Illustrations.

Crown 8vo, cloth extra, with Illustrations, $75,6 d$.

Timbs' English Eccentrics and Eccentricities: Stories of Wealth and Fashion, Delusions, Impostures, and Fanatic Missions, Strange Sights and Sporting Scenes, Eccentric Artists, Theatrical Folks, Men of Letters, \&c. By JoHN Timbs, F.S.A. With nearly 50 Illustrations.

\section{Torrens' The IMarquess Wellesley,}

Architect of Empire. An Historic Portrait. Forming Vol. I. of PROCONSUl and TRIBUNE: WellesleY and O'CONNELL: Historic Portraits. By W. M. TORRENS, M.P. In Two Vols.

Crown 8vo, cloth extra, with Coloured Illustrations, 7s. $6 d$.

Turner's (J. M. W.) Life and Correspondence:

Founded upon Letters and Papers furnished by his Friends and fellowAcademicians. By Walter Thornbury. A New Edition, considerably Enlarged. With numerous Illustrations in Colours, facsimiled from Turner's original Drawings.

Two Vols., crown 8vo, cloth extra, with Map and Ground-Plans, r4s.

Walcott's Church Work and Life in English Minsters; and the English Student's Monasticon. By the Rev. mackenzie E. C. Walcott, B.D.

Large crown 8vo, cloth antique, with Illustrations, 7s. $6 d$.

Walton and Cotton's Complete Angler;

or, The Contemplative Man's Recreation : being a Discourse of Rivers. Fishponds, Fish and Fishing, written by IzAAK WALTON; and Instructions how to Angle for a Trout or Grayling in a clear Stream, by Charles CotTon. With Original Memoirs and Notes by Sir HARris Nicozas, and 6r Copperplate Illustrations.

Carefully printed on paper to imitate the Original, 22 in. by 14 in., 25 .

Warrant to Execute Charles I.

An exact Facsimile of this important Document, with the Fifty-nine Signatures of the Regicides, and corresponding Seals. 
The Twenty-first Annual Edition, for $188 \mathrm{r}$, cloth, full gilt, 50 . Walford's County Families of the United Kingdom. A Royal Manual of the Titled and Untitled Aristocracy of Great Britain and Ireland. By EDWARD WALFORD, M.A., late Scholar of Balliol College, Oxford. Containing Notices of the Descent, Birth, Marriage, Education, \&c., of more than r2,000 distinguished Heads of Families in the United Kingdom, their Heirs Apparent or Presumptive, together with a Record of the Patronage at their disposal, the Offices which they hold or have held, their Town Addresses, Country Residences, Clubs, \&c. [Nearly ready.

Beautifully printed on paper to imitate the Original MS., price 2 .

Warrant to Execute Mary Queen of Scots. An exact Facsimile, including the Signature of Queen Elizabeth, and a Facsimile of the Great Seal.

Crown 8vo, cloth limp, with numerous Illustrations, 4s. $6 d$.

Westropp's Handbook of Pottery and Porce. lain ; or, History of those Arts from the Earliest Period. By HoDDER M. Westropp, Author of "Handbook of Archreology," \&c. With numerous beautiful Illustrations, and a List of Marks.

Seventh Edition. Square 8vo, is.

Whistler $\nabla$. Ruskin: Art and Art Critics. By J. A. MACnetll. Whistler.

Crown 8vo, cloth limp, with Illustrations, 2s, $6 d$.

Williams' A Simple Treatise on Heat.

By W. MattieU Wrlinam, F.R.A.S., F.C.S., Author of "The Fuel of the Sun," \&c.

A HANDSOME GIFT-BOOK.-Small 8vo, cloth extra, 6s.

Wooing (The) of the Water-Witch:

A Northern Oddity. By Evan Daldorne. With One Hundred and Twenty-five fine Illustrations by J. MOYR SMrTH.

Crown 8vo, cloth extra, with Illustrations, 7s, 6d.

Wright's Caricature History of the Georges. (The House of Hanover.) With 400 Pictures, Caricatures, Squibs, Broadsides, Window Pictures, \&c. By Thомas Wright, M.A., F.S.A.

Large post $8 v 0$, cloth extra, gilt, with Illustrations, $75,6 d$.

Wright's History of Caricature and of the Grotesque in Art, Literature, Sculpture, and Painting, from the Earliest Times to the Present Day. By Thomas Wright, M.A., F.S.A. Profusely Illustrated by F. W. FArRHOLT, F.S.A.

J. OGDEN AND CO,, PRINTERS, 172, ST. JOHN STREBT, R,C.

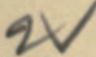





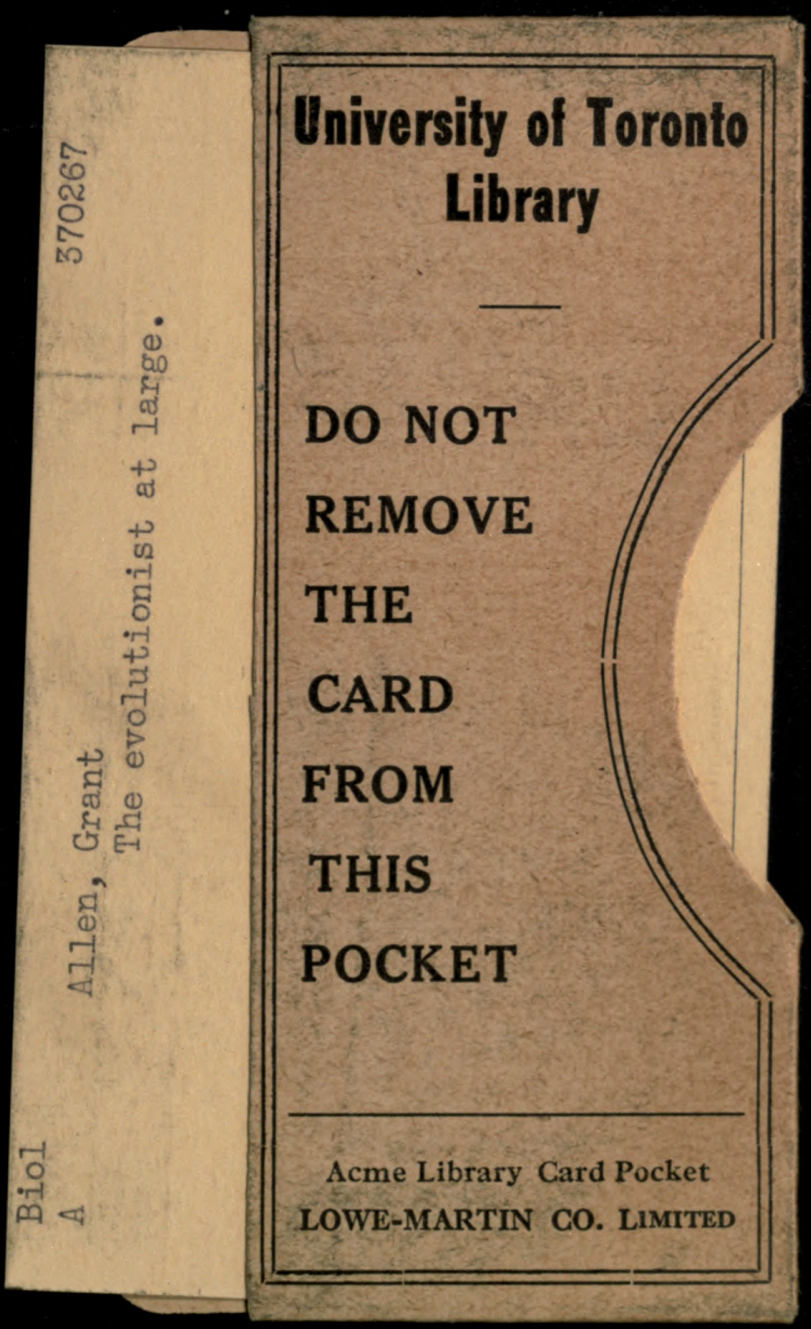


